\title{
Metapopulation dynamics of the softshell clam, Mya arenaria
}

by

\author{
Carly A. Strasser
}

B.A. Marine Science, University of San Diego, 2001

Submitted in partial fulfillment of the requirements for the degree of

Doctor of Philosophy in Biological Oceanography

at the

MASSACHUSETTS INSTITUTE OF TECHNOLOGY

and the

\section{WOODS HOLE OCEANOGRAPHIC INSTITUTION}

June 2008

(C) 2008 Carly A. Strasser, All rights reserved.

The author hereby grants to MIT and WHOI permission to reproduce and distribute publicly paper and electronic copies of this thesis document in whole or in part in any medium now known or hereafter created.

Author

Department of Biology

Massachusetts Institute of Technology

and Woods Hole Oceanographic Institution

1 April 2008

Certified by

Lauren S. Mullineaux

Senior Scientist

Woods Hole Oceanographic Institution

Accepted by

Ed DeLong

Chair, Joint Committee for Biological Oceanography

Massachusetts Institute of Technology and Woods Hole Oceanographic Institution 


\title{
Metapopulation dynamics of the softshell clam, Mya \\ arenaria
}

by

\author{
Carly A. Strasser \\ Submitted to the Department of Biology \\ on 1 April 2008, in partial fulfillment of the \\ requirements for the degree of \\ Doctor of Philosophy in Biological Oceanography
}

\begin{abstract}
In this dissertation, I explored metapopulation dynamics and population connectivity, with a focus on the softshell clam, Mya arenaria. I first worked towards developing a method for using elemental signatures retained in the larval shell as a tag of natal habitat. I designed and implemented an experiment to determine whether existing methods commonly used for fishes would be applicable to bivalves. I found that the instrumentation and setup I used were not able to isolate and measure the first larval shell of $M$. arenaria. In concert with developing this method for bivalves, I reared larval $M$. arenaria in the laboratory under controlled conditions to understand the environmental and biological factors that may influence elemental signatures in shell. My results show that growth rate and age have significant effects on juvenile shell composition, and that temperature and salinity affect larval and juvenile shell composition in variable ways depending on the element evaluated. I also examined the regional patterns of diversity over the current distribution of $M$. arenaria using the mitochondrial gene, cytochrome oxidase I (COI). I found minimal variability across all populations sampled, suggesting a recent population expansion in the Northwest Atlantic. Finally, I employed theoretical approaches to understand patch dynamics in a two-patch metapopulation when one patch is of high quality and the other low quality. I developed a matrix metapopulation model and compared growth rate elasticity to patch parameters under variable migration scenarios. I then expanded the model to include stochastic disturbance. I found that in many cases, the spatial distribution of individuals within the metapopulation affects whether growth rate is most elastic to parameters in the good or bad patch.
\end{abstract}




\section{Acknowledgments}

First and foremost, Lauren Mullineaux deserves a big thanks for her guidance and patience during my graduate education. Lauren was steadfast in her support through the many obstacles I encountered and my attitude towards those obstacles. She allowed me to pursue my own research interests, gave me the opportunity to participate in two amazing research cruises, and was endlessly patient in our conversations. Thanks also to my committee, Mike Neubert, Simon Thorrold, Ed Boyle, Paul Barber, and Jim Lerczak for their many helpful suggestions. A big thanks to Larry Madin, who agreed to chair my defense despite his incredibly busy schedule. I'm indebted to both Mike and Hal Caswell for their patience in developing my theoretical tendencies, and for their willingness to allow me to participate in lab meetings and discussions. I'm grateful to Simon and Paul for their generosity in allowing me to pursue my thesis work in their laboratories.

There were many people at WHOI who contributed to my thesis in immeasurable ways. First, Phil Alatalo was always happy to help solve problems, offer suggestions, and lend supplies during my larval rearing experiments, especially with relation to algal cultures. Anne Cohen and Glen Gaetani generously opened their laboratories to me and answered my many questions regarding ion microprobe sample preparation. Special thanks to Anne for her willingness to donate time and energy to my ion microprobe explorations. I'm also grateful to Delia Oppo for allowing me to use her laboratory space on several occasions, as well to as Kristi Dahl and Rose Came for their help in technique development. Jurek Blusztajn provided me with clean room space. Tim Shank and his lab were always welcoming when I used their computers and wanted to discuss my population genetics work. Dave Schneider, Lary Ball, and Scot Birdwhistell were helpful for ICP-MS analyses and technical questions related to the ICP-MS. The Math Ecology group was a wonderful resource, especially Christine Hunter, Petra Klepac, Stephanie Jenouvrier, and Ariane Verdy. The Anderson, Waterbury, and Gallager labs lent me equipment for my uptake experiments. I am grateful to Vicke Starczak for her statistical expertise and willingness to discuss 
ANOVAs, regressions, and t-tests over the years.

Several people outside of WHOI also contributed to my thesis, most notably Henry Lind of the Eastham Department of Natural Resources. Henry provided me with millions of clams and the finer points of caring for them. He answered many latenight phone calls, allowed me to camp out in his greenhouse facility, and instructed me on how to properly spawn clams. This thesis would not have been possible without him or his staff at the Eastham Hatchery Facility. Dale Leavitt was also helpful in larval rearing techniques and in providing aquaculture expertise. Tom Marcotti of the Barnstable Natural Resources Office provided spawning stock for my uptake experiments. Finally, my population genetics work was conducted almost entirely at the Marine Biological Laboratory in the Barber lab, with the help of Elizabeth Jones, Eric Crandall, and Josh Drew.

Many people helped with clam collections over the years, but special thanks go to Alexis Jackson and Stephanie Pommrehn. Other assistants included Rob Jennings, Susan Mills, Kate Buckman, Diane Adams, and Benjamin Walther. Travis Elsdon and Benjamin Walther were especially helpful for designing and implementing uptake experiments. The Mullineaux Lab was an amazing resource for discussions and debate: Lara Gulman, Heidi Fuchs, Rob Jennings, Diane Adams, Stace Beaulieu, Nathalie Reynes, Skylar Bayer, Meredith White, and Susan Mills, thanks for the experience. A big hug to Julia, Marsha, Shona, and Valerie in Academic Programs for their support.

My graduate experience would be nothing without the love and support of so many friends and family. Marsha, Benjamin, Breea, Kelly, Nathalie, Greg, Travis, and Andrew- I couldn't have done it without you, and that's no exaggeration. And finally, thanks to my family and their seemingly bottomless capacity for useless facts.

Chapter 4 is co-authored by Lauren Mullineaux and Simon Thorrold and was submitted to Marine Ecology Progress Series in January 2008 for publication. Chapter 5 is co-authored by Paul Barber and was accepted to Conservation Genetics in March 2008 for publication. Chapter 6 will result in a publication co-authored by Mike Neubert, Hal Caswell, and Christine Hunter. 
Financial support was provided by the National Defense Science and Engineering Graduate Fellowship; the WHOI Academic Programs Office; NSF grants OCE0326734, OCE-0215905, OCE-0349177, DEB-0235692, DMS-0532378, and ATM-0428122; and by NOAA National Sea Grant College Program Office, Department of Commerce, under Grant No. NA86RG0075 (Woods Hole Oceanographic Institution Sea Grant Project No. R/0-32), and Grant No. NA16RG2273 (WHOI Sea Grant Project No. $\mathrm{R} / 0-35)$. 


\section{Contents}

1 Introduction $\quad \mathbf{1 5}$

1.1 Metapopulations . . . . . . . . . . . . . . . . 15

1.2 Thesis Goals . . . . . . . . . . . . . . . . . . . 17

2 Laser ablation ICP-MS analysis of larval shell in softshell clams (Mya arenaria) poses challenges for natural tag studies

3 Growth rate and age effects on Mya arenaria shell chemistry: Implications for biogeochemical studies

4 Temperature and salinity effects on elemental uptake in the shells of larval and juvenile softshell clams (Mya arenaria) 45

4.1 Introduction . . . . . . . . . . . . . . . . . . . 45

4.2 Methods . . . . . . . . . . . . . . . . . . . . 48

4.2.1 Clam rearing . . . . . . . . . . . . . . . . . . . . . . . . . . . . . . . . . 48

4.2.2 Sample preparation . . . . . . . . . . . . . . . . . . . . . 49

4.2.3 Statistical analyses . . . . . . . . . . . . . . . . 52

4.3 Results . . . . . . . . . . . . . . . . . 53

4.3.1 Rearing conditions ................. . . . 53

4.3.2 Temperature \& salinity effects on uptake . . . . . . . . . 55

4.4 Discussion . . . . . . . . . . . . . . . . . . . 60

4.4.1 Temperature \& Salinity Effects on Uptake . . . . . . . . . . . 61

4.4.2 Differences in Larval \& Juvenile Uptake . . . . . . . . . . . . 65

4.4.3 Conclusions \& Implications for Future Studies . . . . . . . . . 66

4.5 Acknowledgements . . . . . . . . . . . . . . . 67

5 Limited genetic variation and structure in softshell clams (Mya are$\begin{array}{ll}\text { naria) across their native and introduced range } & \mathbf{7 5}\end{array}$

5.1 Introduction . . . . . . . . . . . . . . . . . . . . . . . . . . . . . . . . 75

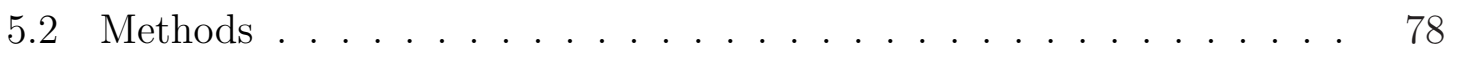

5.3 Results . . . . . . . . . . . . . . . . . . . . 83

5.4 Discussion . . . . . . . . . . . . . . . . . . . 88

5.4.1 Patterns in the Northwest Atlantic . . . . . . . . . . . 88

5.4.2 Patterns across the Northwest Atlantic, European waters and the northeast Pacific . . . . . . . . . . . . . . . 92 
5.4.3 Management Implications . . . . . . . . . . . . . . . . . . 93

5.5 Acknowledgements . . . . . . . . . . . . . . . . 94

6 Sensitivity analyses of a metapopulation model 103

6.1 Introduction . . . . . . . . . . . . . . . . . . 103

6.2 One Stage, No Disturbance . . . . . . . . . . . . . . . . . . . 106

6.3 One Stage, With Disturbance . . . . . . . . . . . . . . . . . . . 109

6.4 Two Stages, With Disturbance . . . . . . . . . . . . . . . . . . 116

6.5 Discussion \& Conclusions . . . . . . . . . . . . . . . . . . 123

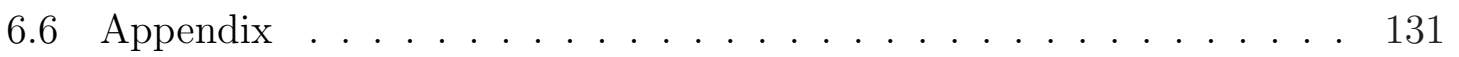

6.6.1 Bivariate Bernoulli Distribution . . . . . . . . . . . . 131

6.6.2 Derivation of $c$ and $p$ Inequalities . . . . . . . . . . . . . . 132

7 Conclusions 135

7.1 General Summary . . . . . . . . . . . . . . . . . . . . . . 135

7.2 Chapter Summaries \& Future Directions . . . . . . . . . . . . . . 135 


\section{List of Figures}

4.1 Seawater chemistry for first week of experiment only . . . . . . . . 53

4.2 Discrimination coefficients for larval shells . . . . . . . . . . . . 57

4.3 Discrimination coefficients for juvenile shells . . . . . . . . . . . . 59

4.4 Correlations comparing larval and juvenile discrimination coefficients $\quad 60$

5.1 Minimum-spanning tree for COI haplotypes . . . . . . . . . . . 79

5.2 Distribution of mitochondrial COI haplotypes in the Northwest Atlantic 85

5.3 Rarefaction curve from Northwest Atlantic populations. . . . . . . . . 88

5.4 Bayesian skyline plot derived from Northwest Atlantic populations. . 89

6.1 Contour plots of $\log E$ for deterministic model . . . . . . . . . . . . . 107

6.2 One-stage, two-patch life cycle graph . . . . . . . . . . . . . . . 109

6.3 Allowable disturbance parameters for two-patch metapopulation . . . 111

6.4 Contour plots of $\log E_{s}$ for stochastic model . . . . . . . . . . . . . . 113

6.5 Elasticity of $\log \lambda_{s}$ to migration parameters for one-stage model . . . 115

6.6 Two-stage, two-patch life cycle graph . . . . . . . . . . . . . . . 117

6.7 Elasticity of $\log \lambda_{s}$ to parameters for two disturbance scenarios . . . . 123

6.8 Elasticity of $\log \lambda_{s}$ to parameters for two migration scenarios . . . . . 124 


\section{List of Tables}

4.1 Number of surviving clams, temperature, salinity, and seawater chemistry for all weeks of experiment . . . . . . . . . . . . . .

4.2 ANOVA results testing for temperature and salinity effects on seawater chemistry . . . . . . . . . . . . . . 55

4.3 Temperature, salinity, and seawater chemistry for first week of experiment . . . . . . . . . . . . . . . 56

4.4 ANOVA results testing for temperature and salinity effects on shells . 57

4.5 Correlation analysis for larval and juvenile discrimination coefficients 59

5.1 Sampling and genetic information for Mya arenaria . . . . . . . . 80

5.2 Haplotype distributions for Mya arenaria . . . . . . . . . . . . . . . . 84

5.3 Results of AMOVAs. . . . . . . . . . . . . . . . . 86

5.4 Pairwise population comparisons, $\mathrm{F}_{S T} \ldots \ldots \ldots$. . . . . . 87 


\section{Chapter 1}

\section{Introduction}

\subsection{Metapopulations}

The concept of a metapopulation, first introduced by Levins $(1969 ; 1970)$, has received much attention in marine ecology over the last two decades (e.g. Roughgarden and Iwasa, 1986; Hanski, 1999; Thorrold et al., 2001; Kritzer and Sale, 2006). Original definitions of the metapopulation centered around extinction/recolonization events as the most important process to examine in metapopulation studies (Levins, 1969). More recently, the concept of a metapopulation has been expanded to include many other questions about interconnected populations, including population size, structure, and long-term trends.

In 2004, Kritzer and Sale examined the validity of Levins' original metapopulation definition from the perspective of marine ecology, drawing heavily from Hanski (1999), and re-defined a metapopulation based on the two spatial scales at which metapopulations exist: the patch (i.e. subpopulation or local population) scale, and the regional scale (Kritzer and Sale, 2004, p. 138). More recently, Sale et al. (2006) defined the degree of connection between patches more explicitly for their definition of a metapopulation:

We define a metapopulation as a system in which (1) local populations inhabit discrete habitat patches and (2) interpatch dispersal is neither 
so low as to negate significant demographic connectivity nor so high as to eliminate any independence of local population dynamics, including a degree of asynchrony with other local populations. (Sale et al., 2006, p. 6)

The degree to which patches are interconnected is determined by the migration of individuals between those patches, which then dictates their demographic connectivity. Because of this link between migration and connectivity, Kritzer and Sale (2004) suggest that estimates of exchange rates should be a priority for future research. Migration is, in fact, one of the most important features for determining metapopulation dynamics (Stacey et al., 1997). Its importance extends beyond the effects of migration on local population dynamics. Migration facilitates gene flow among patches and therefore affects metapopulation genetic structure (Gillespie, 1981), and is especially critical for long-term metapopulation success when patches are subjected to stochastic environmental variability (Howe and Davis, 1991; Bascompte et al., 2002; Hill et al., 2002).

Although the metapopulation concept evolved primarily in the terrestrial literature, it is highly relevant to marine populations. This was not recognized in the literature any appreciable numbers until the mid-90's (Grimm et al., 2003). Prior to that time, marine ecologists had focused on the importance of larval recruitment for structuring marine populations (Connell, 1985), later recognizing the impacts of recruitment variability in population dynamics on coral reefs (Sale, 1977) and along rocky coastlines (Caffey, 1985; Roughgarden et al., 1985). Although evidence from larval dispersal and recruitment dynamics studies alluded to the concept of metapopulations, population structure was not explicitly considered until Roughgarden and Iwasa (1986) and Iwasa and Roughgarden (1986). Since then, there has been much discussion of population connectivity and the importance of migration for structuring marine populations.

Despite interest in population connectivity and marine metapopulations, empirical studies of migration rates are few in number for marine invertebrates. Much of the published literature focuses on migration estimates based on genetics (e.g. Grosberg and Cunningham, 2001; Gilg and Hilbish, 2003; Sotka and Palumbi, 2006) or theoret- 
ical models (e.g. Incze and Naimie, 2000; Roegner, 2000). The paucity of empirical migration estimates for benthic invertebrates is due to characteristics of the stage in which dispersal takes place; the larval stage is very small and is subject to high mortality and dilution rates (Thorson, 1950, 1966). Despite these obstacles, in recent years the field of marine ecology has sought to quantify the exchange of individuals among geographically separated patches in a metapopulation, termed larval connectivity (Cowen et al., 2007). In this thesis, I worked towards developing the use of shell chemistry as a means of measuring migration rates, and therefore connectivity, between patches of the softshell clam, Mya arenaria. I also used genetics as a natural tag of environment to estimate gene flow. Finally, I developed and implemented a theoretical model to explore metapopulation dynamics and understand the effects of migration on metapopulation growth rate.

\subsection{Thesis Goals}

My thesis began as method development; I set out to study connectivity and retention of the softshell clam Mya arenaria in the Northwest Atlantic using elemental signatures incorporated into the larval shell as tags of natal habitat. My first goal was to verify that the instrument commonly used in other natural tagging studies, laser ablation inductively coupled plasma mass spectrometry (ICP-MS), could be used for analyzing bivalve larval shell. Results from my experiment (presented in Chapter 2) instead indicated that this instrument, in the configuration used, was not able to analyze the extremely thin first larval shell of $M$. arenaria. These results were not expected, and I was forced to re-think my approach to my thesis questions. My results serve to discourage ecologists from adopting methods that have proven useful for other systems without first carefully considering and validating the method for their particular species. The general approach of using biogenic carbonate chemistry for connectivity studies is still useful; different sensors may be more sensitive, or even a different application of ICP-MS might be developed to analyze the surface of larval shells. Although I chose not to pursue further technique development, the potential 
for bivalve shell chemistry to provide ecologically relevant information - whether for connectivity or other environment indicators - remains.

If biogenic carbonate is to be used successfully as an environmental indicator (for connectivity studies or otherwise), it is essential to understand the effects of environmental and biological factors on elemental composition. In Chapters 3 and 4 report on experiments I conducted to understand some of the factors potentially affecting the composition of $M$. arenaria shell. Chapter 3 focuses on the effects of growth rate and age on elemental incorporation into shell, and Chapter 4 focuses on temperature and salinity effects on both larval and juvenile shell.

When I discovered that I would not be able to answer connectivity questions about $M$. arenaria using laser ablation ICP-MS, at least in its present configuration, I began pursuing population genetics as a different type of natural tag. The spatial and temporal scale at which genetics is useful for parsing out population variability depends on the genetic marker chosen. I sequenced the mitochondrial cytochrome oxidase I gene, which has proven useful in connectivity studies of other invertebrates. I included populations in the northwest Atlantic, the North Sea, and the Pacific in my study; these sites represent the species' native and introduced range. I was therefore able to assess connectivity on larger temporal and spatial scales, and examine patterns relating to $M$. arenaria's natural history. These results are reported in Chapter 5.

The variability in COI that I was able to detect proved informative about the history of $M$. arenaria over global spatial scales. Although my results showed that populations in New England were not isolated from one another, I was not able to address larval exchange rates over ecologically relevant time scales. In an attempt to return to my original questions about population connectivity and metapopulation dynamics, I began using mathematical models of $M$. arenaria metapopulations. The matrix population model presented in Chapter 6 began by my adding spatial structure to previous work on M. arenaria by Ripley and Caswell (2006). As I developed the model, it metamorphosed into something more generally applicable to any metapopulation subjected to stochastic disturbance. The model can be used to understand how metapopulation dynamics are affected by environmental variability. In addition, 
I used sensitivity analysis to determine the effects of migration on metapopulation growth rate. I found that since migration dictates the relative distributions of individuals in patches, metapopulation growth rate is highly sensitive to the proportion of individuals moving between patches.

Although the chapters of this thesis are presented in chronological order, it might be more useful to consider the results of Chapter 6 as evidence of the importance of migration for determining metapopulation dynamics, providing justification for my attempts to study dispersal in previous data chapters. The themes and questions of this thesis are generally applicable to other marine benthic invertebrates and lend knowledge to the broader concept of population connectivity and the techniques used to explore this important ecological concept. 


\section{References}

Bascompte, J., Possingham, H., Roughgarden, J., 2002. Patchy populations in stochastic environments: critical number of patches for persistence. American Naturalist 159 (2), 128-137.

Caffey, H., 1985. Spatial and temporal variation in settlement and recruitment of intertidal barnacles. Ecological Monographs 55, 313-332.

Connell, J., 1985. The consequences of variation in initial settlement vs. postsettlement mortality in rocky intertidal communities. Journal of Experimental Marine Biology and Ecology 93 (1-2), 11-45.

Cowen, R., Gawarkiewicz, G., Pineda, J., Thorrold, S., Werner, F., 2007. Population connectivity in marine systems: An overview. Oceanography 20 (3), 14-21.

Gilg, M., Hilbish, T., 2003. Patterns of larval dispersal and their effect on the maintenance of a blue mussel hybrid zone in southwestern England. Evolution 57, 10611077.

Gillespie, J. H., 1981. The role of migration in the genetic structure of populations in temporally and spatially varying environments. III. Migration modification. The American Naturalist 117 (3), 223-233.

Grimm, V., Reise, K., Strasser, M., 2003. Marine metapopulations: A useful concept? Helgoland Marine Research 56, 222-228.

Grosberg, R., Cunningham, C., 2001. Marine Community Ecology. Sinauer Associates, Sunderland, MA, Ch. 3: Genetic structure in the sea: From populations to communities, pp. 61-84.

Hanski, I., 1999. Metapopulation Ecology. Oxford University Press, Oxford.

Hill, M., Hastings, A., Botsford, L., 2002. The effects of small dispersal rates on extinction times in structured metapopulation models. American Naturalist 160 (3), 389-402. 
Howe, R., Davis, G., 1991. The demographic significance of 'sink' populations. Biological Conservation 57, 239-255.

Incze, L. S., Naimie, C. E., 2000. Modelling the transport of lobster (Homarus americanus) larvae and postlarvae in the Gulf of Maine. Fisheries Oceanography 9 (1), 99-113.

Iwasa, Y., Roughgarden, J., 1986. Interspecific competition among metapopulations with space-limited subpopulations. Theoretical Population Biology 30 (2), 194-214.

Kritzer, J. P., Sale, P. F., 2004. Metapopulation ecology in the sea: From Levins' model to marine ecology and fisheries science. Fish and Fisheries 5 (2), 131-140.

Kritzer, J. P., Sale, P. F., 2006. Marine Metapopulations. Elsevier Academic Press, Amsterdam.

Levins, R., 1969. Some demographic and genetic consequences of environmental heterogeneity for biological control. Bulletin of the Entomological Society of America $15,237-240$.

Levins, R., 1970. Extinction. In: Desternhaber, M. (Ed.), Some Mathematical Problems in Biology. American Mathematical Society, Providence, RI, pp. 77-107.

Ripley, B., Caswell, H., 2006. Recruitment variability and stochastic population growth of the soft-shell clam, Mya arenaria. Ecological Modelling 193, 517-530.

Roegner, G., 2000. Transport of molluscan larvae through a shallow estuary. Journal of Plankton Research 22 (9), 1779-1800.

Roughgarden, J., Iwasa, Y., 1986. Dynamics of a metapopulation with space-limited subpopulations. Theoretical Population Biology 29 (2), 235-261.

Roughgarden, J., Iwasa, Y., C., B., 1985. Demographic theory for an open marine population with space-limited recruitment. Ecology 66, 54-67.

Sale, P., 1977. Maintenance of high diversity in coral reef fish communities. The American Naturalist 111 (978), 337-359. 
Sale, P., Hanski, I., Kritzer, J., 2006. Marine Metapopulations. Elsevier Academic Press, Burlington, MA, Ch. 1: The merging of metapopulation theory and marine ecology, pp. 3-22.

Sotka, E., Palumbi, S. R., 2006. The use of genetic clines to estimate dispersal distances of marine larvae. Ecology 87 (5), 1094-1103.

Stacey, P., Johnson, V., Taper, M., 1997. Metapopulation Biology: Ecology, Genetics, and Evolution. Academic Press, San Diego, CA, Ch. 12: Migration within Metapopulations: The impact on local population dynamics, pp. 267-292.

Thorrold, S. R., Latkoczy, C., Swart, P. K., Jones, C. M., 2001. Natal homing in a marine fish metapopulation. Science 291, 297-299.

Thorson, G., 1950. Reproductive and larval ecology of marine bottom invertebrates. Biological Review 25, 1-45.

Thorson, G., 1966. Some factors influencing the recruitment and establishment of marine benthic communities. Netherlands Journal of Sea Research 3, 267-293. 


\section{Chapter 2}

\section{Laser ablation ICP-MS analysis of}

larval shell in softshell clams (Mya arenaria) poses challenges for

\section{natural tag studies}

by C.A. Strasser, S.R. Thorrold, V.R. Starczak, and L.S. Mullineaux

Reprinted from Limnology and Oceanography: Methods 5: 241 - 249 


\title{
Laser ablation ICP-MS analysis of larval shell in softshell clams (Mya arenaria) poses challenges for natural tag studies
}

C.A. Strasser, S.R. Thorrold, V.R. Starczak, and L.S. Mullineaux

Woods Hole Oceanographic Institution, Woods Hole, MA 02543

\begin{abstract}
We investigated whether laser ablation inductively coupled plasma mass spectrometry (ICP-MS) could be used to quantify larval shell compositions of softshell clams, Mya arenaria. The composition of aragonitic otoliths has been used as a natural tag to identify natal habitat in connectivity studies of fish. If it is possible to measure larval shell reliably, this technique could also be applied to marine bivalves. To determine whether the first larval shell (prodissoconch I) could be measured independent of underlying material, we conducted laboratory experiments in which larval M. arenaria were exposed to enrichments of the stable isotope ${ }^{138} \mathrm{Ba}$ during different stages in shell development. We were unable to isolate the chemical signature of the prodissoconch I from subsequent life stages in all combinations of shell preparation and instrument settings. Typical instrument settings burned through the prodissoconch I on a post-settlement juvenile and at least $9 \mathrm{~d}$ of second larval shell (prodissoconch II) growth. Our results suggest instrumental and technical improvements are needed before laser ablation ICP-MS can be useful for connectivity studies that require analysis of larval shell on a post-settlement $M$. arenaria juvenile. Laser burn-through is potentially a problem in any connectivity study where it is necessary to assay the small amounts of shell material that are deposited before a larva disperses away from its natal location.
\end{abstract}

Most marine benthic invertebrate life cycles include a planktonic larval phase that facilitates dispersal among adult populations (Thorson 1950). Connectivity, or the degree to which geographically separated populations exchange individuals, is an important factor in the spatial population dynamics of many marine organisms (Moilanen and Nieminen 2002). An understanding of connectivity in marine benthic populations is important because of the role spatial dynamics play in fisheries management and the design and implementation of marine protected areas. However, studying larval dispersal is challenging due to small larval sizes, high dilution rates, and high larval mortality rates (Thorson 1950, 1966).

In recent years, the use of artificial and natural tags to track marine larvae has been explored (e.g., Levin 1990; Thorrold et al. 2002). One type of natural tag that may be useful for identifying natal origins is elemental signatures recorded in biogenic

\footnotetext{
Acknowledgments

This work was supported by NSF project numbers OCE-0241855 and OCE-0215905. Special thanks to Henry Lind of the Eastham Department of Natural Resources for supplying clams and culturing expertise, and to Diane Adams, Benjamin Walther, Travis Elsdon, Anne Cohen, Dale Leavitt, Phil Alatalo, and Susan Mills for helpful discussions. We also thank D. Zacherl and an anonymous reviewer for their helpful comments.
}

carbonate. This technique relies on the observation that some elements are incorporated into the calcium carbonate matrix in amounts that are related to the dissolved concentrations and physical properties of the ambient water (e.g., Bath et al. 2000; Elsdon and Gillanders 2003; Fowler et al. 1995; Thorrold et al. 1997; Vander Putten et al. 2000). Provided water chemistry or temperature is significantly different among natal habitats, such variation can serve as a natural tag, or signature, of the geographic origin of organisms. The use of geochemical signatures in fish otoliths as natural tags for population studies is well established (Campana and Thorrold 2001). Recent efforts have expanded the use of elemental tags to invertebrates including decapods (DiBacco and Levin 2000), gastropods (Zacherl et al. 2003), bivalves (Becker et al. 2005), and cephalopods (Arkhipkin et al. 2004).

Most studies attempting to obtain time-resolved elemental signatures from calcified tissues have used laser ablation inductively coupled plasma mass spectrometry (ICP-MS). Conventional solution-based ICP-MS analyses are generally more precise than laser ablation assays but lack the ability to resolve elemental signatures from individual life stages (Campana et al. 1997). Laser ablation ICP-MS is particularly useful for larval studies because it allows the core of an otolith or the larval shell of a juvenile bivalve to be targeted. Yet, surprisingly few studies have empirically tested the effective spatial resolution of laser 


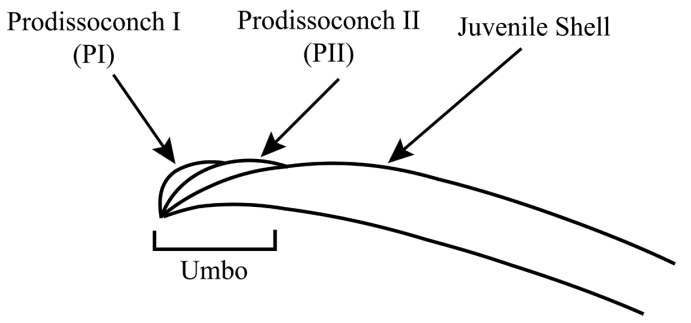

Fig. 1. Shell development in $M$. arenaria. PI and PII larval shells are underlain by juvenile and, ultimately, adult shell.

ablation ICP-MS. The goal of this study was to determine if techniques that have proven successful in otolith studies were also useful for quantifying larval dispersal of the softshell clam, Mya arenaria. Specifically, we tested if it was possible to isolate and measure the early larval shell (prodissoconch I) of $M$. arenaria using laser ablation ICP-MS without contamination from underlying late larval and juvenile shell material. This study is an important step in developing the use of elemental signatures in mollusc shells as tags of natal habitat because isolation of the early larval shell is critical for connectivity studies.

\section{Materials and procedures}

Study species-Adult $M$. arenaria broadcast spawn their gametes into the water, where fertilized eggs develop into non-feeding shell-less trochophore larvae. Within $24 \mathrm{~h}$ of spawning, the trochophore metamorphoses into a veliger and lays down its first larval shell, the prodissoconch I (hereafter PI), which is approximately $90 \mu \mathrm{m}$ in diameter (Loosanoff et al. 1966). After forming the PI, the veliger begins feeding in the plankton. Over the next 1 to 3 weeks, it lays down the second larval shell, the prodissoconch II (hereafter PII), which grows to diameters of 150 to $200 \mu \mathrm{m}$ (Loosanoff et al. 1966). The veliger then finds suitable habitat, settles to the bottom, and metamorphoses into a juvenile $M$. arenaria. Juvenile and, eventually, adult shell is laid underneath larval shell, extending away from the umbo (Fig. 1). Larval shells are retained during clam growth and development, and the PI can be identified easily on newly settled juveniles. Estimated water retention times for typical New England estuaries are 2 days to a week (Asselin and Spaulding 1993; Brooks et al. 1999; Sheldon and Alber 2002). If larvae are essentially passive particles, then they are also retained in estuaries for 2 days to a week after spawning, which would be sufficient for the PI larval shell to form before potential dispersal occurs. If the composition of the larval shell on a juvenile $M$. arenaria can be measured accurately, we may be able to answer questions about larval retention and dispersal.

Clam rearing $-M$. arenaria veligers were obtained from the Eastham Hatchery Facility in Eastham, Massachusetts, within $6 \mathrm{~h}$ of spawning and transported to Woods Hole, Massachusetts.

\section{Unspiked \\ No shell spiked}

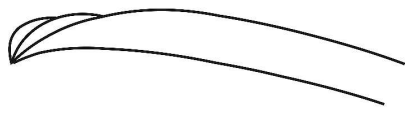

Early Spike

PII, juvenile shell spiked

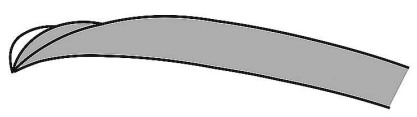

\section{Late Spike}

Some juvenile shell spiked

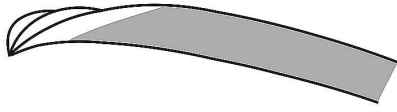

Fig. 2. Location of the ${ }^{138} \mathrm{Ba}$ spike treatments relative to shell development. Shaded regions show areas of spiked shell.

Approximately 400,000 individuals were divided into nine identical covered $10 \mathrm{~L}$ tanks. Tanks were filled with $20^{\circ} \mathrm{C}$ filtered seawater (salinity $\approx 32$ ). Assuming roughly $10 \%$ mortality during transport from Eastham to Woods Hole, initial larval counts were approximately 40,000 per tank. Each tank was randomly assigned one of three treatments described below, with three replicate tanks per treatment.

Several larvae were subsampled from each tank after $48 \mathrm{~h}$, and the PI was present in all sampled larvae. We then exposed clams to one of three treatment conditions that differed in the timing of exposure to the stable isotope ${ }^{138} \mathrm{Ba}$ (Fig. 2). Tanks in the first treatment received no ${ }^{138} \mathrm{Ba}$ spike and therefore the water had a natural ${ }^{138} \mathrm{Ba}:{ }^{137} \mathrm{Ba}$ ratio ("Unspiked"). Tanks in the second treatment received a ${ }^{138} \mathrm{Ba}$ spike of $25 \mu \mathrm{g} \mathrm{g}$ at day 2, immediately after the PI had set ("Early Spike"). Tanks in the third treatment received a ${ }^{138} \mathrm{Ba}$ spike of $25 \mu \mathrm{g} \mathrm{g}-1$ at day 9, $7 \mathrm{~d}$ after the PI set ("Late Spike"). By day 9, most of the larvae appeared to have set the PII and become competent to settle based on their shell size, tendency to accumulate at the bottom of the tank, and use of their foot for locomotion. This is faster than the estimated two to three weeks residence time of $M$. arenaria veligers in the field. Laboratory clams typically grow and mature faster compared with those in the field because of optimized rearing conditions ( $\mathrm{H}$. Lind, pers. comm.).

Larvae swam freely in tanks for the first $10 \mathrm{~d}$, after which time they were contained in mesh sieves suspended in the tanks. Water pumps were used to create a downward current that encouraged larvae to settle out of the water column. Subsampling of tanks indicated that larvae metamorphosed within 2 to $3 \mathrm{~d}$ after downwelling began. Clams were fed Isochrysis sp. and Pavlova sp. algae at least once every $2 \mathrm{~d}$, and the water in each tank was changed every $2 \mathrm{~d}$. In the Early and Late Spike tanks, a ${ }^{138} \mathrm{Ba}$ spike concentration of $25 \mu \mathrm{g} . \mathrm{g}^{-1}$ was maintained for the duration of the experiment by adding ${ }^{138} \mathrm{Ba}$ immediately after each water change. After 60 d, clams ranged in size from $0.5 \mathrm{~mm}$ to $5 \mathrm{~mm}$. They were removed from their tanks and frozen until prepared for ICP-MS analysis. Mortality 
rates were high in all tanks, and seven of the nine tanks had survivors: three replicate tanks from the Unspiked treatment ( $n=35, n=33, n=7)$, two replicate tanks from Early Spike treatment ( $n=75, n=22)$, and two replicate tanks from the Late Spike treatment $(n=14, n=8)$.

Shell preparation-Shells were cleaned thoroughly using techniques developed for foraminiferan tests (Boyle 1981) with modifications specifically for $M$. arenaria. Clams were placed in individual acid-washed vials using acid-washed plastic forceps, and sonicated briefly to remove tissue and debris. Individuals were rinsed three times with ultrapure $\mathrm{H}_{2} \mathrm{O}$, then soaked for $10 \mathrm{~min}$ at $80^{\circ} \mathrm{C}$ in $1 \% \mathrm{H}_{2} \mathrm{O}_{2}$ solution buffered with suprapur $\mathrm{NaOH}(1 \mathrm{~N})$ to remove organic material. Afterward, shells were rinsed three times with ultrapure $\mathrm{H}_{2} \mathrm{O}$, transferred to clean, acid-washed vials, rinsed four times with ultrapure $\mathrm{H}_{2} \mathrm{O}$, then left to dry overnight under a laminar flow hood. Shells were inspected after cleaning and drying for any remaining organic material; dried tissue was removed in the few cases where it was present.

Shells were mounted for laser ablation ICP-MS analysis on glass slides using Devcon@ Super Glue. One valve of each clam was oriented so that the retained larval shell was accessible by the laser (i.e., umbo facing upward), while the second valve was oriented concave side down so that the laser could access the flattest portion of the juvenile shell. All cleaning and preparations were conducted in a Class 100 clean room.

Laser ablation ICP-MS analysis-Shell material was analyzed using a Thermo-Electron Element2 ICP-MS coupled to a New Wave Research $213 \mathrm{~nm}$ laser ablation system. Vaporized material from the ablation was transported via a helium gas stream to the dual-inlet quartz spray chamber where it was mixed with a $2 \% \mathrm{HNO}_{3}$ aerosol from a self-aspirating PFA $20 \mu \mathrm{L} \mathrm{min}{ }^{-1}$ nebulizer. The analyte was then transported to the ICP-MS via an argon carrier gas. An aragonite otolith reference material dissolved in $2 \% \mathrm{HNO}_{3}$ and diluted to a Ca concentration of $40 \mathrm{\mu g} \mathrm{g}^{-1}$ (Yoshinaga et al. 2000) and a $2 \% \mathrm{HNO}_{3}$ blank solution were run periodically to correct for mass bias drift. We measured ${ }^{48} \mathrm{Ca},{ }^{138} \mathrm{Ba}$, and ${ }^{137} \mathrm{Ba}$ in low resolution mode. Isotope ratios of ${ }^{138} \mathrm{Ba}$ to ${ }^{137} \mathrm{Ba}$ were calculated using mass bias correction calculated from calibration standards that we assumed contained natural ${ }^{138} \mathrm{Ba}:{ }^{137} \mathrm{Ba}$ ratios. Blank intensity averages and standard deviations were calculated for each of the three analysis periods (Oct 2005, Jan 2006, Feb 2006). Limits of detection (LOD) were calculated as the ratio of three standard deviations of the blank intensity to the average blank-subtracted sample intensity. For the three time periods over which samples were analyzed, sample intensities were $>100$, $>690$, and $>2800$ times the detection limit for ${ }^{48} \mathrm{Ca} ;>100$, $>30$, and $>20$ times the detection limit for ${ }^{137} \mathrm{Ba}$; and $>290$, $>127$, and $>30$ times the detection limit for ${ }^{138} \mathrm{Ba}$, respectively.

Measurements were taken from two positions on each clam: one on the larval shell at the umbo, and a second on juvenile shell material $600 \mu \mathrm{m}$ away from the umbo (umbo and juvenile measurements, respectively). Shell composition
Table 1. Laser ablation ICP-MS settings used to analyze M. arenaria shell

\begin{tabular}{llc}
\hline & Raster setting & Spot setting \\
\hline Laser pattern & $70 \mu \mathrm{m}^{2}$ raster & $80 \mu \mathrm{m}$ spot \\
Laser power & $80 \%$ & $50 \%$ \\
Beam size & $25 \mu \mathrm{m}$ & $80 \mu \mathrm{m}$ \\
Repetition rate & $10 \mathrm{~Hz}$ & $5 \mathrm{~Hz}$ \\
Scan speed & $12 \mu \mathrm{m} \mathrm{s}^{-1}$ & \\
Line spacing & $10 \mu \mathrm{m}$ & \\
\hline
\end{tabular}

for each clam was analyzed using one of two laser settings (Table 1). In the first case (Raster Setting), the laser removed shell material systematically from a $70 \mu \mathrm{m} \times 70 \mu \mathrm{m}$ square raster pattern. Instrument and laser settings were chosen to maintain ${ }^{48} \mathrm{Ca}$ counts above two million counts $\mathrm{s}^{-1}$. For the second setting (Spot Setting), the laser was focused on a single spot with a beam diameter of $80 \mu \mathrm{m}$, and laser energy was reduced to $50 \%$ power. The laser pulsed on the spot repeatedly, boring down into shell material. Therefore, at least the first few seconds of measurement at the umbo should reflect larval shell; afterward the laser was expected to penetrate underlying material. This setting was used to explore whether the composition of thin larval shell could be quantified at reduced laser power with minimal material removed (i.e., only a few seconds of material ablation).

Rationale for experimental setup-Umbo and juvenile shell were each measured on clams from the three Unspiked treatment tanks ( $n=13, n=9, n=6)$ to test whether uptake differed between umbo and juvenile areas of the shell. No statistically significant differences were found for the three tanks combined (paired $t$ test, $t=0.83, n=28, P=0.42$ ) so only umbo measurements were used to simplify analysis.

Shell ratios of ${ }^{138} \mathrm{Ba}:{ }^{137} \mathrm{Ba}$ were expected to fall into one of three categories: a natural ratio, a fully ${ }^{138} \mathrm{Ba}$-spiked elevated ratio, or somewhere between these two end members. The natural ratio was determined by measuring shell that was not spiked (i.e., clams from the Unspiked treatment). The fully spiked ratio was determined for each clam individually in the Early and Late Spike treatments by measuring juvenile shell. Umbo measurements of clams from Early Spike and Late Spike treatments were expected to show one of three results, depending on the depth of laser penetration (Fig. 3): (A) no laser burn-through: umbo measurements from Early and Late Spike treatments did not significantly differ from unspiked shell; (B) some laser burn-through: umbo measurements from the Early Spike treatment have a significantly higher ratio than unspiked shell; umbo measurements from the Late Spike treatment have a ratio that does not differ significantly from unspiked shell; (C) extensive laser burn-through: umbo measurements from Early and Late Spike treatment have ratios that do not differ significantly from spiked juvenile shell.

If laser burn-through does occur, we may be able to correct for it by subtracting out the signal from any underlying 


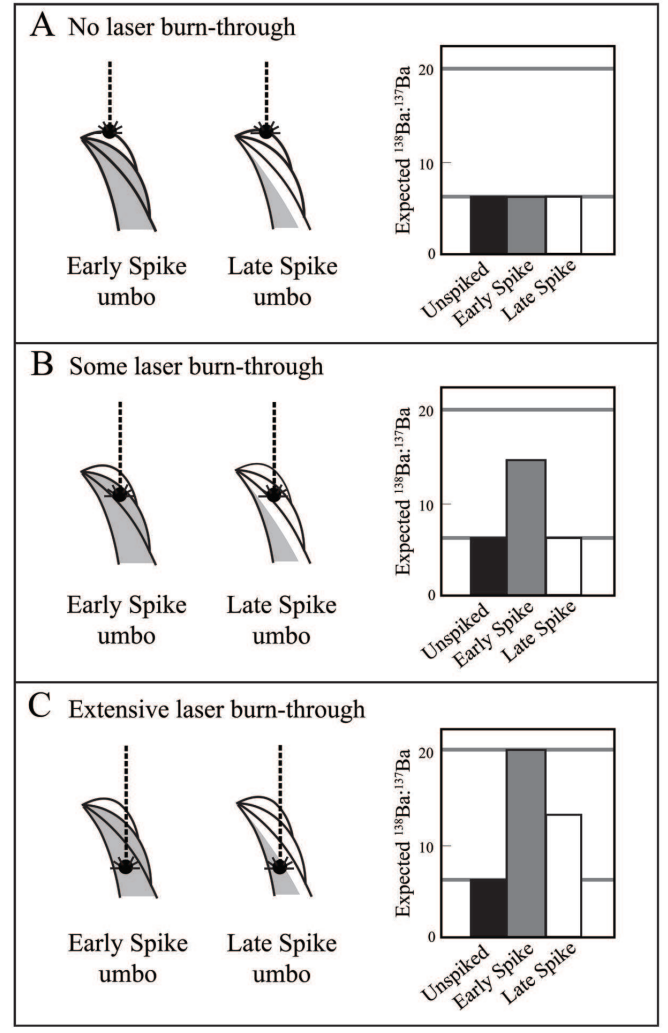

Fig. 3. Three possible scenarios for extent of laser burn-through. Graphs are the expected ${ }^{138} \mathrm{Ba}:{ }^{137} \mathrm{Ba}$ ratios for umbo measurements from the three treatments, depending on depth of laser penetration: (A) no laser burnthrough, (B) some laser burn-through, and (C) extensive laser burnthrough. Shaded regions of the shell graphics indicate spiked material. The shaded horizontal line in each graph at Expected ${ }^{138} \mathrm{Ba}:{ }^{137} \mathrm{Ba} \sim 20$ shows fully spiked shell, while the line at Expected ${ }^{138} \mathrm{Ba}:{ }^{137} \mathrm{Ba} \sim 6$ shows the natural ${ }^{138} \mathrm{Ba}:{ }^{137} \mathrm{Ba}$ ratio.

shell that might be contaminating our results. To determine if this was possible, we used a simple mixing equation (Eq. 1) to calculate the proportion of spiked and unspiked material ablated for each clam's umbo measurement from the spiked treatments:

$$
X\left(\frac{{ }^{138} B a}{{ }^{137} B a}\right)_{\text {Spiked }}+(1-X)\left(\frac{{ }^{138} B a}{{ }^{137} B a}\right)_{\text {Unspiked }}=\left(\frac{{ }^{138} B a}{{ }^{137} B a}\right)_{\text {Umbo }}
$$

where $\mathrm{X}$ is the proportion of spiked versus unspiked material ablated from the umbo of the clam, $\left({ }^{138} \mathrm{Ba}:{ }^{137} \mathrm{Ba}\right)_{\text {Spiked }}$ is the ratio from the juvenile measurement of the clam, $\left({ }^{138} \mathrm{Ba}:{ }^{137} \mathrm{Ba}\right)_{\text {Unspiked }}$ is the average ratio from umbos of clams in the Unspiked treatment, and $\left({ }^{138} \mathrm{Ba}:{ }^{137} \mathrm{Ba}\right)_{\text {Umbo }}$ is the ratio from the umbo measurement. Equation 1 was rearranged to determine the proportion of spiked material for each clam:

$$
\left.X=\left[\frac{\left(\frac{{ }^{138} B a}{{ }^{137} B a}\right)_{\text {Umbo }}-\left(\frac{{ }^{138} B a}{{ }^{137} B a}\right)_{\text {Unspiked }}}{\left(\frac{{ }^{138} B a}{{ }^{137} B a}\right)_{\text {Spiked }}-\left({ }^{138} B a\right.}\right)_{\text {Unspiked }}\right] .
$$

Editing profiles from Spot Setting-The Spot Setting was used to determine if unspiked material could be detected by producing a Ba isotope depth profile centered on the PI position of the shell. Data were initially acquired from a $2 \% \mathrm{HNO}_{3}$ blank solution, with laser ablation beginning approximately $18 \mathrm{~s}$ into data collection. The resulting intensity profiles were edited as follows to determine blank intensities and shell material intensities for the three isotopes of interest. Blank values were calculated as the average of the first $18 \mathrm{~s}$ of analysis. We started collecting data for shell material once a data point was $50 \%$ higher in ${ }^{48} \mathrm{Ca}$ intensity than its predecessor for a total of $20 \mathrm{~s}$. Detection limits were then calculated for the three isotopes based on the blank intensities, and only data with intensities at least $20 \%$ above the detection limit for all three isotopes were included in analyses (Fig. 4). The criterion used to remove data below the detection limit resulted in some profile sequences being shorter than others; time profiles ranged from 9 to 20 data points.

\section{Assessment}

Differences between treatments-Using the Raster Setting, the average $( \pm \mathrm{SD}){ }^{138} \mathrm{Ba}:{ }^{137} \mathrm{Ba}$ ratio in shell material was $6.4 \pm 1.0$ for Unspiked umbo $(n=19), 20.3 \pm 6.1$ for Early Spike umbo $(n=12)$, and $15.5 \pm 2.3$ for Late Spike umbo $(n=11)$ (Fig. 5). Using the Spot Setting, the average ( \pm SD) ratio was $5.8 \pm 1.1$ for unspiked umbo $(n=8), 20.0 \pm 1.9$ for Early Spike umbo $(n=14)$, and 15.5 \pm 3.9 for Late Spike umbo $(n=3)$. To determine if laser burnthrough occurred, we first tested whether there was significant variation in mean umbo measurements among treatments and among tanks within treatments using a mixed model nested ANOVA (Table 2). Under both Raster and Spot Settings, mean umbo measurements were significantly different between the three treatments (Raster, $F_{2,35}=56.4, P<0.0001$; Spot, $F_{2,23}=72.5$, $P<0.0001)$, with Unspiked ratio $<$ Late Spike $<$ Early Spike (Tukey-Kramer Test). We found no significant differences among tanks within treatments for the raster setting $(P=0.88$; number of clams per replicate tank: $n=7, n=6, n=6$ for Unspiked; $n=6$, $n=6$ for Early Spike; $n=6, n=5$ for Late Spike). We were not able to test for differences among tanks within treatments for the spot setting due to insufficient numbers (number of samples: $n$ $=5, n=3$ for Unspiked; $n=14$ for Early Spike; $n=3$ for Late Spike). Hereafter measurements from tanks of the same treatment were pooled. Because both Early and Late Spike umbo ratios differed significantly from Unspiked umbo, we rejected laser burn-through scenarios A and B and concluded that extensive laser burn-through was occurring (Fig. 3C). 

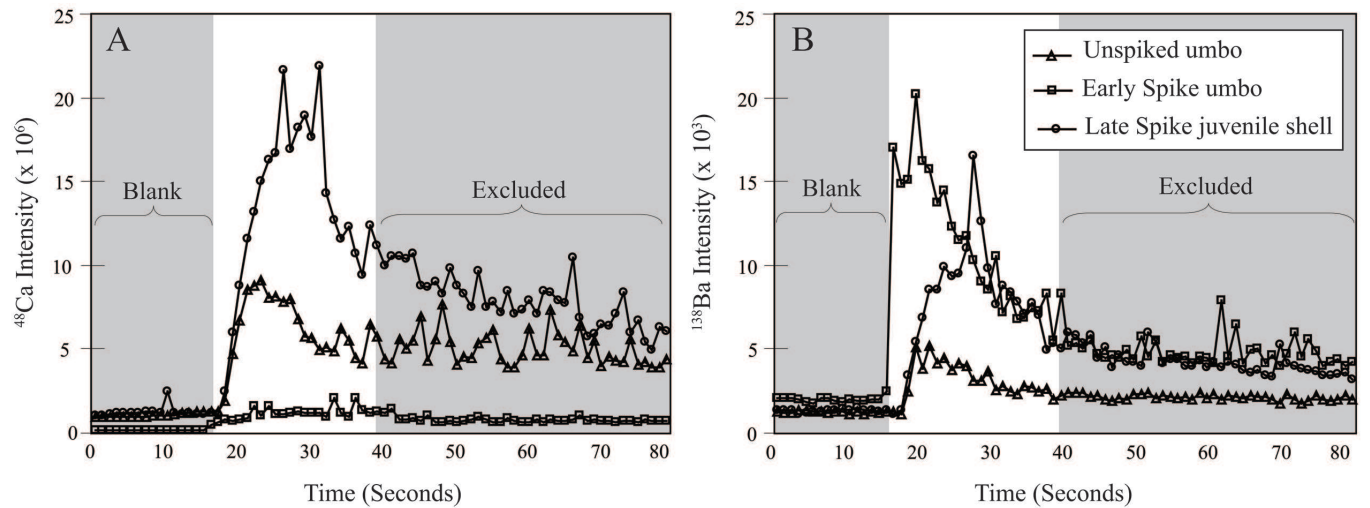

Fig. 4. Representative unedited intensity profiles for individual clams from laser ablation-ICP-MS measurements using the Spot Setting for $(A){ }^{48} \mathrm{Ca}$ and $(B)$ ${ }^{138} \mathrm{Ba}$. The data in the first shaded region were used to calculate the blank levels, and the data in the second shaded region were excluded from analysis.

Ratios for individual clams-The extent of laser burn-through was addressed by comparing umbo measurements with spiked juvenile shell for each clam using a paired $t$ test. If the umbo ratio was not significantly different from spiked juvenile shell, it suggests that a measurable quantity of unspiked shell was not present at the umbo. For the Raster Setting, umbo measurements were not significantly different from juvenile measurements in Unspiked clams $(t=-0.45, \mathrm{n}=19, P=0.66)$ or Early Spike clams $(t=-1.0, n=12, P=0.34)$. In Late Spike clams, the umbo ${ }^{138} \mathrm{Ba}:{ }^{137} \mathrm{Ba}$ ratio of 15.6 was slightly lower than the juvenile shell ratio of $18.3(t=2.7, n=11, P<0.05)$. Results were similar using the Spot Setting. Unspiked and Early Spike umbo means were not significantly different from juvenile measurements $(t=1.6, n=9, P=0.15$; and $t=0.85, n=14$, $P=0.41$, respectively), whereas Late Spike mean umbo and juvenile ratios differed, although sample size was small $(t=-7.0$, $\mathrm{n}=3, P<0.05)$. The umbo and juvenile ratios are plotted for each clam from the Raster Setting (Fig. 6). Results were similar for Spot Setting analyses and are not presented. The data were again consistent with a scenario of extensive laser burnthrough (Fig. 3C). Umbo shell ratios tended to be more similar to juvenile shell ratios than to unspiked shell, indicating that umbo measurements were not isolating the unspiked larval shell from underlying shell material.

For some clams, umbo ratios were unexpectedly higher than juvenile ratios (Fig. 6). In theory, all juvenile clams experienced the maximum amount of spike, but ratios in juvenile shell were variable among clams, ranging from 9.4 to 22.3. Some of this variability might be attributed to physiological differences among clams, but much of it likely originates from variability in the laser ablation ICP-MS measurements. For instances when umbo ratios were higher than juvenile ratios for the same clam, the magnitude of the difference was within the range of variability expected based on the range seen in juvenile shell ratios.
Late Spike umbo ratios were slightly lower than Early Spike umbo ratios, indicating that a larger proportion of unspiked shell was being ablated in Late Spike clams. Clams in this treatment were allowed to set shell for $9 \mathrm{~d}$ without spike; however measurements from the umbo still showed only a small difference from fully spiked shell. This is a surprising result with implications for the usefulness of ICP-MS in connectivity studies. Measurements taken at the umbo may not represent natal habitat signatures alone, but rather the integration of habitats encountered by the organism over more than $9 \mathrm{~d}$ of life.

Time profiles of umbo measurements-Spot Setting data were used to investigate whether unspiked larval shell could be

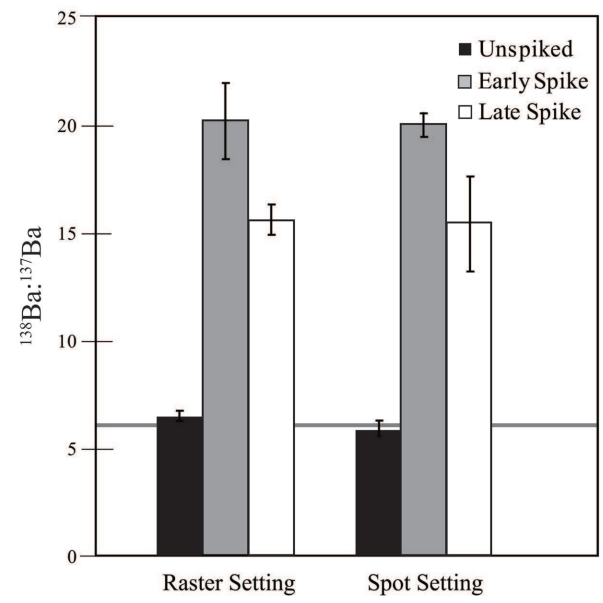

Fig. 5. Average umbo ${ }^{138} \mathrm{Ba}:{ }^{137} \mathrm{Ba}$ ratios ( \pm standard error) for clams measured using Raster and Spot Settings in the three treatments. The shaded horizontal line shows the natural ${ }^{138} \mathrm{Ba}:{ }^{137} \mathrm{Ba}$ ratio. 
Table 2. Results from ANOVA testing for differences among treatment mean ratios

\begin{tabular}{lrrrc}
\hline Source & df & MS & F & p \\
\hline Raster Setting & & & & \\
$\quad$ Treatment & 2 & 760 & 56.4 & $<0.0001$ \\
$\quad$ Tank (Treatment) & 3 & 5.36 & 0.397 & 0.877 \\
$\quad$ Error & 35 & 13.5 & & \\
Spot Setting & & & & \\
$\quad$ Treatment & 2 & 497 & 72.5 & $<0.0001$ \\
$\quad$ Error & 23 & 6.86 & & \\
\hline
\end{tabular}

For the raster setting, results are from a mixed model nested ANOVA testing for differences among treatment means and for variation among tanks nested within treatments. For the spot setting, results are from a one-way ANOVA; data from tanks were combined to have sufficient sample size to test for differences among treatment means (see Methods).

detected in the first seconds of laser ablation. This would be evident if initial ${ }^{138} \mathrm{Ba}:{ }^{137} \mathrm{Ba}$ ratios were near natural levels, or at least significantly lower than subsequent ratios. Visual inspection of depth profiles suggested that unspiked shell was not being detected early during ablation (Fig. 7). To statistically test this, we averaged the first five points of shell ablation data and compared the value with an average of the remaining 15 points using a paired $t$ test. Five points were averaged to represent initial shell because single data points are highly variable and subject to small fluctuations in the amount of material ablated and instrument sensitivity (Guillong et al. 2001; Russo 1995). If a significant proportion of material ablated early was composed of unspiked shell, the first five points should be significantly lower than the last 15 . In all treatments, the first five points were not significantly lower than the last 15 (Unspiked: $t=1.2, \mathrm{n}=7, P=0.29$; Early Spike: $t=1.979, n=13, P=0.071$; Late Spike: $t=-1.2, n=5, P=.30$ ). The lack of unspiked material might be due to the overwhelming signal of underlying spiked shell, or that the points representing unspiked shell fell below the $>20 \%$ detection limit cutoff and were excluded. In either case, our results suggested that unspiked larval shell was not detectable even when laser power was reduced and minimal material ablated.

Neither Early nor Late Spike treatments were spiked during PI formation. As a result, initial shell measurements at the umbo should have reflected unspiked shell if only the PI was measured. Measurements taken later (deeper) were expected to have an increase in the ratio of ${ }^{138} \mathrm{Ba}:{ }^{137} \mathrm{Ba}$, and the timing of that increase would be related to the time when the spike was added during shell formation. The absence of detectable unspiked shell at the beginning of ablation for both Early and Late Spike treatments suggests that laser ablation does not isolate and measure the first larval shell accurately. Furthermore, based on results from Late Spike clams, the first few seconds of laser ablation removes at least $9 \mathrm{~d}$ worth of shell growth from laboratory-reared clams.

Although we were unsuccessful at measuring the larval shell in our study, there is no evidence that the PI larval shell is meta-
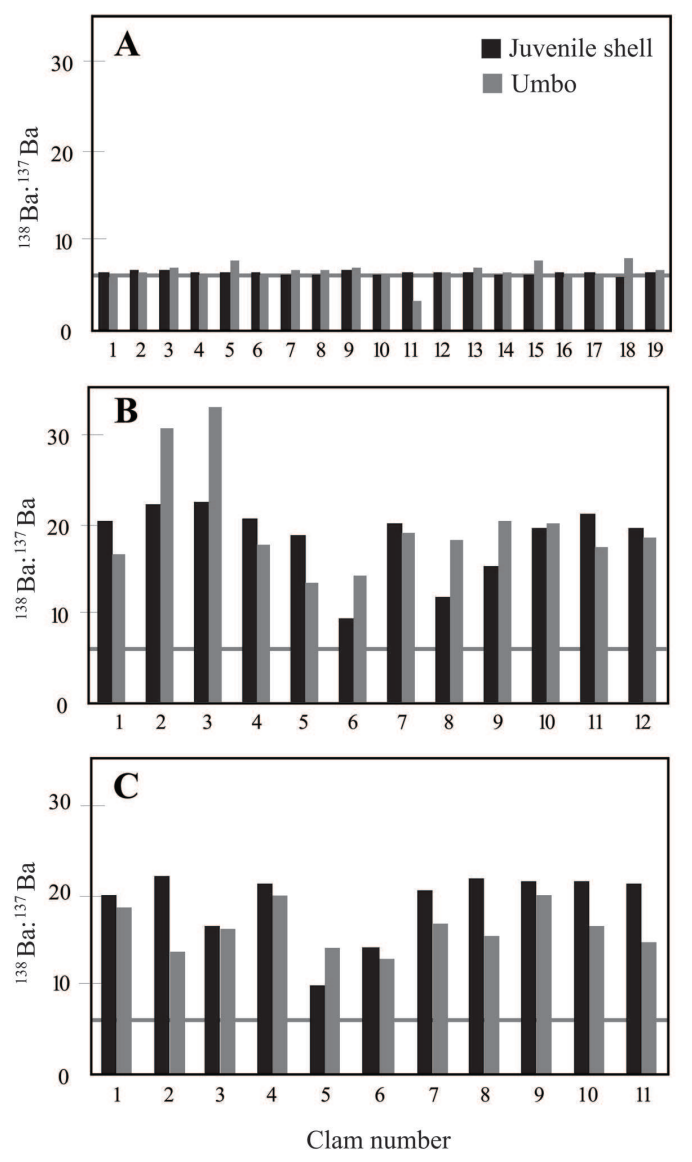

Fig. 6. ${ }^{138} \mathrm{Ba}:{ }^{137} \mathrm{Ba}$ ratios for each clam, for each of the three treatments as measured by the Raster setting: (A) Unspiked, (B) Early Spike, and (C) Late Spike. The shaded horizontal line in each graph shows the natural ${ }^{138} \mathrm{Ba}:{ }^{137} \mathrm{Ba}$ ratio.

bolically reworked, absent from the juvenile shell, or otherwise unusable for connectivity studies. However, our study demonstrated that regardless of the presence, absence, or inert qualities of the larval shell, we were unable to detect or measure the larval shell with the settings and instrumentation reported.

Proportion spiked material-We calculated the proportion of spiked material for Early and Late Spike umbo measurements from the Raster Setting using Eq. 2 (Fig. 8). Average proportions of spiked material $( \pm \mathrm{SD})$ were $1.3 \pm 0.7(n=12)$ for Early Spike umbo measurements and $0.9 \pm 0.5(n=11)$ for Late Spike umbo. A one-sample $t$ test showed no significant difference between mean proportions and unspiked material, i.e., the 

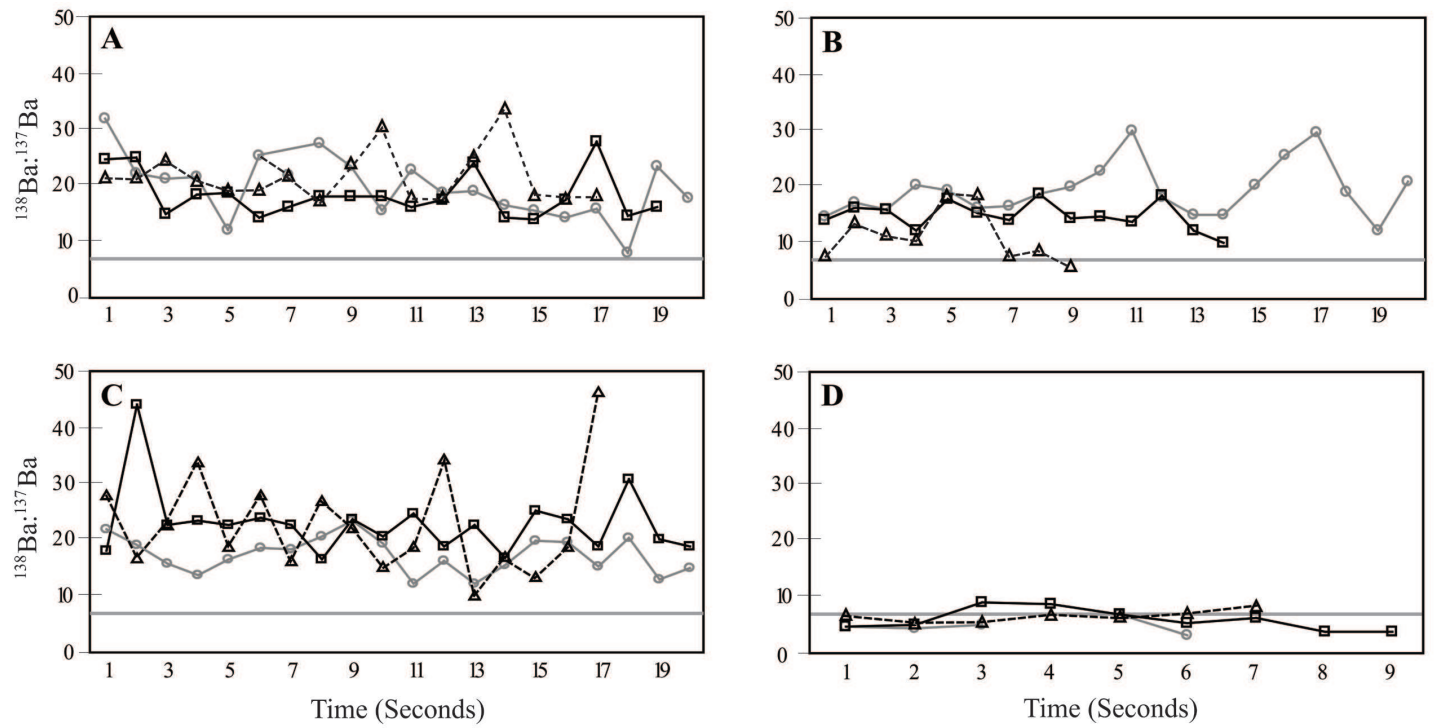

Fig. 7. Three representative edited time profiles of ${ }^{138} \mathrm{Ba}:{ }^{137} \mathrm{Ba}$ for individual clams using the Spot Setting: (A) Early Spike umbo, (B) Late Spike umbo, (C) spiked juvenile shell, and (D) Unspiked umbo. The horizontal gray line indicates the natural ${ }^{138} \mathrm{Ba}:{ }^{137} \mathrm{Ba}$ ratio. Profiles not shown had similar patterns.

mean proportion did not differ from 1.0 (Early Spike: $t=1.5$, $P=0.16$; Late Spike: $t=-0.7, P=.48$ ). Results were similar for Spot Setting clams and are not shown.

Variability in the ratios of umbo measurements among individuals from the two spiked treatments resulted in a high degree of variability in the calculated proportion of spiked material. We were able to detect this variability and quantify the amount of spiked versus unspiked shell since material underneath the larval shell was tagged using ${ }^{138} \mathrm{Ba}$. However, this variability is not easily predicted or quantified in field samples of $M$. arenaria since there is no known element with different, and constant, concentrations in larval versus juvenile shell. Therefore, we concluded that correcting for laser burn-through using Eq. 2 likely would not be useful for field samples.

\section{Discussion}

Implications for connectivity -We were unable to isolate and measure the larval shell of $M$. arenaria using laser ablation ICP-MS settings designed for minimal shell removal. The laser consistently burned through the larval shell and into underlying late-stage larval and juvenile material. In addition, the proportion of underlying shell ablated was too variable to allow for any reliable correction to account for the burnthrough. Our study suggests laser burn-through is a significant problem for connectivity studies of $M$. arenaria, and possibly of other molluscan species that may spend only a short time in their natal location.
New England estuaries tend to have residence times on the order of $2 \mathrm{~d}$ to more than a week (Asselin and Spaulding 1993; Sheldon and Alber 2002), suggesting that larvae may experience their natal habitat for as few as $48 \mathrm{~h}$. Our results indicate that we burned through at least $9 \mathrm{~d}$ of shell growth in the umbo region of laboratory-reared juvenile $M$. arenaria. The number of days of growth ablated depends on shell growth rate, which varies depending on field environmental conditions and laboratory rearing conditions (LaValley 2001). Although there may be some differences between growth rates in the field and those of clams in our experiment, our results show that laser ablation removes significantly more shell than what is laid in the first 24 to $48 \mathrm{~h}$, when clams are most likely retained in their natal habitat.

Laser burn-through appears to be a substantial problem for connectivity studies of organisms with rapid dispersal, but it may be less problematic in other scenarios. Species that brood their larvae may produce more shell material before potential dispersal, making isolation of natal habitat signatures possible. Similarly, larvae that are broadcast spawned but retained in their natal habitat for most of their larval stage due to physics might have time to deposit sufficient shell for reliable measurement. However, requiring that organisms experience their natal habitat for long periods of time limits the species we can study using natural tagging techniques.

Alternative approaches - In this study, we chose to explore laser burn-through issues relating to laser ablation ICP-MS because it 

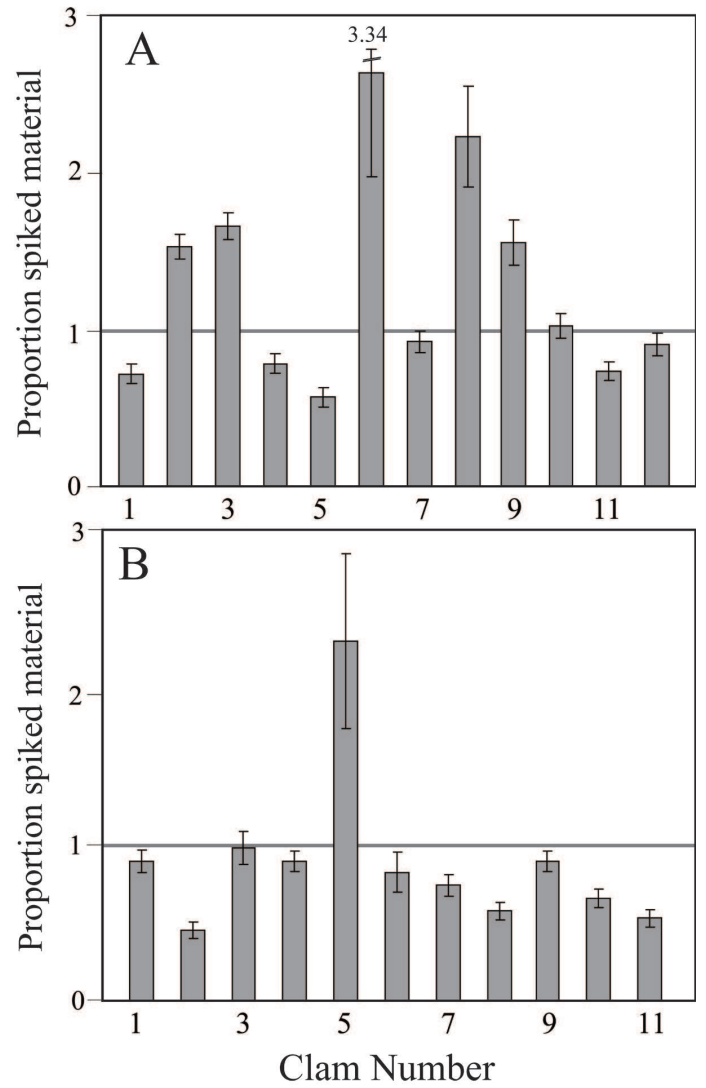

Fig. 8. Proportion spiked material for umbo measurements of ${ }^{138}$ Ba-treated clams using the Raster Setting, for (A) Early Spike and (B) Late Spike treatments.

is an instrument commonly used for carbonate analysis and has been chosen by other molluscan tagging studies. Our results suggest that other techniques and instrument configurations should be tested to determine whether they might more reliably isolate the thin larval components of shell. For instance, researchers have reported that excimer lasers operating at $193 \mathrm{~nm}$ generate shallower craters than we were able to achieve in the present study (e.g., Patterson et al. 2005), while the burn-through problem is likely more pronounced with instruments using lasers with longer wavelengths (e.g., FitzGerald et al. 2004; Jones and Chen 2003). We are unaware of any formal studies comparing crater depths in carbonates for lasers of different wavelengths. Gonzalez et al. (2002) showed, however, that crater shapes and depths produced in glass standards were similar for $193 \mathrm{~nm}$ and $213 \mathrm{~nm}$ lasers, and both of these lasers produced shallower and more regular craters than $266 \mathrm{~nm}$ lasers.
Instrument sensitivity also plays a significant role in determining the amount of material that needs to be transported to the plasma to make a sufficiently precise and accurate measurement of shell chemistry. We did not experiment with running the ICP-MS in dry plasma mode with a desolvating nebulizer, because in our experience such changes lead to only small increases in sensitivity. Barnes et al. (2004) reported that combining a laser with an ICP ionization source and a Mattuch-Herzog mass spectrograph can dramatically increase limits of detection (i.e., instrument sensitivity) and allow for accurate measurement of material from single laser pulses (5 nm depth per pulse). However, development of such unique, customized systems designed for specific types of analysis is difficult and expensive, making it an intractable solution for most researchers.

Other instruments that may warrant further investigation include secondary ionization mass spectrometry (SIMS) and proton induced $\mathrm{x}$-ray emission (PIXE). Although they have been used successfully in otolith studies, LOD and penetration depths of the secondary ion beam (SIMS) and x-rays (PIXE) suggest that neither instrument is likely to isolate larval shell material effectively (Campana et al. 1997). Another potential problem with SIMS and PIXE is that present configurations are not able to analyze trace elements such as $\mathrm{Ba}, \mathrm{Cd}, \mathrm{Mn}$, and $\mathrm{Pb}$ as effectively as ICP-MS (Campana 1999). Such elements have proven useful for distinguishing different habitats in natural tagging studies of fishes (e.g., Patterson et al. 2005; Thorrold et al. 1998; Thorrold et al. 2001). Finally, both SIMS and PIXE require the surface of the analyte to be flat. For bivalve larval shell analysis, this requires that the juvenile shell be embedded in epoxy, then cross-sectioned so that the larval shell is visible, and then polished. Obtaining a cross-section that includes the larval shell after polishing is nearly impossible in our experience.

Shells, statoliths, and otoliths are three-dimensional structures, and the materials underlying the carbonate of interest may confound elemental analysis. Based on our results, laser ablation ICP-MS analysis may result in contamination of natal habitat signatures by underlying carbonate material formed later in the organism's life. Laser burn-through issues are especially important in connectivity studies where it is often necessary to target an extremely small area of a shell that represents the material deposited before potential dispersal away from natal locations. We emphasize that any system should be closely scrutinized to assure that analyses are not compromised by laser burn-through.

\section{References}

Arkhipkin, A. I., S. E. Campana, J. FitzGerald, and S. R. Thorrold. 2004. Spatial and temporal variation in elemental signatures of statoliths from the Patagonian longfin squid (Loligo gahi). Can. J. Fish. Aquat. Sci. 61:1212-1224.

Asselin, S., and M. L. Spaulding. 1993. Flushing times for the Providence River based on tracer experiments. Estuaries 16:830-839. Barnes, J. H., G. D. Schilling, G. M. Hieftje, R. P. Sperline, 
M. B. Denton, C. J. Barinaga, and D. W. Koppenaal. 2004. Use of a novel array detector for the direct analysis of solid samples by laser ablation inductively coupled plasma sectorfield mass spectrometry. J. Am. Soc. Mass Spectrom. 15: 769-776.

Bath, G. E., S. R. Thorrold, C. M. Jones, S. E. Campana, J. W. McLaren, and J. W. H. Lam. 2000. Strontium and barium uptake in aragonitic otoliths of marine fish. Geochim. Cosmochim. Acta 64:1705-1714.

Becker, B. J., F. J. Fodri.e., P. McMillan, and L. A. Levin. 2005. Spatial and temporal variation in trace elemental fingerprints of mytilid mussel shells: a precursor to invertebrate larval tracking. Limnol. Oceanogr. 50:48-61.

Boyle, E. A. 1981. Cadmium, zinc, copper, and barium in foraminifera tests. Earth Planet. Sci. Lett. 53:11-35.

Brooks, D. A., M. W. Baca, and Y. Lo. 1999. Tidal circulation and residence time in a macrotidal estuary: Cobscook Bay, Maine. Estuar. Coast. Shelf Sci. 49:647-665.

Campana, S. E. 1999. Chemistry and composition of fish otoliths: pathways, mechanisms and applications. Mar. Ecol. Prog. Ser. 188:263-297.

_ and S. R. Thorrold. 2001. Otoliths, increments, and elements: keys to a comprehensive understanding of fish populations? Can. J. Fish. Aquat. Sci. 58:30-38.

and others. 1997. Comparison of accuracy, precision, and sensitivity in elemental assays of fish otoliths using the electron microprobe, proton-induced X-ray emission, and laser ablation inductively coupled plasma mass spectrometry. Can. J. Fish. Aquat. Sci. 54:2068-2079.

DiBacco, C., and L. A. Levin. 2000. Development and application of elemental fingerprinting to track the dispersal of marine invertebrate larvae. Limnol. Oceanogr. 45:871-880.

Elsdon, T. S., and B. M. Gillanders. 2003. Relationship between water and otolith elemental concentrations in juvenile black bream Acanthopagrus butcheri. Mar. Ecol. Prog. Ser. 260:263-272.

FitzGerald, J. L., S. R. Thorrold, K. M. Bailey, A. L. Brown, and K. P. Severin. 2004. Elemental signatures in otoliths of larval walleye pollock (Theragra chalcogramma) from the northeast Pacific Ocean. Fish. Bull. 102:604-616.

Fowler, A. J., S. E. Campana, C. M. Jones, and S. R. Thorrold. 1995. Experimental assessment of the effect of temperature and salinity on elemental composition of otoliths using solution-based ICPMS. Can. J. Fish. Aquat. Sci. 52:1421-1430.

Gonzalez, J., X. L. Mao, J. Roy, S. S. Mao, and R. E. Russo. 2002. Comparison of 193, 213, and $266 \mathrm{~nm}$ laser ablation ICPMS. J. Anal. At. Spectrom. 17:1108-1113.

Guillong, M., I. Horn, and D. Gunther. 2001. Capabilities of a homogenized $266 \mathrm{~nm}$ Nd:YAG laser ablation system for LA-ICP-MS. J. Anal. At. Spectrom. 17:8-14.

Jones, C. M., and Z. Chen. 2003. New techniques for sampling larval and juvenile fish otoliths for trace-element analysis with laser-ablation SF-ICP-MS. In Browman HI, Skiftesvik $\mathrm{AB}$ (eds) The Big Fish Bang. Proceedings of the 26th Annual
Larval Fish Conference. Institute of Marine Research, 22-26 July 2002, Bergen, Norway. pp. 431-443.

LaValley, K. J. 2001. Effects of nursery culture technique on the morphology and burrowing capability of the softshell clam, Mya arenaria. J. Shellfish Res. 20:522.

Levin, L. A. 1990. A review of methods for labeling and tracking marine invertebrate larvae. Ophelia 32:115-144.

Loosanoff, V. L., H. C. Davis, and P. E. Chanley. 1966. Dimensions and shapes of larvae of some bivalve mollusks. Malacologia 4:351-435.

Moilanen, A., and M. Nieminen. 2002. Simple connectivity measures in spatial ecology. Ecology 83:1131-1145.

Patterson, H. M., M. J. Kingsford, and M. T. McCulloch. 2005. Resolution of the early life history of a reef fish using otolith chemistry. Coral Reefs 24:222-229.

Russo, R. E. 1995. Laser ablation. Appl. Spectrosc. 49:14A-28A. Sheldon, J. E., and M. Alber. 2002. A comparison of residence time calculations using simple compartment models of the Altamaha River Estuary, Georgia. Estuaries 25:1304-1317.

Thorrold, S. R., C. M. Jones, and S. E. Campana. 1997. Response of otolith microchemistry to environmental variations experienced by larval and juvenile Atlantic croaker (Micropogonias undulatus). Limnol. Oceanogr. 42:102-111.

, C. M. Jones, S. E. Campana, J. W. McLaren, and J. W. H. Lam. 1998. Trace element signatures in otoliths record natal river of juvenile American shad (Alosa sapidissima). Limnol. Oceanogr. 43:1826-1835.

, G. P. Jones, M. E. Hellberg, R. S. Burton, S. E. Swearer, J. E. Neigel, S. G. Morgan, and R. R. Warner. 2002. Quantifying larval retention and connectivity in marine populations with artificial and natural markers. Bull. Mar. Sci. 70: 291-308.

, C. Latkoczy, P. K. Swart, and C. M. Jones. 2001. Natal homing in a marine fish metapopulation. Science 291: 297-299.

Thorson, G. 1950. Reproductive and larval ecology of marine bottom invertebrates. Biol. Rev. 25:1-45.

- 1966. Some factors influencing the recruitment and establishment of marine benthic communities. Neth. J. Sea Res. 3:267-293.

Vander Putten, E., F. Dehairs, E. Keppens, and W. Baeyens. 2000. High resolution distribution of trace elements in the calcite shell layer of modern Mytilus edulis: Environmental and biological controls. Geochim. Cosmochim. Acta 64: 997-1011.

Yoshinaga, J., A. Nakama, M. Morita, and J. S. Edmonds. 2000. Fish otolith reference material for quality assurance of chemical analyses. Mar. Chem. 69:91-97.

Zacherl, D. C., and others. 2003. Trace elemental fingerprinting of gastropod statoliths to study larval dispersal trajectories. Mar. Ecol. Prog. Ser. 248:297-303.

Submitted 19 October 2006 Revised 18 April 2007 Accepted 8 May 2007 


\section{Chapter 3}

\section{Growth rate and age effects on}

\section{Mya arenaria shell chemistry:}

Implications for biogeochemical

\section{studies}

by Carly A. Strasser, Lauren S. Mullineaux, and Benjamin D. Walther

Reprinted from Journal of Experimental Marine Biology and Ecology 355: 153 - 163 


\title{
Growth rate and age effects on Mya arenaria shell chemistry: Implications for biogeochemical studies
}

\author{
Carly A. Strasser ${ }^{\mathrm{a}, *}$, Lauren S. Mullineaux ${ }^{\mathrm{a}}$, Benjamin D. Walther ${ }^{\mathrm{b}}$ \\ ${ }^{a}$ Biology Department, Woods Hole Oceanographic Institution, Woods Hole MA 02543, USA \\ ${ }^{\mathrm{b}}$ Southern Seas Ecology Laboratories, School of Earth and Environmental Science, University of Adelaide, South Australia 5005, Australia \\ Received 9 November 2007; received in revised form 18 December 2007; accepted 20 December 2007
}

\begin{abstract}
The chemical composition of bivalve shells can reflect that of their environment, making them useful indicators of climate, pollution, and ecosystem changes. However, biological factors can also influence chemical properties of biogenic carbonate. Understanding how these factors affect chemical incorporation is essential for studies that use elemental chemistry of carbonates as indicators of environmental parameters. This study examined the effects of bivalve shell growth rate and age on the incorporation of elements into juvenile softshell clams, Mya arenaria. Although previous studies have explored the effects of these two biological factors, reports have differed depending on species and environmental conditions. In addition, none of the previous studies have examined growth rate and age in the same species and within the same study. We reared clams in controlled laboratory conditions and used solution-based inductively coupled plasma mass spectrometry (ICP-MS) analysis to explore whether growth rate affects elemental incorporation into shell. Growth rate was negatively correlated with $\mathrm{Mg}$, Mn, and Ba shell concentration, possibly due to increased discrimination ability with size. The relationship between growth rate and $\mathrm{Pb}$ and $\mathrm{Sr}$ was unresolved. To determine age effects on incorporation, we used laser ablation ICP-MS to measure changes in chemical composition across shells of individual clams. Age affected incorporation of $\mathrm{Mn}, \mathrm{Sr}$, and $\mathrm{Ba}$ within the juvenile shell, primarily due to significantly different elemental composition of early shell material compared to shell accreted later in life. Variability in shell composition increased closer to the umbo (hinge), which may be the result of methodology or may indicate an increased ability with age to discriminate against ions that are not calcium or carbonate. The effects of age and growth rate on elemental incorporation have the potential to bias data interpretation and should be considered in any biogeochemical study that uses bivalves as environmental indicators.
\end{abstract}

Published by Elsevier B.V.

Keywords: Bivalve shell; Carbonate chemistry; Element incorporation; Growth rate; Mya arenaria

\section{Introduction}

Marine bivalves have been used successfully as indicators of environmental properties for several decades (e.g. Dodd, 1965; Klein et al., 1996; Boisson et al., 1998). Bivalves are ideally suited for this purpose given their sedentary nature after recruiting to the benthos, high abundances, relatively large sizes, longevity, and hardiness (Phillips, 1977). In particular, bivalve shells have proven useful for environmental reconstructions since shell and ambient water elemental concentrations exhibit a monotonically increasing relationship (Wilbur, 1972). This

* Corresponding author. MS 34 Redfield 120, 266 Woods Hole Road, Woods Hole MA 02543, USA. Tel.: +1 508289 2358; fax: +1 5084572134 .

E-mail address: cstrasser@whoi.edu (C.A. Strasser). doi:10.1016/j jembe 2007.12 .022

relationship is sometimes affected by environmental properties such as temperature and salinity; researchers exploit this characteristic to explore environmental conditions that occurred during shell development (e.g. Rucker and Valentine, 1961; Dodd, 1965; Lerman, 1965; Dodd and Crisp, 1982; Pitts and Wallace, 1994; Lazareth et al., 2003). In studies where bivalves are used as indicators of environment, whole shells or portions of individual shells are analyzed for their elemental composition, and then related to spatial or temporal variation in elemental concentrations, temperature, or salinity of the seawater of formation.

Although the relationship between shell composition and water chemistry has been studied in the past, there are no consistent results across different species. For instance, $\mathrm{Sr}: \mathrm{Ca}$ in molluscan shell has been reported as correlating both positively 
(Dodd, 1965; Smith et al., 1979; Stecher et al., 1996) and negatively (Zacherl et al., 2003) to temperature, depending on the species examined. These differences likely originate in the physiological underpinnings of shell formation and deposition, such as regulation of extrapallial fluid composition by the mantle, which differs depending on species (Wilbur, 1972). Such contradictory results highlight the need for understanding biological factors that potentially influence elemental composition of shell.

Despite some uncertainty about the physiological processes that drive the monotonic relationship between shell chemistry and water composition, many fields of study take advantage of the relationship to answer questions about the environment and the ecosystem as a whole. For instance, environmental managers use bivalves as bioindicators of metal contamination in coastal habitats by measuring the trace metal content of shells (Lindh et al., 1988; Bourgoin, 1990; Fuge et al., 1993; Pearce and Mann, 2006). Another use of bivalve shell composition is as a recorder of habitat use. For instance, population biologists are exploring the use of geographically variable chemical signatures recorded in larval shell as natural tags to track dispersal (Zacherl, 2005; Becker et al., 2007). Shell chemistry also can be used as a proxy for changes in water properties. Biological monitors of water chemistry, such as bivalves, are especially important in habitats that are difficult to extensively sample on relevant time scales, such as deep-sea hydrothermal vents (Hart and Blusztajn, 1998), or in paleoclimatic studies of salinity or temperature change on millennial time scales (e.g. Bourgoin and Risk, 1987).

In this study, we were most concerned with biological factors that might affect elemental incorporation into shell, specifically the effect of growth rate and age. Declines in elemental incorporation into the shell's crystal latice have been reported to occur with age for $\mathrm{Pb}$ in the abalone Haliotis spp. (Hirao et al., 1994; Arai et al., 2003) and for $\mathrm{Sr}$ and $\mathrm{Mg}$ in the bivalve Mytilus spp. (Dodd, 1965). In addition to age, growth rate may impact elemental incorporation into shell. Individuals with rapid growth rates have been shown to incorporate higher amounts of elements into carbonate compared to slower-growing individuals of the same species (Wilbur, 1972). This effect has been observed in coral skeletons (Marshall and McCulloch, 2002; Mitsuguchi et al., 2003), fish otoliths (Hamer and Jenkins, 2007), and adult bivalve shells (Stecher et al., 1996; Gillikin et al., 2005; Carre et al., 2006). These two biological factors have the potential to decouple relationships between ambient water properties and biogenic carbonate composition. As such, they must be understood and taken into account during any attempts to reconstruct environmental conditions or habitat use based on shell chemistry.

Although the studies above have explored the effects of growth rate and age on elemental incorporation into carbonate, none have explored the effects of these two biological factors in the same species and within the same study. The goal of this study was to understand the relationships between growth rate and age on shell chemistry in the commercially important softshell clam, Mya arenaria. First, we examined the effects of growth rate on shell elemental composition by comparing shells of clams from the same cohort, reared in the same conditions, but with different final sizes and therefore different growth rates. Second, we compared different regions of shell within the juvenile stage to explore the effects of age on incorporation. Previous studies have focused on one or two elements for exploring the relationship between biological factors and elemental incorporation into shell (e.g. Hirao et al., 1994; Gillikin et al., 2005; Carre et al., 2006). Here we look at five elements found to be useful indicators of environmental properties in previous studies. In addition, we used controlled laboratory conditions to distinguish between biological factors and environmental factors that vary in natural settings, such as temperature and salinity. Our results have implications for biogeochemical studies that use bivalve shell elemental composition as an indicator of environmental parameters. If age or growth rate affects incorporation of elements into carbonate, investigators are obliged to take these factors into consideration when interpreting environmental variables based on shell chemistry.

\section{Methods}

\subsection{Clam rearing}

Adult $M$. arenaria with ripe gonads were obtained from Cotuit, Massachusetts in April 2006 and transported to the Environmental Systems Laboratory (ESL) at Woods Hole Oceanographic Institution, where they were placed in mesh bags and suspended in a $750 \mathrm{~L}$ tank with filtered seawater. Spawning activity commenced approximately $1 \mathrm{~h}$ later, and the tank was left undisturbed to allow spawning to complete and for fertilization to take place. After $5 \mathrm{~h}$ the adult clams were removed, and the tank contents were filtered through a $35 \mu \mathrm{m}$ synthetic nylon mesh sieve to concentrate the larvae into a small volume $(\sim 20 \mathrm{~L})$. We counted a subsample of larvae and obtained a total estimate of 16 million trochophore larvae.

Trochophore larvae were placed into $12 \mathrm{~L}$ high-density polyethylene tanks (three tanks per experiment) at a density of approximately 45 larvae $\mathrm{mL}^{-1}$. Clams whose shells were intended for the growth rate experiment (see explanation of experiments below) were reared in water with salinity $\sim 22.5 \%$ o at $20{ }^{\circ} \mathrm{C}$. Clams whose shells were intended for the age experiment were reared in undiluted seawater $(\sim 30 \%)$ at $24^{\circ} \mathrm{C}$. Temperatures and salinities were within the range experienced by this species in temperate tidal estuaries and were chosen because the tanks were in use as part of a larger set of experiments; no comparisons were made between shells of clams reared in different salinities. Tanks were placed into large water baths to maintain experimental temperatures. The $20{ }^{\circ} \mathrm{C}$ water bath received a continuous supply of $20^{\circ} \mathrm{C}$ water, which was regulated for the facility's seawater supply line by largevolume chillers and heaters. The water bath for $24^{\circ} \mathrm{C}$ tanks was maintained using a 120 -volt tank heater regulated by a thermostat (Process Technology EasyPlug TM Heater with Digital Controller, $1800 \mathrm{~W})$. Seawater for tanks was obtained from the in-house supply line, which pumps water from Vineyard Sound $100 \mathrm{~m}$ offshore at a water depth of $4 \mathrm{~m}$. All 
seawater was filtered to remove particles $>1 \mu \mathrm{m}$ before use. Salinity was reduced to $22.5 \%$ by adding ultrapure $\mathrm{H}_{2} \mathrm{O}$ to Vineyard Sound seawater. Tank temperatures and salinities were measured every other day, and water samples were taken weekly to determine ambient elemental ratios over the course of the experiment (see Section 2.2).

Clams were raised for 60 days under treatment conditions, with complete water changes every 2 days. New tank water was adjusted to the appropriate temperature and salinity before clams were added. Larvae metamorphosed into juveniles within 2 weeks of spawning. Larvae and juveniles were fed a mix of live Isochrysis sp. and concentrated algae (Instant Algae(C) Shellfish Diet 1800) one to two times daily based on clearance rates. All tanks received the same food mixture over the course of the experiment. After 60 days, clams ranged in size from $0.8 \mathrm{~mm}$ to $7.1 \mathrm{~mm}$; they were removed from their tanks and frozen until cleaned and prepared for analysis. There were $>200$ surviving clams in each of the six tanks, and we analyzed 25 , 27 , and 25 individuals from the three growth rate experiment tanks and 7, 5, and 5 individuals from the three age experiment tanks. These sample sizes were chosen based on statistical tests that determined ideal sizes of 25 and 5 for solution and laser ablation ICP-MS, respectively. We prepared two additional samples from each tank when possible to account for losses during the shell cleaning process. If samples remained intact after cleaning, we kept the resulting larger sample size to improve statistical power.

\subsection{Seawater analysis}

We quantified variability in seawater composition by measuring elemental ratios in each tank for each week of the experiment ( $n=9$ per tank). Thus it was possible to distinguish differences in elemental incorporation due to variable seawater chemistry versus ontogeny or growth rate. Samples were vacuum filtered using acid-washed plastic funnels with $0.2 \mu \mathrm{m}$ cellulose nitrate membrane filters. Samples were then transferred to acid-washed HDPE bottles, acidified to $\mathrm{pH} \sim 2$ using ultrapure $\mathrm{HNO}_{3}$, and refrigerated for up to two months before analysis. Seawater samples were prepared for analysis by diluting 50 -fold with ultrapure $2 \% \mathrm{HNO}_{3}$.

Water samples were analyzed using a Thermo-Finnigan MAT Element2 magnetic sector field inductively coupled plasma mass spectrometer (ICP-MS). To correct for mass bias and instrument drift, a $2 \% \mathrm{HNO}_{3}$ blank solution and CASS-4 Nearshore Seawater Reference Material (National Research Council Canada Certified Reference Material) were run periodically. During analyses we monitored ${ }^{25} \mathrm{Mg},{ }^{48} \mathrm{Ca},{ }^{55} \mathrm{Mn},{ }^{88} \mathrm{Sr}$, ${ }^{138} \mathrm{Ba}$, and ${ }^{208} \mathrm{~Pb}$ in low resolution mode. These elements were chosen because of their previous use as environmental tags (Kalish, 1989; Campana, 1999; Elsdon and Gillanders, 2003; Zacherl et al., 2003). Molar ratios of each element to Ca were calculated using mass bias corrections calculated from calibration standards. Limits of detection (LOD, $3 \sigma$ of blank) were as follows: $27 \mu \mathrm{g} \mathrm{g}^{-1}$ for $\mathrm{Mg} ; 7.7 \mu \mathrm{g} \mathrm{g}^{-1}$ for $\mathrm{Ca} ; 5.6 \mu \mathrm{g} \mathrm{g}^{-1}$ for $\mathrm{Mn}$; $5.9 \mu \mathrm{g} \mathrm{g}^{-1}$ for $\mathrm{Sr} ; 0.42 \mu \mathrm{g} \mathrm{g}^{-1}$ for $\mathrm{Ba}$; and $0.50 \mu \mathrm{g} \mathrm{g}^{-1}$ for $\mathrm{Pb}$. We tested for differences in seawater chemistry among tanks and over time within a tank using a two-way analysis of variance (ANOVA). Significant differences in seawater composition were accounted for by using partition coefficients to report shell elemental incorporation. Partition coefficients, or the ratio between Element:Ca values in carbonate and ambient water, are used in biogeochemistry literature to relate seawater elemental ratios to those of carbonate (Lea and Spero, 1992). We conducted all analyses for growth rate and age effects using both elemental ratios and partition coefficients. Both methods yielded the same results, and we report only elemental ratios hereafter.

\subsection{Growth rate experiment}

Since all clams were from the same spawning event and were allowed to grow for 60 days after fertilization, differences in final shell size were attributed to different growth rates. We recorded the final length along the longest axis of the shell to the nearest $0.01 \mathrm{~mm}$ of each individual. This length was converted to growth rate $\left(\mu \mathrm{m}\right.$ day $\left.^{-1}\right)$ by assuming a linear relationship between size and age. Typically, the nonlinear Von Bertalanffy equation is used to describe bivalve growth rate (Brousseau, 1979; Appeldoorn, 1983). This equation, however, is most applicable to clams much older than 60 days. The portion of the Von Bertalanffy curve which accounts for clam growth during the first 60 days is approximately linear (Von Bertalanffy, 1938), therefore the assumption of linear growth was appropriate for our purposes.

Shells were cleaned thoroughly using techniques developed for foraminiferan tests (Boyle, 1981) with modifications specifically for $M$. arenaria. The most notable modification was removal of the reductive cleaning step because it dissolved the proteinaceous structure of the shell so that it could not be prepared for laser ablation. Clam shells were placed in individual acid-washed vials using acid-washed plastic forceps, and sonicated briefly to remove organic matter. Individuals were rinsed three times with ultrapure water, and then soaked for 10 min at $80{ }^{\circ} \mathrm{C}$ in $1 \% \mathrm{H}_{2} \mathrm{O}_{2}$ solution buffered in $1 \mathrm{~N}$ ultrapure $\mathrm{NaOH}$ to remove organic material. Afterward, shells were rinsed three times with ultrapure water, transferred to clean, acid-washed vials, rinsed four times with ultrapure water, then left to dry overnight in a laminar flow hood. After shells were dry, they were weighed to the nearest $0.1 \mathrm{mg}$ and dissolved in $2 \%$ ultrapure $\mathrm{HNO}_{3}$ to achieve a 20,000-fold dilution of calcium carbonate for each clam based on weight. All shell cleaning and preparation was done in a Class 100 clean room.

Shell material was analyzed using ICP-MS with corrections for mass bias and instrument drift as for seawater analyses using two solution-based standards, an aragonitic otolith reference material (Yoshinaga et al., 2000) and the certified reference material FEBS-1 (Sturgeon et al., 2005). The same elements noted above were analyzed in low resolution mode and converted into molar ratios relative to $\mathrm{Ca}$ using mass bias corrections calculated from calibration standards. Limits of detection were as follows: $0.218 \mu \mathrm{g} \mathrm{g}^{-1}$ for $\mathrm{Mg} ; 0.819 \mu \mathrm{g} \mathrm{g}^{-1}$ for $\mathrm{Ca} ; 1.36 \mu \mathrm{g} \mathrm{g}^{-1}$ for $\mathrm{Mn} ; 0.632 \mu \mathrm{g} \mathrm{g}^{-1}$ for $\mathrm{Sr} ; 0.150 \mu \mathrm{g} \mathrm{g}^{-1}$ for $\mathrm{Ba}$; and $0.122 \mu \mathrm{g} \mathrm{g}^{-1}$ for $\mathrm{Pb}$. Elemental ratios that were more than two standard deviations from the mean of all sample 


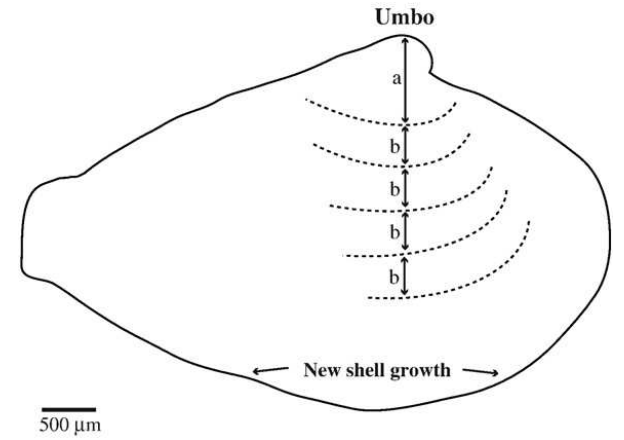

Fig. 1. Diagram of juvenile shell showing positions of the laser tracks for the age experiment. The distances $\mathrm{a}=700 \mu \mathrm{m}$ and $\mathrm{b}=360 \mu \mathrm{m}$. Lines ablated along growth rings (dashed) are $1400 \mu \mathrm{m}$ each.

intensities for a particular element (i.e. the global mean) were eliminated from further analysis, and the entire shell was eliminated if three or more elemental ratios met the exclusion criteria. We removed $17 / 380(4.5 \%)$ of the elemental ratios for the age experiment, plus all data from one entire clam shell, before further analyses. There was no evidence of matrix effects for any element based on plots of $\mathrm{E}: \mathrm{Ca}$ versus ${ }^{48} \mathrm{Ca}$ intensity.

To determine whether growth rate affected elemental incorporation into shell, ideally we would pool data from each replicate tank of the growth rate experiment to increase statistical power. However because clam sizes differed among tanks, we first performed regression analysis on growth rate versus elemental ratios for each tank separately (analysis of covariance). We then compared slopes among tanks to determine the validity of pooling using equations from Zar (1999). In the case where slopes were not significantly different (i.e. $F<F_{\text {crit }}$ ), we calculated the regression slope for all three tanks combined.

Our method assumes a linear relationship between growth rate and elemental incorporation into shell. If the relationship is instead nonlinear, then slope differences among tanks may result from the different ranges in growth rates represented in each tank. To test for this possibility, we repeated the regression analysis described above with the data selected to include only the range in growth rates observed in all three tanks $(0.040$ $0.064 \mathrm{~mm} \mathrm{day}{ }^{-1}$ ). If a nonlinear relationship was responsible for slope differences among tanks, we would expect those differences to disappear when only selected data are used.

\subsection{Age experiment}

All clams were of the same age (60 days) when the experiment was terminated. To determine variability in elemental incorporation with age, we measured and compared elemental composition at different growth rings along the shell of an individual clam, which correspond to different clam ages. Growth rings located closer to the umbo were laid earlier in the clam's life, and rings further from the umbo were laid more recently. We chose individuals that were of similar size to minimize the effects of differences due to growth rate. Exploratory statistics showed that there were no significant correlations between elemental composition and growth rate for any of the individuals analyzed for the age experiment, allowing us to interpret the effects of age without the confounding effects of growth rate.

Shells were cleaned as in the growth rate experiment, and their lengths were recorded to the nearest $0.01 \mathrm{~mm}$. Individual shell valves were then mounted on glass slides using Devcon $($ ) Super Glue. We were not able to polish shells to an even plane for analysis as this would have resulted in excessive sample loss due to the combined effects of the shells' curvature and thinness $(<500 \mu \mathrm{m})$. Shell material was analyzed using ICP-MS coupled to a New Wave Research UP213 laser. We ablated material by tracking the laser along five concentric growth increments of juvenile clam shells radiating out from the umbo. Each ring ablated was $1400 \mu \mathrm{m}$ in length and traced one of the growth increments of the shell. Measurements were taken at the same distances from the umbo for all shells, with the assumption that the resulting measurements represented similar ages among individuals. This assumption was valid since growth rates did not differ significantly. The first ring measured was $700 \mu \mathrm{m}$ away from the umbo as measured along the axis of growth, and the remaining four rings measured were spaced $360 \mu \mathrm{m}$ from one another (Fig. 1). The laser was set to $80 \%$ output $(0.12 \mathrm{~mJ}$ per pulse), with a $10 \mathrm{~Hz}$ repetition rate, $30 \mu \mathrm{m}$ spot size, and a scan speed of $10 \mu \mathrm{m} \mathrm{s}^{-1}$.

Vaporized material from the ablation was transported via a helium gas stream to the dual-inlet quartz spray chamber where it was mixed with $1 \% \mathrm{HNO}_{3}$ aerosol from a self-aspirating PFA $20 \mu \mathrm{L} \mathrm{min}^{-1}$ nebulizer. The analyte was then transported to the

Table 1

Mean temperature, salinity, and dissolved ambient seawater elemental ratios to calcium $( \pm \mathrm{SE})$ for tanks from both experiments

\begin{tabular}{|c|c|c|c|c|c|c|c|}
\hline & Temp & Salinity & $\mathrm{Mg}: \mathrm{Ca}$ & $\mathrm{Mn}: \mathrm{Ca}$ & $\mathrm{Sr}: \mathrm{Ca}$ & $\mathrm{Ba}: \mathrm{Ca}$ & $\mathrm{Pb}: \mathrm{Ca}$ \\
\hline & ${ }^{\circ} \mathrm{C}$ & $\%$ & $\left(\mathrm{~mol} \mathrm{~mol}^{-1}\right)$ & $\left(\mu \mathrm{mol} \mathrm{mol}^{-1}\right)$ & $\left(\mathrm{mmol} \mathrm{mol}{ }^{-1}\right)$ & $\left(\mu \mathrm{mol} \mathrm{mol}{ }^{-1}\right)$ & $\left(\mathrm{nmol} \mathrm{mol}{ }^{-1}\right)$ \\
\hline \multicolumn{8}{|c|}{ Growth rate experiment } \\
\hline Tank 1 & $19.4 \pm 0.04$ & $22.4 \pm 0.07$ & $5.09 \pm 0.04$ & $18.6 \pm 4.94$ & $8.56 \pm 0.03$ & $14.9 \pm 1.38$ & $15.3 \pm 4.12$ \\
\hline Tank 2 & $19.4 \pm 0.04$ & $22.4 \pm 0.05$ & $5.09 \pm 0.03$ & $13.6 \pm 3.55$ & $8.64 \pm 0.03$ & $15.1 \pm 1.41$ & $9.37 \pm 2.27$ \\
\hline Tank 3 & $19.5 \pm 0.04$ & $22.3 \pm 0.05$ & $5.05 \pm 0.02$ & $14.7 \pm 3.98$ & $8.57 \pm 0.03$ & $15.1 \pm 1.19$ & $9.32 \pm 1.53$ \\
\hline \multicolumn{8}{|c|}{ Age experiment } \\
\hline Tank 1 & $23.9 \pm 0.05$ & $29.5 \pm 0.02$ & $5.03 \pm 0.01$ & $12.8 \pm 3.26$ & $8.58 \pm 0.03$ & $14.9 \pm 0.68$ & $11.0 \pm 2.04$ \\
\hline Tank 2 & $23.8 \pm 0.05$ & $29.7 \pm 0.06$ & $5.03 \pm 0.02$ & $11.6 \pm 3.66$ & $8.61 \pm 0.03$ & $14.5 \pm 0.17$ & $8.31 \pm 1.91$ \\
\hline Tank 3 & $23.9 \pm 0.05$ & $29.5 \pm 0.25$ & $5.01 \pm 0.03$ & $12.6 \pm 2.65$ & $8.61 \pm 0.04$ & $15.6 \pm 1.03$ & $9.45 \pm 2.26$ \\
\hline
\end{tabular}


Table 2

Results of ANOVA testing for differences of seawater elemental ratios due to week of experiment or tank

\begin{tabular}{|c|c|c|c|c|c|c|c|c|c|c|c|c|c|c|c|c|}
\hline \multirow[t]{2}{*}{ Source } & \multirow[t]{2}{*}{ DF } & \multicolumn{3}{|c|}{$\mathrm{Mg}: \mathrm{Ca}$} & \multicolumn{3}{|l|}{$\mathrm{Mn}: \mathrm{Ca}$} & \multicolumn{3}{|l|}{$\mathrm{Sr}: \mathrm{Ca}$} & \multicolumn{3}{|l|}{$\mathrm{Ba}: \mathrm{Ca}$} & \multicolumn{3}{|l|}{$\mathrm{Pb}: \mathrm{Ca}$} \\
\hline & & MS & $F$ & $p$ & MS & $F$ & $p$ & MS & $F$ & $p$ & MS & $F$ & $p$ & MS & $F$ & $p$ \\
\hline \multicolumn{17}{|c|}{ Growth rate experiment } \\
\hline Week & 8 & 0.017 & 9.441 & 0.000 & 479.173 & 18.409 & 0.000 & 0.012 & 3.303 & 0.020 & 17.085 & 1.405 & 0.267 & 186.687 & 6.899 & 0.001 \\
\hline Tank & 2 & 0.003 & 1.769 & 0.202 & 2.699 & 0.104 & 0.902 & 0.011 & 3.101 & 0.073 & 0.211 & 0.017 & 0.983 & 61.525 & 2.286 & 0.134 \\
\hline Error & 16 & 0.002 & & & 26.029 & & & 0.004 & & & 12.164 & & & 26.917 & & \\
\hline \multicolumn{17}{|c|}{ Age experiment } \\
\hline Week & 8 & 0.006 & 1.884 & 0.134 & 183.184 & 5.282 & 0.002 & 0.011 & 1.625 & 0.194 & 4.193 & 0.878 & 0.555 & 82.594 & 4.936 & 0.003 \\
\hline Tank & 2 & 0.001 & 0.485 & 0.624 & 3.680 & 0.106 & 0.900 & 0.001 & 0.174 & 0.842 & 2.713 & 0.568 & 0.578 & 16.065 & 0.960 & 0.404 \\
\hline Error & 16 & 0.003 & & & 34.681 & & & 0.007 & & & 4.778 & & & 16.732 & & \\
\hline
\end{tabular}

Bold $F$ statistics and $p$ values are significant.

ICP-MS via an argon carrier gas. We corrected for mass bias and instrument drift using standards as in the growth rate experiment. Elements were measured in medium resolution mode, and molar ratios of each element to ${ }^{48} \mathrm{Ca}$ were calculated using mass bias corrections as above. LOD were as follows: $0.153 \mu \mathrm{g} \mathrm{g}^{-1}$ for $\mathrm{Mg}$; $0.581 \mu \mathrm{g} \mathrm{g}^{-1}$ for $\mathrm{Ca}$; $0.836 \mu \mathrm{g} \mathrm{g}^{-1}$ for $\mathrm{Mn} ; 1.04 \mu \mathrm{g} \mathrm{g}^{-1}$ for $\mathrm{Sr} ; 0.095 \mu \mathrm{g} \mathrm{g}^{-1}$ for $\mathrm{Ba}$; and $0.169 \mu \mathrm{g} \mathrm{g}^{-1}$ for $\mathrm{Pb}$. Elemental ratios that were more than two standard deviations from the global mean were eliminated from further analysis, and results for an entire growth ring were removed if three or more of the elemental ratios met the exclusion criteria. We removed $14 / 450(3.1 \%)$ of the elemental ratios for the age experiment, plus all data from two entire clam shells, before analyses. There was no evidence of matrix effects for any element based on plots of E/Ca versus ${ }^{48} \mathrm{Ca}$ intensity. To test for differences in elemental incorporation due to age, we compared shell composition between growth rings within a clam using multivariate repeated measures ANOVA (Winer, 1971; Barcikowski and Robey, 1984). Data were log-transformed to achieve a normal distribution; log-transformed data were used for the plots and for all regression calculations.

\section{Results}

\subsection{Seawater analyses}

Although seawater for all tanks originated from the same source, ambient elemental composition varied over time for tanks in both experiments (Tables 1 and 2). Temporal variability in seawater chemistry for the growth rate experiment was not expected to affect our analyses since we compared only the bulk shell composition with the time-averaged water composition. For the age experiment, however, temporal variability might affect our analyses since we measured areas of shell that correspond to specific time periods. Results from ANOVA and plots of tank elemental ratios over the course of the age experiment showed that tanks differed over time for $\mathrm{Mn}: \mathrm{Ca}$ and $\mathrm{Pb}: \mathrm{Ca}$ (Table 2, Fig. 2). Elemental ratios for weeks 1-3 were
A
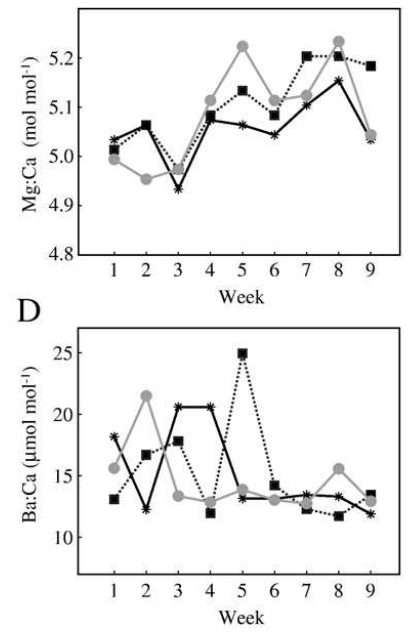

B
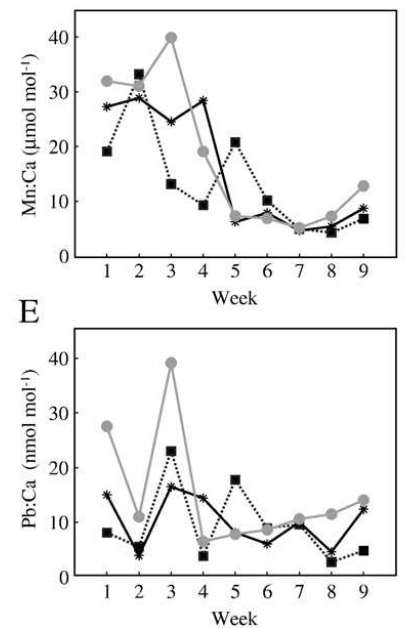

$\mathrm{C}$

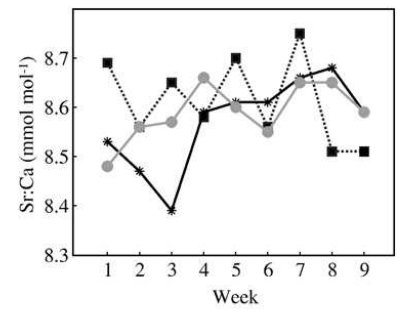

Fig. 2. Seawater elemental ratios over 9 weeks for each tank in the age experiment for (A) $\mathrm{Mg}: \mathrm{Ca}$, (B) $\mathrm{Mn}: \mathrm{Ca},(\mathrm{C}) \mathrm{Sr}: \mathrm{Ca}$, (D) $\mathrm{Ba}: \mathrm{Ca}$, and (E) $\mathrm{Pb}: \mathrm{Ca}$ (tank $1=$ circles; $\operatorname{tank} 2$ = squares; $\operatorname{tank} 3=$ crosses). 

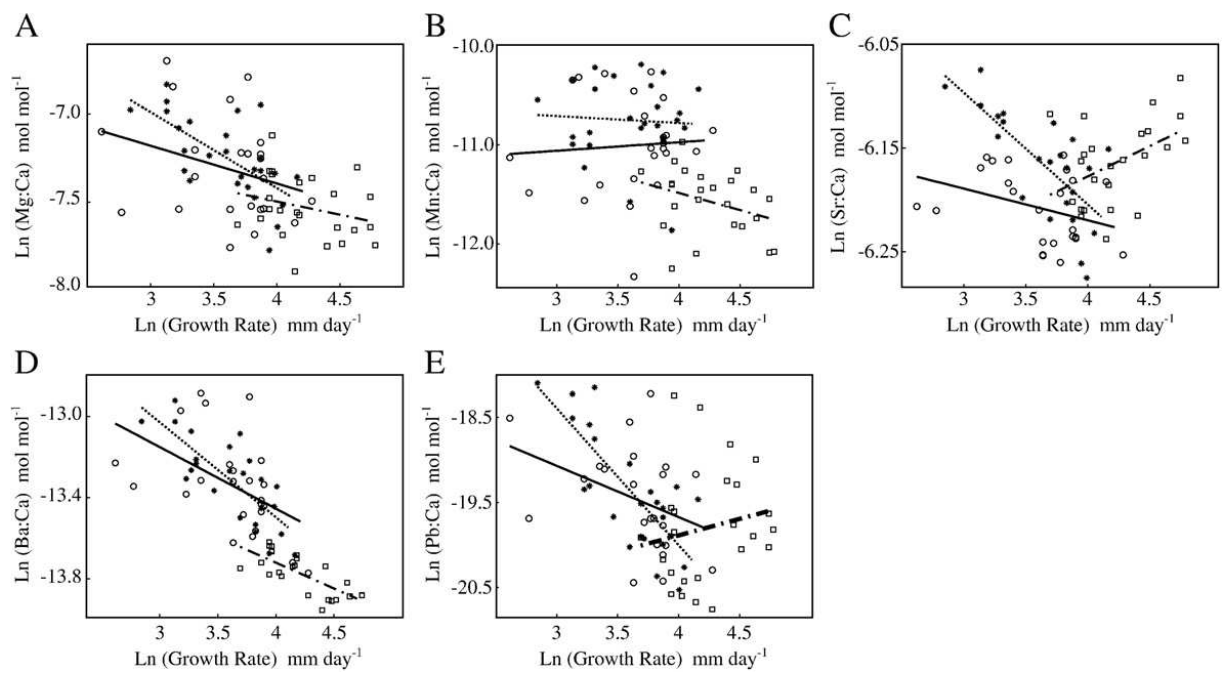

Fig. 3. Elemental ratios of individual clam shells for Mya arenaria growing at different rates for (A) Mg:Ca, (B) Mn:Ca, (C) $\mathrm{Sr}: \mathrm{Ca}$, (D) $\mathrm{Ba}: \mathrm{Ca}$, and (E) $\mathrm{Pb}: \mathrm{Ca}$. Data are from three replicate tanks (tank $1=$ circles; $\operatorname{tank} 2=$ squares; $\operatorname{tank} 3=$ stars). Regression lines are for each tank separately: $\operatorname{tank} 1=\operatorname{solid} ; \operatorname{tank} 2=$ dotted; $\operatorname{tank} 3=$ dashed and dotted.

higher than for weeks 6-9 for $\mathrm{Mn}$, and week 3 had higher $\mathrm{Pb}: \mathrm{Ca}$ than other weeks ( $p<0.01$, Tukey-Kramer pairwise tests).

\subsection{Growth rate effects}

We used solution-based ICP-MS analysis of juvenile clam shells from three replicate tanks $(n=25,27,25)$ to test the effects of growth rate on elemental incorporation into shell (Fig. 3). Growth rates ranged from 0.014 to $0.119 \mathrm{~mm}^{-1 a y}{ }^{-1}$ $\left(0.050 \pm 0.023 \mathrm{~mm} \mathrm{day}{ }^{-1}\right.$, mean $\left.\pm \mathrm{SD}\right)$. To determine the relationship between shell elemental incorporation and growth rate, we plotted elemental ratios versus growth rates for each tank separately (Fig. 3). Values of $R^{2}$ ranged from 0.005 to 0.634 , with 7 of the 15 regression slopes significantly differing from zero $(p<0.05$, Table 3$)$. There was a general trend of decreasing elemental ratios with increasing growth rate, with the exception of $\mathrm{Sr}: \mathrm{Ca}$ and $\mathrm{Pb}: \mathrm{Ca}$ from tank 3 (Fig. 3).

Slopes significantly differed among replicate tanks for two of the five elemental ratios $(p<0.001$, Table 4). For Sr:Ca, the slope of tank 3 differed from the other two, and for $\mathrm{Pb}: \mathrm{Ca}$ the slopes of tanks 2 and 3 differed. As a result of the differences among tanks for these two elements, we were not able to draw conclusions from the regression statistics for combined tanks. For the remaining three elemental ratios $(\mathrm{Mg}: \mathrm{Ca}, \mathrm{Mn}: \mathrm{Ca}, \mathrm{Ba}: \mathrm{Ca})$, slopes did not differ significantly among tanks, so we calculated the common slope for each element with equation 18.30 in Zar (1999) using data from all three tanks (Table 4).

We performed the same regression analyses on selected data to test whether significant differences in slopes were due to a nonlinear relationship between growth rate and elemental incorporation into shell. However data truncation resulted in the elimination of $\sim 50 \%$ of data points $(n=10,9,9)$, and as a consequence we lost statistical power and were not able to detect significant relationships for any tanks or elements. We could not, therefore, use the selected data to pool values from replicate tanks, and the issue of nonlinearity remains unresolved.

\subsection{Age effects}

We analyzed shell along five growth rings of juvenile clams from three replicate tanks $(n=7,5,5)$ to determine whether elemental incorporation varied as the individual aged (Fig. 4).

Table 3

Results of regression analysis for growth rate experiment for individual tanks

\begin{tabular}{llllrl}
\hline Source & $\beta_{0}$ & $\beta_{1}$ & $R^{2}$ & $F$ & $p$ \\
\hline Mg:Ca & & & & & \\
Tank 1 & -6.537 & -0.214 & 0.089 & 2.057 & 0.166 \\
Tank 2 & -5.696 & -0.431 & 0.434 & $\mathbf{1 8 . 3 7 4}$ & $\mathbf{0 . 0 0 0 3}$ \\
Tank 3 & -6.896 & -0.150 & 0.070 & 1.662 & 0.211 \\
Mn:Ca & & & & & \\
Tank 1 & -11.311 & 0.084 & 0.005 & 0.103 & 0.751 \\
Tank 2 & -10.510 & -0.079 & 0.004 & 0.106 & 0.766 \\
Tank 3 & -10.124 & -0.338 & 0.109 & 2.682 & 0.116 \\
Sr:Ca & & & & & \\
Tank 1 & -6.098 & -0.031 & 0.120 & 3.010 & 0.097 \\
Tank 2 & -5.775 & -0.108 & 0.518 & $\mathbf{2 2 . 5 5 8}$ & $\mathbf{0 . 0 0 0 1}$ \\
Tank 3 & -6.410 & 0.0583 & 0.199 & $\mathbf{5 . 4 8 3}$ & $\mathbf{0 . 0 2 9}$ \\
Ba:Ca & & & & & \\
Tank 1 & -12.245 & -0.303 & 0.243 & $\mathbf{7 . 0 5 1}$ & $\mathbf{0 . 0 1 4}$ \\
Tank 2 & -11.629 & -0.469 & 0.606 & $\mathbf{3 3 . 8 6 1}$ & $\mathbf{0 . 0 0 0}$ \\
Tank 3 & -12.710 & -0.255 & 0.566 & $\mathbf{2 7 . 6 1 9}$ & $\mathbf{0 . 0 0 0}$ \\
Pb:Ca & & & & & \\
Tank 1 & -17.262 & -0.602 & 0.144 & 3.363 & 0.082 \\
Tank 2 & -13.570 & -1.608 & 0.634 & $\mathbf{4 1 . 4 9 0}$ & $\mathbf{0 . 0 0 0}$ \\
Tank 3 & -21.435 & 0.387 & 0.032 & 0.737 & 0.400 \\
\hline
\end{tabular}

The coefficients $\beta_{0}$ and $\beta_{1}$ correspond to the regression equation, where $y=\beta_{0}+\beta_{1} x$. Bold $F$ statistics and $p$ values are significant. 
Table 4

Results of statistic testing for differences among regression functions of replicate tanks

\begin{tabular}{lrcr}
\hline Elemental ratio & \multicolumn{1}{l}{$p$} & \multicolumn{1}{c}{$\beta_{1}$} \\
\hline $\mathrm{Mg}: \mathrm{Ca}$ & 1.320 & 0.273 & -0.271 \\
$\mathrm{Mn}: \mathrm{Ca}$ & 0.745 & 0.465 & 0.078 \\
$\mathrm{Sr}: \mathrm{Ca}$ & $\mathbf{1 2 . 9 3 6}$ & $<0.0005$ & -0.032 \\
$\mathrm{Ba}: \mathrm{Ca}$ & 1.439 & 0.244 & -0.347 \\
$\mathrm{~Pb}: \mathrm{Ca}$ & $\mathbf{8 . 0 1 0}$ & $<0.001$ & -0.692 \\
\hline $\mathrm{Bo}$ &
\end{tabular}

Bold $F$ statistics are significant and indicate that slopes are different among tanks, making it invalid to pool data.

Repeated measures multivariate ANOVA indicated that there were significant differences in elemental ratios among growth rings for $\mathrm{Mn}: \mathrm{Ca}, \mathrm{Sr}: \mathrm{Ca}$ and $\mathrm{Ba}: \mathrm{Ca}$ (Table 5). In all three cases, the first growth ring $(0.70 \mathrm{~mm}$ away from the umbo) differed from the remaining four growth rings for individuals in one or more replicate tanks (Tukey-Kramer pairwise comparisons). There were also significant differences among measurements of clam shells from the same tank for $\mathrm{Mn}: \mathrm{Ca}, \mathrm{Ba}: \mathrm{Ca}$, and $\mathrm{Pb}: \mathrm{Ca}$. Finally, we detected a tank effect for one elemental ratio; mean $\mathrm{Ba}: \mathrm{Ca}$ of shells in tank 1 was higher than in tanks 2 or 3 .

Although clam shells of similar size were chosen for the age experiment, total lengths ranged from 3.36 to $6.45 \mathrm{~mm}(5.32 \pm$ $0.77 \mathrm{~mm}$, mean $\pm \mathrm{SD}$ ), as measured along the shell approximately perpendicular to the axis of growth. The difference in size after 60 days resulted in a range of growth rates from 0.056 to $0.107 \mathrm{~mm} \mathrm{day}^{-1}\left(0.089 \pm 0.013 \mathrm{~mm} \mathrm{day}^{-1}\right.$, mean $\left.\pm \mathrm{SD}\right)$. We tested for a correlation between growth rate and elemental incorporation for each clam (averaged over growth rings) analyzed in the age experiment and found none $\left(R^{2}\right.$ ranged from 0.0007 to $0.124 ; p$ values ranged from 0.15 to 0.91 ). This lack of correlation suggests that the range of growth rates for clam shells was sufficiently small so as not to impact elemental incorporation.

\section{Discussion \\ 4.1. Growth rate effects}

Previous studies have suggested that the rate of calcium carbonate crystal formation, which is closely tied to growth rate, influences elemental incorporation in bivalves (Stecher et al., 1996; Gillikin et al., 2005; Carre et al., 2006). Intuitively, a higher growth rate might be expected to result in more crystal defects during shell formation: increased active transport of $\mathrm{Ca}^{2+}$ molecules into the extrapallial fluid would lead to higher rates of inclusion of non- $\mathrm{Ca}^{2+}$ ions that are of similar size and charge (Wilbur and Saleuddin, 1983). Indeed, higher growth rates have been reported as corresponding to increased inclusion of $\mathrm{Mg}, \mathrm{Mn}$, and $\mathrm{Ba}$ in fish otoliths (Bath Martin and Thorrold, 2005; Hamer and Jenkins, 2007), and bivalve shells (Stecher et al., 1996; Carre et al., 2006). However in our study, we found that elemental ratios of $\mathrm{Mg}: \mathrm{Ca}, \mathrm{Mn}: \mathrm{Ca}$, and $\mathrm{Ba}: \mathrm{Ca}$ were all negatively correlated to growth rate in $M$. arenaria. One explanation for our disparate results may be that the organism's physiological ability to discriminate between $\mathrm{Ca}^{2+}$ and other ions improves with size. Clams with higher growth rates would have reached the threshold size for improved discrimination for $\mathrm{Ca}^{2+}$ sooner than those with slower growth rates. As a consequence, proportionally more shell would have been laid with lower elemental ratios to calcium over our two-month study, resulting in the negative correlation that we observed. Although such an age effect has not been observed in $M$. arenaria, previous studies of molluscs have reported decreased elemental incorporation with size (Dodd, 1965; Hirao et al., 1994; Arai et al., 2003).
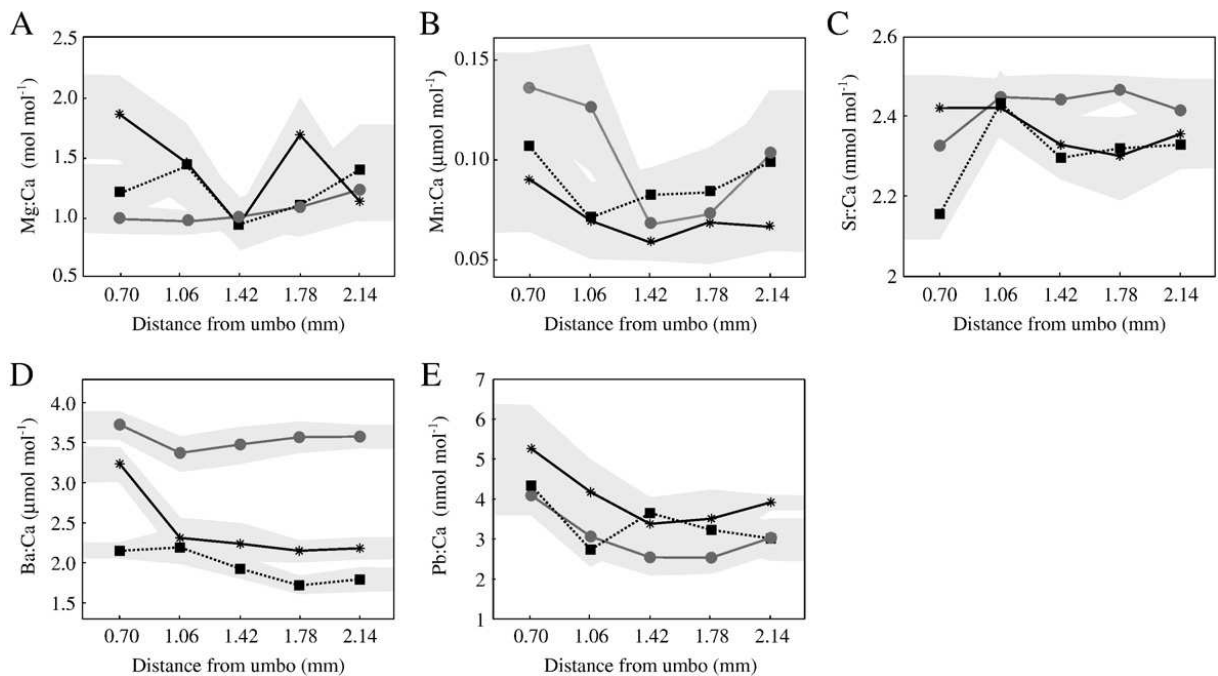

Fig. 4. Mean elemental ratios for Mya arenaria from three replicate tanks for shell measurements taken at different distances from the umbo for (A) Mg:Ca, (B) Mn:Ca, (C) $\mathrm{Sr}: \mathrm{Ca}$, (D) $\mathrm{Ba}: \mathrm{Ca}$, and (E) $\mathrm{Pb}: \mathrm{Ca}$ (tank $1=$ circles; tank 2 = squares; tank 3 = stars). Shaded regions are $\pm 1 \mathrm{SD}$ of mean. 
Table 5

Results of multivariate repeated measures ANOVA testing for differences between growth rings in three replicate tanks

\begin{tabular}{|c|c|c|c|c|c|c|c|c|c|c|c|c|c|c|c|c|}
\hline \multirow[b]{2}{*}{ Univariate } & \multirow[b]{2}{*}{ DF } & \multicolumn{3}{|c|}{$\mathrm{Mg}: \mathrm{Ca}$} & \multicolumn{3}{|c|}{$\mathrm{Mn}: \mathrm{Ca}$} & \multicolumn{3}{|c|}{$\mathrm{Sr}: \mathrm{Ca}$} & \multicolumn{3}{|c|}{$\mathrm{Ba}: \mathrm{Ca}$} & \multicolumn{3}{|c|}{$\mathrm{Pb}: \mathrm{Ca}$} \\
\hline & & MS & $F$ & $p$ & MS & $F$ & $p$ & MS & $F$ & $p$ & MS & $F$ & $p$ & MS & $F$ & $p$ \\
\hline $\begin{array}{l}\text { Among tanks } \\
\text { Within tanks }\end{array}$ & 2 & 0.33 & 0.93 & 0.42 & 0.01 & 0.68 & 0.53 & 0.07 & 1.92 & 0.19 & 9.11 & 25.29 & 0.0001 & 10.1 & 2.36 & 0.13 \\
\hline Among rings & 2 & 0.22 & 0.86 & 0.49 & 0.01 & 3.25 & 0.02 & 0.05 & 2.65 & 0.09 & 0.72 & 4.44 & 0.01 & 5.02 & 3.48 & 0.03 \\
\hline Ring $\times$ Tank & 8 & 0.14 & 0.53 & 0.79 & 0.01 & 1.33 & 0.25 & 0.03 & 1.80 & 0.16 & 0.25 & 0.53 & 0.21 & 0.83 & 0.80 & 0.74 \\
\hline Multivariate & DF & $\lambda$ & $F$ & $p$ & $\lambda$ & $F$ & $p$ & $\lambda$ & $F$ & $p$ & $\lambda$ & $F$ & $p$ & $\lambda$ & $F$ & $p$ \\
\hline Among rings & 4 & 0.70 & 1.06 & 0.42 & 0.38 & 4.05 & 0.03 & 0.27 & 5.41 & 0.02 & 0.31 & 4.44 & 0.04 & 0.52 & 2.56 & 0.10 \\
\hline Ring $\times$ Tank & 8 & 0.74 & 0.40 & 0.91 & 0.49 & 1.07 & 0.42 & 0.24 & 2.06 & 0.10 & 0.47 & 0.92 & 0.52 & 0.49 & 1.18 & 0.35 \\
\hline
\end{tabular}

Bold $F$ statistics and $p$ values are significant.

Although every attempt was made to assure environmental conditions were consistent across tanks, we found a wide range of growth rates for clams among the three replicate tanks. Our analyses indicated no significant differences in water chemistry, temperature, or salinity (Tables 1 and 2), however there may be additional factors we did not account for that are the source of the variability in growth rates. For instance, different biological conditions were present in each of the tanks owing to a variety of processes potentially occurring, such as algal growth and microbial activity. Although we sampled the seawater weekly to quantify the changes in its chemistry over time, we did not attempt to identify or quantify biological activity. This biological activity might in turn affect clam growth and elemental incorporation into shell. For example, increases in food supply due to algal growth would result in faster growth rates, or the presence of additional oxygen-consuming organisms might result in decreased oxygen supply to the clams and therefore reduced metabolic and growth rates.

The most notable tank effect was seen in the relationships between growth rate and $\mathrm{Sr}: \mathrm{Ca}$ and $\mathrm{Pb}: \mathrm{Ca}$; we found positive or negative correlations depending on tank. Our mixed results are particularly interesting for $\mathrm{Sr}: \mathrm{Ca}$ since previously reported relationships indicated positive correlations in bivalves (Stecher et al., 1996; Gillikin et al., 2005) and corals (Weber, 1973). Sr:Ca correlations to growth rate from otoliths are mixed (Kalish, 1989; Arai et al., 1996; Bath et al., 2000; Martin et al., 2004) but studies generally report negative correlations between $\mathrm{Sr}: \mathrm{Ca}$ and growth rate (Sadovy and Severin, 1992, 1994; Hamer and Jenkins, 2007; Lin et al., 2007). Since Sr ions are of the same charge as Ca ions and only slightly larger, they are substituted directly into the aragonite crystal lattice (Speer, 1983). As a result, Sr:Ca ratios should decrease with calcification rate (i.e. growth rate) since higher $\mathrm{Ca}$ concentrations in the extrapallial fluid would dilute $\mathrm{Sr}$ ions (Sinclair, 2005). Consequently we expected to find negative correlations for $\mathrm{Sr}: \mathrm{Ca}$ and growth rate in all of the replicate tanks, and the mixed results suggest that other factors are influencing $\mathrm{Sr}$ incorporation into bivalve shell.

We cannot attribute our results to variable $\mathrm{Sr}$ :Ca available in seawater since we found no significant differences in $\mathrm{Sr}: \mathrm{Ca}$ among tanks (Table 2). The more likely cause is the different ranges in growth rate depending on tank. Tank 3 growth rates were higher on average than those of tanks 1 and 2, and tank 3 is the only replicate tank with clams having growth rates higher than
$75 \mu \mathrm{m}$ day $^{-1}$. Indeed, shells from tank 3 had $\mathrm{Sr}: \mathrm{Ca}$ and $\mathrm{Pb}: \mathrm{Ca}$ that negatively correlated with growth rate, while shells from the other two tanks positively correlated. There may be different physiological processes operating as the clam grows larger, causing a shift in the correlation between growth rate and elemental ratios with size. For instance, Carre et al. (2006) found that curved shell sections in bivalves had higher $\mathrm{Sr}: \mathrm{Ca}$ than flat sections. This occurs because there is more organic matrix in the curved sections of shell than in flat sections, and therefore also more binding sites for $\mathrm{Ca}^{2+}$ and its competing ions (Rosenberg and Hughes, 1991). As the clam grows, proportionally more shell is composed of flat sections, and whole-shell analysis of a larger individual would have lower $\mathrm{Sr}: \mathrm{Ca}$ and $\mathrm{Pb}: \mathrm{Ca}$ than a smaller individual.

In addition to a wide range of growth rates for clams among tanks, we found a wide range within tanks as well. Explanations for the observed range within tanks cannot be attributed to biological activity or chemical differences since these factors would affect all of the individuals of a particular tank. The source of variability within tanks is therefore likely to be due to physiology at the individual clam level. Metabolic rate and growth rate are closely linked, and differences in metabolic rate among clams might result in different growth rates (Bayne and Newell, 1983; Rosenberg and Hughes, 1991). Variable metabolic rates, and therefore growth rates, may originate from genetic variability. If the genetic types of larvae produced in our laboratory spawning varied widely in their metabolic rates, then we might expect to see differences among individuals within a given tank.

\subsection{Age effects}

Based on significant differences among growth rings within individual clams, age significantly influenced the incorporation of $\mathrm{Mn}, \mathrm{Sr}$ and $\mathrm{Ba}$ into M. arenaria juvenile shell. This result is most likely attributable to increased variability in elemental ratios with decreasing distance from the umbo. Visual inspection of data plots indicates that variability in elemental ratios is highest near the umbo (Fig. 4). Indeed, statistical analyses confirm that all significant differences among growth rings disappear when the first growth ring measured is removed from analyses. This result may be an artifact of the laser ablation method used. Although laser parameters are consistent over all 
measurements, the time period that ablated shell material represents is not known. For instance, if a clam produces more material per day at week 4 compared to previous weeks, then measurements taken before week 4 will represent a larger time period sampled, and therefore may result in larger variability in the elemental ratios (see Elsdon and Gillanders, 2003 for a complete discussion of problems associated with the analysis of elements in calcified structures). This hypothesis contradicts our assumption of linear growth over the course of our experiment, however the data are not sufficiently conclusive to render our assumption false. Another explanation for increased variability in the first growth ring measured might be that seawater varied more at the beginning of the experiment (Fig. 2). However this hypothesis is not testable since we were not able to match shell growth rings to particular experimental weeks, and therefore to specific water chemistry. This is because growth patterns in molluscan shell are a result of complex interactions between physiology and environment, especially during early shell formation, preventing accurate estimates of the shell formation timeline in daily or weekly increments (see Lutz and Rhodes, 1980 for a complete discussion). Furthermore, based on observations over the course of the experiment, the first growth ring measured was likely accreted around week four, at which point seawater chemistry variability was in decline.

Our results for $\mathrm{Mn}: \mathrm{Ca}$ are at least in part attributable to changes in seawater $\mathrm{Mn}: \mathrm{Ca}$ over time. $\mathrm{Mn}: \mathrm{Ca}$ significantly differed in tank seawater over the course of the experiment (Table 2, Fig. 2). There are two possible explanations for this pattern. First, organic ligands may be in higher quantities later in the experiment due to excretion by clams or biological activity relating to food input; these ligands may bond to $\mathrm{Mn}$ and remove it from solution (Libes, 1992). We would detect a drop in the Mn: $\mathrm{Ca}$ ratios in seawater over time as a result, even though the input water $\mathrm{Mn}: \mathrm{Ca}$ is unchanged. Another explanation is that some event occurred between seawater samples taken at weeks 4 and 5 that caused a decrease in $\mathrm{Mn}: \mathrm{Ca}$ in the seawater. The unknown event might have been natural, affecting the source of seawater to the supply line, or it may have occurred within the supply infrastructure (e.g. the pipes were flushed to remove a blockage, causing seawater chemistry to change). Clams grew to $\sim 1 \mathrm{~mm}$ in length (as measured perpendicular to the axis of growth) until around week 4, which corresponds to approximately $0.8 \mathrm{~mm}$ in width along the axis of growth. It is therefore likely that only the first growth ring measured, located $0.70 \mathrm{~mm}$ from the umbo, would have been affected by the elevated $\mathrm{Mn}: \mathrm{Ca}$ ratios seen in the seawater. Indeed, the highest $\mathrm{Mn}$ :Ca level for seawater was during week 3 in tank 1, where clam shells also had the highest two $\mathrm{Mn}$ :Ca ratios measured, for growth rings located 0.70 and $1.06 \mathrm{~mm}$ away from the umbo.

\subsection{Conclusions and future directions}

In this study, we found that both growth rate and age significantly affect elemental incorporation into the shell of $M$. arenaria. Growth rate significantly correlated negatively with elemental ratios for 7 of the 15 analyses, which was surprising since previously published studies tended to report positive correlations. There were significant tank effects in $\mathrm{Sr}: \mathrm{Ca}$ and $\mathrm{Pb}: \mathrm{Ca}$ correlations to growth rate, potentially due to disparate biological activity occurring in the three replicate tanks. We found that growth rates varied widely within tanks, indicating that there is a physiological factor that we did not control for in our experiment, potentially originating at the genetic level. Our analysis of the effects of age on elemental incorporation into $M$. arenaria shell revealed higher variability closer to the umbo than further away, which caused significant differences with age for clams. When the first growth ring measured was removed from analyses, these significant differences disappeared. We hypothesize that the age effect is primarily a result of the shell's more pronounced curvature near the umbo, which affects physiological processes such as uptake of $\mathrm{Ca}^{2+}$ relative to other ions of similar size and charge.

The effects of size on elemental incorporation have the potential to bias data interpretation in any biogeochemical study that uses bivalves as indicators of environment. Juvenile bivalves are ideal candidates for environmental indicators: predictable spawning behavior allows one to be sure what season their shell is laid, and they are more susceptible to some environmental contaminants, making them an early indicator of problems that might not yet affect adults. However studies that use juveniles in this capacity must be careful to take into account the variability in shell composition with age and growth rate. Variability in shell chemistry could be interpreted as indicating shifting environmental conditions when in fact composition may reflect individual or ontogenetic variability in physiological processes. As our data show, clams reared in identical environments may incorporate different elemental signatures in their shells depending on their age or growth rate. Care must be taken to understand the potentially confounding effects of physiology for this and other bivalve species before making inferences about the environment based on shell chemistry.

This study was the first to explicitly examine the effects of variable growth rates and age in bivalves on incorporation of a suite of elements into shell, and in the same species during the same study. Although the variability we found is not cause for dismissing bivalves as useful environmental indicators, further studies should focus on the cause of variable incorporation within a cohort, especially with relation to the variables we were not able to control for in this set of experiments. The bioavailable levels of elements in the seawater should be measured to ascertain whether the source of variability in ratios is due to water chemistry or physiology. The sizes of clams should be tracked and recorded over the entire experiment to assess individual growth rates rather than averages, and to identify exactly when individual growth rings are accreted so they can be matched to the correct water sample taken. Parental analysis would be useful to establish genetic contributions of individuals and to determine if certain genetic combinations lead to higher or lower growth rates, explaining the variability that we saw within tanks.

\section{Acknowledgements}

This work was supported by NSF project numbers OCE0241855 and OCE-0215905. T. Elsdon was an indispensable 
resource for experimental design and implementation and provided helpful comments on the manuscript. We thank H. Lind of the Eastham Natural Resources Department and P. Alatalo of WHOI for helpful aquaculture advice and suggestions. We thank T. Marcotti for providing spawning stock. V. Starczak, A. Solow and S. Thorrold were helpful with data interpretation. We also thank D. Adams, K. McMahon, M. White, S. Beaulieu, N. Reyns, I. Garcia-Berdeal, J. Lerczak, E. Boyle, and S. Mills for comments on early drafts. Finally we thank three anonymous reviewers for their insightful comments that greatly improved the quality of the paper. [RH]

\section{References}

Appeldoorn, R.S., 1983. Variation in the growth rate of Mya arenaria and it relationship to the environment as analyzed through principal components analysis and the $\omega$ parameter of the Von Bertalanffy equation. Fish. Bull. 81, $75-84$

Arai, N., Sakamoto, W., Maeda, M., 1996. Correlation between ambien seawater temperature and strontium-calcium concentration ratios in otolith of red sea bream Pagrus major. Fish. Sci. 62, 652-653.

Arai, T., Maeda, M., Yamakawa, H., Kamatani, A., Ohji, M., Miyazaki, N., 2003. Uptake and elimination of trace metals in shells of abalones Haliotis spp. Bull. Environ. Contam. Toxicol. 71, 75-82.

Barcikowski, R.S., Robey, R.R., 1984. Decisions in single group repeated measures analysis: statistical tests and three computer packages. Am. Stat. $38,148-150$.

Bath, G.E., Thorrold, S.R., Jones, C.M., Campana, S.E., McLaren, J.W., Lam, J.W.H., 2000. Strontium and barium uptake in aragonitic otoliths of marine fish. Geochim. Cosmochim. Acta 64, 1705-1714.

Bath Martin, G.B., Thorrold, S.R., 2005. Temperature and salinity effects on magnesium, manganese, and barium incorporation in otoliths of larval and early juvenile spot Leiostomus xanthurus. Mar. Ecol. Prog. Ser. 293, 223-232.

Bayne, B.L., Newell, R.C., 1983. Physiological energetics of marine molluscs. In: Saleuddin, A.S.M., Wilbur, K.M. (Eds.), The Mollusca: Physiology Part 1. Academic Press, New York, pp. 407-415.

Becker, B.J., Levin, L.A., Fodrie, F.J., McMillan, P.A., 2007. Complex larva connectivity patterns among marine invertebrate populations. Proc. Natl. Acad. Sci. 104, 3267-3272.

Boisson, F., Cotret, O., Fowler, S.W., 1998. Bioaccumulation and retention of lead in the mussel Mytilus galloprovincialis following uptake from seawater. Sci. Total Environ. 222, 55-61.

Bourgoin, B.P., 1990. Mytilus edulis shell as a bioindicator of lead pollution: considerations on bioavailability and variability. Mar. Ecol. Prog. Ser. 61 253-262

Bourgoin, B.P. Risk, M.J. 1987. Historical changes in lead in the eastern Canadian Arctic, determined from fossil and modern Mya truncata shells. Sci. Total Environ. 67, 287-291.

Boyle, E.A., 1981. Cadmium, zinc, copper, and barium in foraminifera tests Earth Planet. Sci. Lett. 53, 11-35.

Brousseau, D.J., 1979. Analysis of growth rate in Mya arenaria using the Von Bertalanffy equation. Mar. Biol. 51, 221-227.

Campana, S.E., 1999. Chemistry and composition of fish otoliths: pathways mechanisms and applications. Mar. Ecol. Prog. Ser. 188, 263-297.

Carre, M., Bentaleb, I., Bruguier, O, Ordinola, E., Barrett, N.T., Fontugne, M. 2006. Calcification rate influence on trace element concentrations in aragonitic bivalve shells: evidences and mechanisms. Geochim. Cosmochim. Acta 70, 4906-4920.

Dodd, J.R., 1965. Environmental control of strontium and magnesium in Mytilus. Geochim. Cosmochim. Acta 29, 385-398.

Dodd, J.R., Crisp, E.L., 1982. Non-linear variation with salinity of $\mathrm{Sr} / \mathrm{Ca}$ and $\mathrm{Mg} / \mathrm{Ca}$ ratios in water and aragonitic bivalve shells and implications fo paleosalinity studies. Palaeogeogr. Palaeoclimatol. Palaeoecol. 38, 45-56.

Elsdon, T.S., Gillanders, B.M., 2003. Reconstructing migratory patterns of fish based on environmental influences on otolith chemistry. Rev. Fish Biol. Fish. 13, 217-235
Fuge, R., Palmer, M.A., Pearce, N.J.G., Perkins, W.T., 1993. Minor and trace element chemistry of modern shells: a laser ablation inductively coupled plasma mass spectrometry study. Appl. Geochem. Supplement 111-116.

Gillikin, D.P., Lorrain, A., Navez, J., Taylor, J.W., Andre, L., Keppens, E., Baeyens, W., Dehairs, F., 2005. Strong biological controls on $\mathrm{Sr} / \mathrm{Ca}$ ratios in aragonitic marine bivalve shells. Geochem. Geophys. Geosyst. 6, Q05009.

Hamer, P.A., Jenkins, G.P., 2007. Comparison of spatial variation in otolith chemistry of two fish species and relationships with water chemistry and otolith growth. J. Fish Biol. 71, 1035-1055.

Hart, S.R., Blusztajn, J., 1998. Clams as recorders of ocean ridge volcanism and hydrothermal vent field activity. Science $280,883-886$.

Hirao, Y., Matsumoto, A., Yamakawa, H., Maeda, M., Kimura, K., 1994. Lead behavior in abalone shell. Geochim. Cosmochim. Acta 58, 3183-3189.

Kalish, J.M., 1989. Otolith microchemistry: validation of the effects of physiology, age and environment on otolith composition. J. Exp. Mar. Biol. Ecol. 132, 151-178

Klein, R.T., Lohmann, K.C., Thayer, C.W., 1996. Bivalve skeletons record seasurface temperature and $\delta^{18} \mathrm{O}$ via $\mathrm{Mg} / \mathrm{Ca}$ and ${ }^{18} \mathrm{O} /{ }^{16} \mathrm{O}$ ratios. Geology 24 , 415-418.

Lazareth, C.E., Vander Putten, E., Andre, L., Dehairs, F., 2003. High-resolution trace element profiles in shells of the mangrove bivalve Isognomon ephippium: a record of environmental spatio-temporal variations? Estuar. Coast. Shelf Sci. 57, 1103-1114.

Lea, D., Spero, H.J., 1992. Experimental determination of barium uptake in shells of the planktonic foraminifera Orbulina unviersa at $22{ }^{\circ} \mathrm{C}$. Geochim. Cosmochim. Acta 56, 2673-2680.

Lerman, A., 1965. Strontium and magnesium in water and Crassostrea calcite. Science $150,745-746$

Libes, S.M., 1992. Trace metals in seawater. In: Libes, S.M. (Ed.), An Introduction to Marine Biogeochemistry. John Wiley \& Sons, Inc., New York, pp. 168-188.

Lin, S.-H., Chang, C.-W., Iizuka, Y., Tzeng, W.-N., 2007. Salinities, not diets, affect strontium/calcium ratios in otoliths of Anguilla japonica. J. Exp. Mar. Biol. Ecol. 341, 254-263.

Lindh, U., Mutvei, H., Sunde, T., Westermark, T., 1988. Environmental history told by mussel shells. Nucl. Instrum. Methods, B 30, 388-392.

Lutz, R.A., Rhodes, D.C., 1980. Growth patterns within the molluscan shell: an overview. In: Rhoads, D.C., Lutz, R.A. (Eds.), Skeletal Growth of Aquatic Organisms. Plenum Press, New York, pp. 203-254.

Marshall, J.F., McCulloch, M.T., 2002. An assessment of the $\mathrm{Sr} / \mathrm{Ca}$ ratio in shallow water hermatypic corals as a proxy for sea surface temperature. Geochim. Cosmochim. Acta 66, 3263-3280.

Martin, G.B., Thorrold, S.R., Jones, C.M., 2004. Temperature and salinity effects on strontium incorporation in otoliths of larval spot (Leiostomus xanthurus). Can. J. Fish. Aquat. Sci. 61, 34-42.

Mitsuguchi, T., Matsumoto, E., Uchida, T., 2003. $\mathrm{Mg} / \mathrm{Ca}$ and $\mathrm{Sr} / \mathrm{Ca}$ ratios of Porites coral skeleton: evaluation of the effect of skeletal growth rate. Coral Reefs 22, 381-388

Pearce, N.J.G., Mann, V.L., 2006. Trace metal variations in the shells of Ensis siliqua record pollution and environmental conditions in the sea to the west of mainland Britain. Mar. Pollut. Bull. 52, 739-755.

Phillips, D.J.H., 1977. The use of biological indicator organisms to monitor trace metal pollution in marine and estuarine environments: a review. Environ. Pollut. 13, 281-317.

Pitts, L.C., Wallace, G.T., 1994. Lead deposition in the shell of the bivalve, Mya arenaria: an indicator of dissolved lead in seawater. Estuar. Coast. Shelf Sci. 39, 93-104.

Rosenberg, G.D., Hughes, W.W., 1991. A metabolic model for the determination of shell composition in the bivalve mollusc, Mytilus edulis. Lethaia 24 $83-96$.

Rucker, J.B., Valentine, J.W., 1961. Salinity response of trace element concentration in Crassostrea virginica. Nature 190, 1099-1100.

Sadovy, Y., Severin, K.P., 1992. Trace elements in biogenic aragonite: correlation of body growth rate and strontium levels in the otoliths of the white grunt, Haemulon plumieri (Pisces; Haemulidae). Bull. Mar. Sci. 50, 237-257.

Sadovy, Y., Severin, K.P., 1994. Elemental patterns in red hind (Epinephelus guttatus) otoliths from Bermuda and Puerto-Rico reflect growth rate, not temperature. Can. J. Fish. Aquat. Sci. 51, 133-141. 
Sinclair, D.J., 2005. Correlated trace element "vital effects" in tropical corals: a new geochemical tool for probing biomineralization. Geochim. Cosmochim. Acta 69, 3265-3284.

Smith, S.V., Buddemeier, R.W., Redalje, R.C., Houck, J.E., 1979. Strontiumcalcium thermometry in coral skeletons. Science 204, 404-407.

Speer, J.A., 1983. Crystal chemistry and phase relations of orthorhombic carbonates. In: Reeder, R.J. (Ed.), Carbonates: Mineralogy and Chemistry. Mineralogy Society of America, Washington, D.C., p. 397.

Stecher, H.A., Krantz, D.E., Lord III, C.J., Luther III, G.W., Bock, K.W., 1996. Profiles of strontium and barium in Mercenaria mercenaria and Spisula solidissima shells. Geochim. Cosmochim. Acta 60, 3445-3456.

Sturgeon, R.E., Willie, S.N., Yang, L., Greenberg, R., Spatz, R.O., Chen, Z. Scriver, C., Clancy, V., Lam, J.W.H., Thorrold, S.R., 2005. Certification of a fish otolith reference material in support of quality assurance for trace element analysis. J. Anal. At. Spectrom. 10, 1067-1071.

Von Bertalanffy, L., 1938. A quantitative theory of organic growth. Hum. Biol. $10,181-213$

Weber, J.N., 1973. Incorporation of strontium into reef coral skeletal carbonate. Geochim. Cosmochim. Acta 37, 2173-2190.
Wilbur, K.M., 1972. Shell formation in mollusks. In: Florkin, M., Scheer, B.T (Eds.), Chemical Zoology Vol. VII: Mollusca. Academic Press, New York, pp. 103-145.

Wilbur, K.M., Saleuddin, A.S.M., 1983. Shell formation. In: Saleuddin, A.S.M., Wilbur, K.M. (Eds.), The Mollusca: Physiology Part 1. Academic Press, New York, pp. 235-287.

Winer, B.J., 1971. Statistical Principles in Experimental Design. McGraw-Hill, New York.

Yoshinaga, J., Nakama, A., Morita, M., Edmonds, J.S., 2000. Fish otolith reference material for quality assurance of chemical analyses. Mar. Chem. 69, 91-97.

Zacherl, D.C., 2005. Spatial and temporal variation in statolith and protoconch trace elements as natural tags to track larval dispersal. Mar. Ecol. Prog. Ser. 290, 145-163.

Zacherl, D.C., Paradis, G., Lea, D.W., 2003. Barium and strontium uptake into larval protoconchs and statoliths of the marine neogastropod Kelletia kelletii. Geochim. Cosmochim. Acta 67, 4091-4099.

Zar, J.H., 1999. Comparing simple linear regression equations. Biostatistical Analysis. Prentice Hall, New Jersey, pp. 360-376 


\section{Chapter 4}

\section{Temperature and salinity effects on elemental uptake in the shells of}

\section{larval and juvenile softshell clams}

\section{(Mya arenaria)}

\subsection{Introduction}

Most marine benthic invertebrate life cycles include a planktonic larval phase that facilitates dispersal among adult populations (Thorson, 1950). Connectivity, or the degree to which geographically separated populations exchange individuals, is an important factor in the spatial population dynamics of many marine organisms (Moilanen and Nieminen, 2002). Understanding connectivity in marine benthic populations is important because of the role spatial dynamics may play in new fisheries management approaches, including the design and implementation of marine protected areas (Palumbi, 2003; Shanks et al., 2003). However, studying larval dispersal (and therefore its role in connectivity) is challenging due to small larval sizes, high dilution rates, and high larval mortality rates (Thorson, 1950, 1966). In recent years, the use of artificial and natural tags to track marine larvae has been explored (e.g. 
Levin, 1990; Thorrold et al., 2002). One type of natural tag that may be useful for identifying natal origins is the elemental signature recorded in biogenic carbonate. This technique relies on the observation that some elements are incorporated into the calcium carbonate matrix in amounts related to the dissolved concentrations or physical properties of the ambient water (e.g. Bath et al., 2000; Vander Putten et al., 2000; Elsdon and Gillanders, 2003). Provided water chemistry or temperature is significantly different between natal habitats, such variation can serve as a natural tag, or signature, of the geographic origin of organisms. The use of geochemical signatures in fish otoliths as natural tags for population studies is well established (Campana and Thorrold, 2001). Recent efforts have expanded the use of elemental tags to invertebrates including decapods (DiBacco and Levin, 2000), gastropods (Zacherl et al., 2003a), bivalves (Becker et al., 2005, 2007), and cephalopods (Arkhipkin et al., 2004; Zumholz et al., 2007).

Although it is well established that biogenic carbonate composition reflects the elemental concentrations of waters where it was formed, additional factors are known to influence elemental uptake (Dodd, 1967; Wilbur, 1972). Environmental conditions, such as temperature, salinity, oxygen levels, and nutrient load, may alter the direct relationship between environmental and carbonate composition. Also, physiological and biochemical factors may affect the signature, including differences in uptake between species or between stages within a species. These factors may potentially act in combination, thereby complicating a simple relationship between ambient elemental concentration and carbonate composition. Understanding the role each factor plays in determining carbonate chemistry is critical to the appropriate design and interpretation of studies that use natural elemental signatures as a proxy for geographic origins or to reconstruct environmental conditions.

Our ultimate goal is to develop elemental signatures in shell as tags of natal habitat for the softshell clam, Mya arenaria, a commercially important bivalve commonly found in New England estuaries. In this study, we measured larval and juvenile shell elemental composition of $M$. arenaria reared in the laboratory under controlled temperature and salinity to understand their effects on elemental uptake and therefore 
allow us to interpret variability in elemental signatures. Temperature and salinity are likely to vary on small time scales in estuaries (Bowden, 1980), and are known to influence elemental uptake into biogenic carbonate.

First, we determined how the relationship between elemental composition of seawater and larval shell varied with temperature and salinity. Many studies have detailed the various factors controlling elemental compositions of fish otoliths (e.g. Hoff and Fuiman, 1995; Bath et al., 2000; Arai et al., 2003; Martin et al., 2004) and adult mollusc shells (e.g. Rucker and Valentine, 1961; Dodd, 1965; Lerman, 1965; Dodd and Crisp, 1982; Pitts and Wallace, 1994; Lazareth et al., 2003; Zacherl et al., 2003b). For mollusc larvae, however, shell uptake has been examined only in one gastropod (Zacherl et al., 2003b) and in no bivalves. We explored the relationships between temperature and salinity and uptake of $\mathrm{Mg}, \mathrm{Mn}, \mathrm{Sr}, \mathrm{Ba}$, and $\mathrm{Pb}$ based on the demonstrated utility of these elements in previous uptake experiments.

Second, we determined how the relationship between elemental composition of seawater and juvenile shell varied with temperature and salinity, and compared the uptake into shells of larval and juvenile clams to look for predictable correlations. The physiological aspects of shell formation in larval and juvenile bivalves are likely to vary due to morphological differences in these two life stages. Although the mantle (or the precursor to the mantle, the shell gland) is responsible for shell production in both larval and post-larval clams, there are drastic changes in the tissue during development that might result in differences in shell composition. The differences between larval and juvenile shell composition may offer insight into the physiological factors potentially affecting elemental incorporation into shell. If temperature or salinity affects incorporation of elements into carbonate, investigators may need to consider these factors when interpreting environmental variables based on shell chemistry. 


\subsection{Methods}

\subsubsection{Clam rearing}

Adult Mya arenaria were obtained from Cotuit, Massachusetts in April 2006 and were transported to the Environmental Systems Laboratory (ESL) at Woods Hole Oceanographic Institution, where they were placed in mesh bags and suspended in a $750 \mathrm{~L}$ tank with filtered seawater. Spawning activity commenced approximately one hour later, and the tank was left undisturbed to allow spawning to finish and for fertilization to take place. After five hours the adult clams were removed, and the tank contents were filtered through a $35 \mu \mathrm{m}$ nylon mesh sieve to concentrate the larvae into a small volume $(20 \mathrm{~L})$. We subsampled and counted larvae to obtain a total estimate of 16 million trochophore larvae. Although polyspermy was evident due to the high ratio of sperm to eggs, most larvae were well formed and regular in appearance and behavior.

Trochophore larvae were placed into one of $2412 \mathrm{~L}$ high-density polyethylene (HDPE) tanks at a density of 45 larvae $\mathrm{ml}^{-1}$. The tanks were divided among six treatments representing all combinations of two salinities (22.5, 30 PSU; hereafter low and high) and three temperatures $\left(15,20\right.$, and $\left.24{ }^{\circ} \mathrm{C}\right)$, with four replicate tanks per treatment combination. These temperatures and salinities represent the range of conditions experienced by this species during the summer months in its natural estuarine habitats. Treatment temperatures were maintained by placing tanks in large water baths. Water baths for the 15 and $20^{\circ} \mathrm{C}$ treatments received a continuous supply of 15 and $20^{\circ} \mathrm{C}$ water, respectively, regulated for the entire seawater supply line by chillers and heaters. The water bath for $24^{\circ} \mathrm{C}$ treatment tanks was maintained using a 120-volt tank heater regulated by a thermostat (Process Technology EasyPlug ${ }^{T M}$ Heater with Digital Controller, 1800W). Seawater for all tanks was obtained from the in-house seawater supply line, which pumps water from Vineyard Sound 100 $\mathrm{m}$ offshore of ESL at a water depth of $4 \mathrm{~m}$. All seawater was filtered to remove particles $>1 \mu \mathrm{m}$ before use. Salinity was reduced for the low-salinity treatments by adding ultrapure $\mathrm{H}_{2} \mathrm{O}$ (Milli-Q) to Vineyard Sound seawater. Tank temperatures 
and salinities were measured every other day, and water samples were taken weekly to determine ambient elemental ratios over the course of the experiment.

Subsamples of larvae were removed from each tank after $36 \mathrm{~h}$ for larval shell analysis. The remaining individuals were raised for 60 days under treatment conditions, with complete water changes every two days. Temperature and conductivity measurements were taken daily for each tank. New tank water was adjusted to the appropriate temperature and salinity before larvae were added. For the first 10 days the larvae were allowed to swim freely in tanks. Water changes consisted of filtering out larvae through a series of mesh sieves, then returning them to the cleaned tanks. Most larvae were large, negatively buoyant pediveligers in the $20^{\circ} \mathrm{C}$ and $24^{\circ} \mathrm{C}$ tanks at $8 \mathrm{~d}$ and in the $15^{\circ} \mathrm{C}$ tanks at $10 \mathrm{~d}$. After 10 days, larvae were retained within mesh sieves suspended in the tank, which restricted settlement to sieve surfaces and facilitated tank cleaning. Larvae metamorphosed into juveniles within two weeks of spawning. Larvae and juveniles were fed a mix of live Isochrysis sp. and concentrated algae (Instant Algae@ Shellfish Diet 1800) one to two times daily based on clearance rates. All treatments and tanks received the same food mixture over the course of the experiment. After 60 days, clams ranged in size from $0.5 \mathrm{~mm}$ to $10 \mathrm{~mm}$; they were removed from their tanks and frozen until the shells were cleaned and prepared for analysis.

\subsubsection{Sample preparation}

\section{Seawater preparation}

We monitored the elemental composition of ambient seawater in the tanks during the experiment. Water samples from each tank were collected weekly over the course of the experiment. The samples were vacuum filtered using acid-washed plastic Millipore(c) funnels with $0.2 \mu \mathrm{m}$ cellulose nitrate membrane filters. Samples were then transferred to acid-washed HDPE bottles, acidified to $\mathrm{pH} 2$ using ultrapure $\mathrm{HNO}_{3}$ (Seastar Chemicals Inc.), and refrigerated for up to two months. Seawater samples were prepared for elemental analysis by diluting 50 -fold with ultrapure $2 \%$ 
$\mathrm{HNO}_{3}$.

\section{Larval shell preparation}

Subsamples of roughly 1000 individual larvae were removed from each tank 36 hours after spawning. This allowed for the larval prodissoconch I (PI) shell to set under treatment conditions, with minimal addition of post-PI shell material. Individual larvae were pooled into one vial per tank. Shells were soaked in $1 \% \mathrm{NaClO}$ (bleach) for 6 hours to remove organic material. The cleaning solution was removed and shells were transferred to clean $0.5 \mathrm{ml}$ centrifuge tubes. Tubes were centrifuged to concentrate larval shells, and then were rinsed three times with ultrapure $\mathrm{H}_{2} \mathrm{O}$ (MilliQ). Shells were soaked in $200 \mu \mathrm{l}$ of $1 \%$ ultrapure $\mathrm{H}_{2} \mathrm{O}_{2}$ (ULTREX* II Ultrapure through VWR International) buffered to $1 \mathrm{~N}$ in ultrapure $\mathrm{NaOH}$ (EMD Chemicals through VWR International) for five minutes, then rinsed three times with ultrapure $\mathrm{H}_{2} \mathrm{O}$, transferred to clean acid-washed $1 \mathrm{ml}$ vials, and then rinsed four more times. Vials were transferred to a laminar flow hood to dry overnight. After all fluid had evaporated, $1 \mathrm{ml}$ of $2 \% \mathrm{HNO}_{3}$ was added to each vial to dissolve the shells for solutionbased ICP-MS analyses.

\section{Juvenile shell preparation}

Juvenile clams were placed in individual acid-washed vials using acid-washed plastic forceps, and sonicated briefly to remove tissue and debris. Individuals were rinsed three times with ultrapure $\mathrm{H}_{2} \mathrm{O}$, and then soaked for 10 minutes at $80^{\circ} \mathrm{C}$ in $1 \% \mathrm{H}_{2} \mathrm{O}_{2}$ solution buffered in $1 \mathrm{~N}$ ultrapure $\mathrm{NaOH}$ to remove organic material. Afterward, shells were rinsed three times with ultrapure $\mathrm{H}_{2} \mathrm{O}$, transferred to clean, acid-washed vials, rinsed four times with ultrapure $\mathrm{H}_{2} \mathrm{O}$, then left to dry overnight under a laminar flow hood. After the shells were dry, they were dissolved for solution-based analyses. The retained larval shell was not removed prior to dissolution of the juvenile shell since any contribution to elemental signal by the larval shell $(<0.05 \mu \mathrm{g})$ was assumed to be negligible compared to the more massive juvenile material (mean weight $=2.5$ mg). We measured elemental ratios of seawater from experimental tanks to calcu- 
late discrimination coefficients for both larval and juvenile Mya arenaria (Morse and Bender, 1990). The discrimination coefficient $D$ describes the relationship between the elemental composition of carbonate and of its water of formation:

$$
D=\frac{(\text { Element }: \mathrm{Ca})_{\text {carbonate }}}{(\text { Element:Ca })_{\text {seawater }}}
$$

where $D<1$ indicates discrimination against inclusion of the element, $D=1$ suggests there is no discrimination, and $D>1$ suggests elemental enrichment.

\section{ICP-MS analyses}

Shell material and water samples were analyzed using a Thermo-Finnigan MAT Element2 magnetic sector field inductively coupled plasma mass spectrometer (ICP-MS). To correct for mass bias and instrument drift, standards were run periodically during the analyses. For shell analyses, the solution-based standards included an aragonitic otolith reference material (Yoshinaga et al., 2000) and the certified reference material (CRM) FEBS-1 (Sturgeon et al., 2005). For seawater analyses, CASS-4 Nearshore Seawater Reference Material was used as the standard (National Research Council Canada CRM).

During analyses we monitored ${ }^{25} \mathrm{Mg},{ }^{55} \mathrm{Mn},{ }^{88} \mathrm{Sr},{ }^{114} \mathrm{Cd},{ }^{138} \mathrm{Ba}$, and ${ }^{208} \mathrm{~Pb}$ in low resolution mode. These elements were chosen because of their previous use in successful elemental tagging studies (Kalish, 1989; Elsdon and Gillanders, 2002; Zacherl et al., 2003b; Martin and Thorrold, 2005). Molar ratios of each element to Ca (hereafter E:Ca) were calculated using mass bias corrections calculated from calibration standards. Limits of detection (LOD) were calculated as the ratio of three standard deviations of the blank intensity to the average blank-subtracted sample intensity. For seawater and solution-based analyses respectively, sample intensities were as follows: > 10000 and $>1200$ times the LOD for ${ }^{25} \mathrm{Mg}$; $>700$ and $>10000 \times$ LOD for ${ }^{48} \mathrm{Ca}$; $>16$ and $>57 \times$ LOD for ${ }^{55} \mathrm{Mn} ;>5500$ and $>1100 \times$ LOD for ${ }^{88} \mathrm{Sr} ;>1600$ and $>130 \times$ LOD for ${ }^{138} \mathrm{Ba}$; and $>75$ and $>15 \times$ LOD for ${ }^{208} \mathrm{~Pb}$. The intensities of ${ }^{114} \mathrm{Cd}$ were not routinely above detection limits and this element was excluded from 
the remaining analyses. Elemental ratios that were more than two standard deviations from the global mean were eliminated from further analysis as the anomalous values likely arose from sample contamination. This resulted in removal of $6.5 \%$ (66 of 1010) of all shell measurements and 7.4\% (74 of 1001) of all seawater measurements. Measured precision (\% relative standard deviation) of E:Ca during analysis of juvenile shells $(n=32)$, larval shells $(n=10)$, and seawater $(n=52)$ respectively was 2.4\%, 4.8\%, and 7.9\% for Mg:Ca; 8.6\%, 11.9\%, and 7.1\% for Mn:Ca; 0.31\%, 0.12\%, and $0.47 \%$ for $\mathrm{Sr}: \mathrm{Ca} ; 1.8 \%, 1.4 \%$, and $2.1 \%$ for Ba:Ca; and $2.5 \%, 7.1 \%$, and $3.5 \%$ for $\mathrm{Pb}: \mathrm{Ca}$.

\subsubsection{Statistical analyses}

Although seawater for all tanks was obtained from the same supply line, it was important to quantify any differences among tanks as these differences may have influenced patterns in shell uptake. We used two-way analysis of variance (ANOVA) to test for the effects of temperature and salinity on seawater E:Ca, with individual tank analyses for each week as the unit of measurement $(n=216)$. Both temperature and salinity were treated as fixed variables.

For each shell measurement, E:Ca was translated into a discrimination coefficient. Larval shell discrimination coefficients were calculated by dividing E: Ca in the shell by E:Ca for corresponding tank seawater sampled on day 2 of the experiment. Juvenile shell discrimination coefficients were calculated by dividing the shell E:Ca by the corresponding mean tank seawater E:Ca (averaged from samples taken over the nine weeks of the experiment). We used discrimination coefficients rather than elemental ratios of shell for statistical analyses because the discrimination coefficient accounts for possible differences in water chemistry among tanks. We used a three-way ANOVA to explore the effects of temperature, salinity and stage (i.e. larval versus juvenile shell) on uptake. There were significant stage effects on discrimination coefficients ( $p<0.01$ for Mg; $p<0.0001$ for $\mathrm{Mn}, \mathrm{Sr}, \mathrm{Ba}, \mathrm{Pb}$; data not shown) and consequently we chose to analyze larval and juvenile shells separately using two-way ANOVAs to test for temperature and salinity effects. Finally, we tested for differences between 

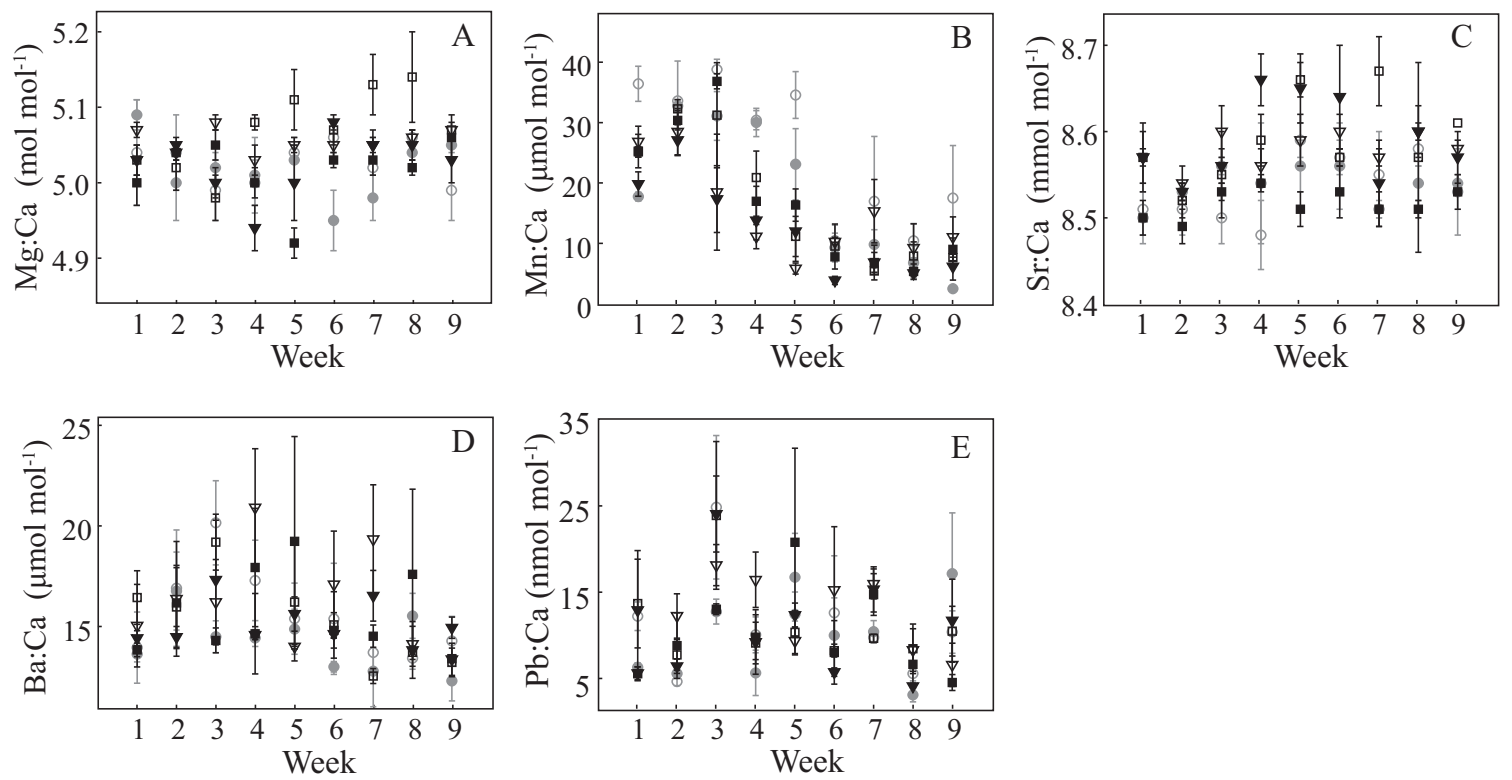

Figure 4.1: Seawater elemental ratios (mean of replicate tanks \pm SE) for treatments over experimental week for (a)Mg:Ca, (b)Mn:Ca, (c)Sr:Ca, (d)Ba:Ca, and (e)Pb:Ca. Gray, dotted, and black lines are $15^{\circ} \mathrm{C}, 20^{\circ} \mathrm{C}$, and $24^{\circ} \mathrm{C}$ treatments respectively. Open symbols are low-salinity treatments, and closed symbols are high-salinity treatments.

larval and juvenile uptake using simple linear correlation analysis of discrimination coefficients.

\subsection{Results}

\subsubsection{Rearing conditions}

Although we made efforts to optimize conditions for survival and growth, survivorship was highly variable between tanks. Some tanks had hundreds of surviving clams after the 60 day interval of the experiment, while two tanks had no survivors (Table 4.1). We therefore analyzed juvenile clam shells from 22 of 24 tanks, with at least three replicate tanks for each treatment. Elemental ratios were obtained from a total of 23 larval shell samples (from 23 tanks) and 174 juvenile shells (from 22 tanks) to examine temperature, salinity, and stage effects on uptake. Seawater elemental composition varied among treatments and tanks (Fig. 4.1). A two-way ANOVA showed that elemental ratios significantly varied with salinity for $\mathrm{Mg}$ and $\mathrm{Mn}$ (low salinity > 


\begin{tabular}{|c|c|c|c|c|c|c|c|c|}
\hline Tank & $\mathbf{N}$ & Temp & Sal & Mg:Ca & Mn:Ca & Sr:Ca & Ba:Ca & $\mathrm{Pb}: \mathrm{Ca}$ \\
\hline 1 & 32 & $15.4(0.10)$ & $22.6(0.06)$ & $5.00(0.03)$ & $30.3(4.74)$ & $8.53(0.02)$ & $14.7(0.83)$ & $9.17(1.03)$ \\
\hline 2 & 2 & $15.5(0.10)$ & $22.6(0.07)$ & $5.03(0.02)$ & $27.5(3.80)$ & $8.52(0.02)$ & $16.9(1.54)$ & $15.9(3.40)$ \\
\hline 3 & 30 & $15.3(0.09)$ & $22.5(0.06)$ & $5.05(0.02)$ & $21.4(5.01)$ & $8.54(0.02)$ & $14.4(1.09)$ & $8.61(1.46)$ \\
\hline 4 & 0 & $15.3(0.10)$ & $22.5(0.05)$ & $5.02(0.02)$ & $18.7(6.34)$ & $8.54(0.03)$ & $16.6(1.58)$ & $14.1(5.02)$ \\
\hline 5 & 5 & $15.3(0.09)$ & $30.1(0.04)$ & $5.00(0.02)$ & $20.0(5.20)$ & $8.53(0.02)$ & $15.0(0.77)$ & $10.0(2.37)$ \\
\hline 6 & 5 & $15.4(0.09)$ & $30.0(0.04)$ & $5.03(0.02)$ & $15.6(3.76)$ & $8.56(0.02)$ & $13.2(0.85)$ & $6.29(1.10)$ \\
\hline 7 & 6 & $15.4(0.09)$ & $30.0(0.05)$ & $5.03(0.02)$ & $17.9(4.09)$ & $8.55(0.03)$ & $13.0(0.61)$ & $11.6(3.74)$ \\
\hline 8 & 7 & $15.4(0.09)$ & $30.0(0.05)$ & $5.05(0.01)$ & $18.5(3.58)$ & $8.51(0.02)$ & $15.2(0.79)$ & $12.2(3.19)$ \\
\hline 9 & 1 & $19.4(0.04)$ & $22.3(0.07)$ & $5.04(0.01)$ & $17.9(3.27)$ & $8.56(0.02)$ & $15.1(1.06)$ & $10.0(1.12)$ \\
\hline 10 & $>100$ & $19.4(0.04)$ & $22.4(0.07)$ & $5.09(0.04)$ & $18.6(4.94)$ & $8.56(0.03)$ & $14.9(1.38)$ & $15.3(4.12)$ \\
\hline 11 & $>100$ & $19.4(0.04)$ & $22.4(0.07)$ & $5.09(0.03)$ & $13.6(3.55)$ & $8.64(0.03)$ & $15.1(1.41)$ & $9.37(2.27)$ \\
\hline 12 & $>100$ & $19.5(0.04)$ & $22.3(0.05)$ & $5.05(0.02)$ & $14.7(3.98)$ & $8.57(0.03)$ & $15.1(1.19)$ & $9.32(1.53)$ \\
\hline 13 & $>100$ & $19.4(0.03)$ & $29.7(0.04)$ & $5.02(0.02)$ & $13.6(3.00)$ & $8.52(0.01)$ & $14.9(0.44)$ & $6.80(1.75)$ \\
\hline 14 & 4 & $19.4(0.04)$ & $29.8(0.05)$ & $5.00(0.02)$ & $15.8(4.09)$ & $8.51(0.01)$ & $15.2(1.08)$ & $9.12(2.01)$ \\
\hline 15 & 8 & $19.4(0.03)$ & $29.8(0.06)$ & $5.01(0.02)$ & $19.6(3.45)$ & $8.51(0.01)$ & $18.3(2.58)$ & $11.2(2.09)$ \\
\hline 16 & 4 & $19.4(0.03)$ & $29.8(0.06)$ & $5.02(0.01)$ & $14.9(4.13)$ & $8.53(0.01)$ & $15.2(0.91)$ & $12.0(4.03)$ \\
\hline 17 & 0 & $23.9(0.05)$ & $22.5(0.10)$ & $5.06(0.01)$ & $13.8(3.13)$ & $8.55(0.01)$ & $17.5(2.21)$ & $12.9(2.29)$ \\
\hline 18 & 15 & $23.9(0.05)$ & $22.7(0.27)$ & $5.06(0.01)$ & $16.2(4.11)$ & $8.60(0.01)$ & $16.3(1.32)$ & $9.99(1.52)$ \\
\hline 19 & 1 & $23.8(0.05)$ & $22.4(0.09)$ & $5.05(0.01)$ & $15.4(3.13)$ & $8.55(0.01)$ & $15.0(0.77)$ & $14.1(3.46)$ \\
\hline 20 & $>100$ & $23.9(0.05)$ & $22.4(0.09)$ & $5.05(0.02)$ & $15.5(4.25)$ & $8.61(0.01)$ & $16.8(1.75)$ & $11.5(2.26)$ \\
\hline 21 & $>100$ & $23.9(0.05)$ & $29.5(0.25)$ & $5.03(0.01)$ & $12.8(3.26)$ & $8.58(0.03)$ & $14.9(0.68)$ & $11.0(2.04)$ \\
\hline 22 & $>100$ & $23.8(0.05)$ & $29.7(0.06)$ & $5.03(0.02)$ & $11.6(3.66)$ & $8.61(0.03)$ & $14.5(0.17)$ & $8.31(1.91)$ \\
\hline 23 & 40 & $24.0(0.05)$ & $29.7(0.08)$ & $5.01(0.03)$ & $12.6(2.65)$ & $8.61(0.04)$ & $15.6(1.03)$ & $9.45(2.26)$ \\
\hline 24 & $>100$ & $23.9(0.05)$ & $29.5(0.25)$ & $5.02(0.01)$ & $12.2(3.30)$ & $8.56(0.01)$ & $15.5(0.38)$ & $18.7(5.83)$ \\
\hline
\end{tabular}

Table 4.1: Number of surviving clams $(\mathrm{N})$ at the end of the 60 day experiment and mean water temperature (Temp., ${ }^{\circ} \mathrm{C}[ \pm \mathrm{SE}], n=30$ ), salinity (Sal., PSU $[ \pm \mathrm{SE}]$, $n=30)$, dissolved $\mathrm{Mg}: \mathrm{Ca}\left(\mathrm{mol} \mathrm{mol}{ }^{-1}, \pm \mathrm{SE}\right), \mathrm{Mn}: \mathrm{Ca}\left(\mu \mathrm{mol} \mathrm{mol}{ }^{-1}, \pm \mathrm{SE}\right), \mathrm{Sr}: \mathrm{Ca}$ $\left(\mathrm{mmol} \mathrm{mol}{ }^{-1}, \pm \mathrm{SE}\right), \mathrm{Ba}: \mathrm{Ca}\left(\mu \mathrm{mol} \mathrm{mol}{ }^{-1}, \pm \mathrm{SE}\right)$, and $\mathrm{Pb}: \mathrm{Ca}\left(\mathrm{nmol} \mathrm{mol}{ }^{-1}, \pm \mathrm{SE}\right)$ for treatment tanks ( $n=9$ for each tank). 


\begin{tabular}{lcccccccccccc}
\hline & \multicolumn{4}{c}{ Mg:Ca } & \multicolumn{2}{c}{ Mn:Ca } & \multicolumn{2}{c}{ Sr:Ca } & \multicolumn{2}{c}{ Ba:Ca } & \multicolumn{2}{c}{ Pb:Ca } \\
Source & DF & MS & F & MS & F & MS & F & MS & F & MS & F \\
\hline \hline $\mathrm{T}$ & 2 & $7 \times 10^{-3}$ & 2.04 & 968 & $7.62^{* *}$ & $4 \times 10^{-2}$ & $10.7^{* *}$ & 11.1 & 0.903 & 29.4 & 0.46 \\
$\mathrm{~S}$ & 1 & $4 \times 10^{-2}$ & $12.3^{* *}$ & 510 & $4.02^{*}$ & $1 \times 10^{-2}$ & 2.98 & 28.5 & 2.33 & 92.1 & 1.44 \\
$\mathrm{~T} \times \mathrm{S}$ & 2 & $8 \times 10^{-3}$ & 2.42 & 164 & 1.29 & $3 \times 10^{-2}$ & $7.02^{* *}$ & 21.0 & 1.72 & 5.51 & 0.09 \\
Error & 195 & $3 \times 10^{-3}$ & & 127 & \multicolumn{3}{c}{$4 \times 10^{-3}$} & & 12.3 & & 63.9 & \\
\hline
\end{tabular}

Table 4.2: Results of ANOVA testing the effects of temperature (T) and salinity (S) on tank water sample dissolved elemental ratios. All tank measurements for all weeks were used as the experimental unit $(n=216)$. F statistics are significant at the level of ${ }^{*} p<0.01$ or ${ }^{* *} p<0.001$.

high salinity), and with temperature for Mn and Sr (Table 4.2). Seawater elemental composition also varied temporally (Fig. 4.1). In order to account for this variability in seawater chemistry across treatments, we calculated discrimination coefficients for shells using seawater values from week one only for larval discrimination coefficients (Table 4.3), and using seawater values averaged over the nine-week experiment for juvenile discrimination coefficients (Table 4.1). Whole-shell solution analysis of juveniles resulted in shell E:Ca values that represent an average of elemental uptake over the experiment. By using the nine-week average for each tank to calculate juvenile shell discrimination coefficients, we are accounting for this averaging.

\subsubsection{Temperature \& salinity effects on uptake}

\section{Larval shell}

Across all treatments and tanks, the average $( \pm \mathrm{SE})$ larval shell elemental ratios were $3.1 \pm 0.83 \mathrm{mmol} \mathrm{mol}^{-1}$ for $\mathrm{Mg}: \mathrm{Ca}, 44.8 \pm 4.1 \mu \mathrm{mol} \mathrm{mol}^{-1}$ for $\mathrm{Mn}: \mathrm{Ca}, 2.5 \pm 0.04 \mathrm{mmol}$ $\mathrm{mol}^{-1}$ for $\mathrm{Sr}: \mathrm{Ca}, 3.37 \pm 0.30 \mu \mathrm{mol} \mathrm{mol}{ }^{-1}$ for $\mathrm{Ba}: \mathrm{Ca}$, and $157 \pm 17.6 \mathrm{nmol} \mathrm{mol}^{-1}$ for $\mathrm{Pb}: \mathrm{Ca}$. Average discrimination coefficients were less than one for $\mathrm{Mg}\left(6.2 \times 10^{-4} \pm\right.$ $\left.1.7 \times 10^{-4}\right), \operatorname{Sr}(0.30 \pm 0.005)$, and $\mathrm{Ba}(0.24 \pm 0.02)$, and greater than one for $\mathrm{Mn}$ $(1.86 \pm 0.19)$ and $\mathrm{Pb}(22.3 \pm 3.8)$.

Temperature significantly affected larval uptake of Ba and Mn (Table 4.4; Fig. 4.2). Mean $\mathrm{D}_{B a}$ for larval shells from $15^{\circ} \mathrm{C}$ tanks was higher than those from $20^{\circ} \mathrm{C}$ or $24^{\circ} \mathrm{C}$ 


\begin{tabular}{|c|c|c|c|c|c|c|c|}
\hline Tank & Temp & Sal & Mg:Ca & Mn:Ca & Sr:Ca & Ba:Ca & $\mathrm{Pb}: \mathrm{Ca}$ \\
\hline 1 & $14.9(0.15)$ & $22.7(0.06)$ & 4.91 & 44.0 & 8.53 & 17.49 & 11.4 \\
\hline 2 & $15.1(0.20)$ & $22.8(0.45)$ & 5.10 & 37.77 & 8.45 & 15.42 & 17.1 \\
\hline 3 & $14.9(0.12)$ & $22.9(0.34)$ & 5.15 & 31.40 & 8.46 & 12.18 & 9.88 \\
\hline 4 & $14.8(0.12)$ & $22.6(0.30)$ & 5.06 & 32.47 & 8.60 & 12.19 & 10.5 \\
\hline 5 & $15.0(0.23)$ & $30.1(0.11)$ & 5.10 & 17.68 & 8.46 & 13.24 & 5.20 \\
\hline 6 & $15.2(0.12)$ & $30.0(0.10)$ & 5.05 & 17.15 & 8.55 & 13.57 & 5.74 \\
\hline 7 & $15.1(0.07)$ & $30.2(0.26)$ & 4.86 & 16.41 & 8.44 & 12.98 & 6.83 \\
\hline 8 & $15.0(0.09)$ & $30.0(0.22)$ & 5.11 & 19.78 & 8.56 & 14.72 & 7.43 \\
\hline 9 & $19.5(0.26)$ & $22.1(0.11)$ & 5.09 & 23.65 & 8.53 & 12.59 & 6.27 \\
\hline 10 & $19.5(0.17)$ & $22.1(0.15)$ & 5.06 & 24.85 & 8.60 & 20.97 & 4.92 \\
\hline 11 & $19.5(0.26)$ & $22.2(0.06)$ & 5.04 & 24.37 & 8.51 & 14.54 & 7.31 \\
\hline 12 & $19.5(0.26)$ & $22.0(0.08)$ & 5.09 & 34.48 & 8.63 & 1205 & 3.93 \\
\hline 13 & $19.5(0.20)$ & $29.7(0.17)$ & 5.05 & 21.74 & 8.60 & 14.62 & 7.95 \\
\hline 14 & $19.5(0.21)$ & $29.4(0.05)$ & 5.01 & 17.09 & 8.55 & 13.71 & 6.25 \\
\hline 15 & $19.5(0.19)$ & $29.3(0.09)$ & 5.06 & 15.92 & 8.58 & 13.97 & 3.98 \\
\hline 16 & $19.5(0.19)$ & $29.4(0.19)$ & 4.99 & 24.56 & 8.54 & 15.37 & 33.5 \\
\hline 17 & $23.8(0.38)$ & $22.3(0.30)$ & 5.09 & 22.91 & 8.57 & 18.91 & 4.06 \\
\hline 18 & $23.8(0.19)$ & $22.1(0.26)$ & 4.99 & 31.95 & 8.48 & 15.61 & 27.5 \\
\hline 19 & $23.4(0.20)$ & $22.2(0.44)$ & 5.01 & 19.09 & 8.69 & 13.08 & 8.11 \\
\hline 20 & $23.5(0.13)$ & $22.1(0.19)$ & 5.03 & 27.28 & 8.53 & 18.17 & 15.0 \\
\hline 21 & $23.6(0.15)$ & $29.4(0.08)$ & 4.99 & 23.08 & 8.50 & 13.53 & 5.12 \\
\hline 22 & $23.5(0.09)$ & $29.7(0.31)$ & 5.07 & 27.23 & 8.52 & 13.51 & 3.56 \\
\hline 23 & $23.7(0.15)$ & $29.1(0.34)$ & 4.98 & 25.51 & 8.53 & 13.45 & 6.17 \\
\hline 24 & $23.8(0.35)$ & $29.7(0.09)$ & 4.96 & 24.84 & 8.46 & 14.87 & 7.33 \\
\hline
\end{tabular}

Table 4.3: Mean water temperature (Temp., ${ }^{\circ} \mathrm{C}[ \pm \mathrm{SE}], n=3$ ), mean salinity (Sal., $\mathrm{PSU}[ \pm \mathrm{SE}], n=3)$, and dissolved $\mathrm{Mg}: \mathrm{Ca}\left(\mathrm{mol} \mathrm{mol}^{-1}\right), \mathrm{Mn}: \mathrm{Ca}\left(\mu \mathrm{mol} \mathrm{mol}{ }^{-1}\right), \mathrm{Sr}: \mathrm{Ca}$ $\left(\mathrm{mmol} \mathrm{mol}{ }^{-1}\right), \mathrm{Ba}: \mathrm{Ca}\left(\mu \mathrm{mol} \mathrm{mol}{ }^{-1}\right)$, and $\mathrm{Pb}: \mathrm{Ca}\left(\mathrm{nmol} \mathrm{mol}{ }^{-1}\right)$ for treatment tanks during the first week only. 


\begin{tabular}{|c|c|c|c|c|c|c|c|c|c|c|c|}
\hline \multirow[b]{2}{*}{ Source } & \multirow[b]{2}{*}{ DF } & \multicolumn{2}{|c|}{$\mathbf{D}_{\mathrm{Mg}}$} & \multicolumn{2}{|c|}{$\mathbf{D}_{\mathrm{Mn}}$} & \multicolumn{2}{|c|}{$\mathbf{D}_{\mathrm{Sr}}$} & \multicolumn{2}{|c|}{$\mathbf{D}_{\mathrm{Ba}}$} & \multicolumn{2}{|c|}{$\mathbf{D}_{\mathbf{P b}}$} \\
\hline & & MS & $\mathrm{F}$ & MS & $\mathrm{F}$ & MS & $\mathrm{F}$ & MS & $\mathrm{F}$ & MS & $\mathrm{F}$ \\
\hline \multicolumn{12}{|c|}{ Larval shell } \\
\hline $\mathrm{T}$ & 2 & $7.3 \times 10^{-7}$ & 1.34 & 2.50 & $9.50 *$ & $9.9 \times 10^{-4}$ & 3.45 & 0.081 & $27.7 * *$ & 357 & 1.03 \\
\hline $\mathrm{S}$ & 1 & $4.4 \times 10^{-7}$ & 0.81 & 2.59 & $9.85^{*}$ & $1.0 \times 10^{-3}$ & 3.75 & $9.6 \times 10^{-3}$ & 3.26 & 537 & 1.55 \\
\hline $\mathrm{T} \times \mathrm{S}$ & 2 & $2.5 \times 10^{-7}$ & 0.46 & 2.19 & $8.33 *$ & $1.2 \times 10^{-3}$ & 4.06 & $7.7 \times 10^{-3}$ & 2.62 & 184 & 0.53 \\
\hline Error & 15 & $5.5 \times 10^{-7}$ & & 0.26 & & $2.9 \times 10^{-4}$ & & $2.9 \times 10^{-3}$ & & 347 & \\
\hline \multicolumn{12}{|c|}{ Juvenile shell } \\
\hline $\mathrm{T}$ & 2 & $2.3 \times 10^{-10}$ & 0.82 & 0.39 & $6.43^{*}$ & $3.4 \times 10^{-4}$ & 4.55 & $6.6 \times 10^{-3}$ & $9.24 *$ & 0.72 & $10.5^{*}$ \\
\hline $\mathrm{S}$ & 1 & $6.4 \times 10^{-11}$ & 0.23 & $1.0 \times 10^{-3}$ & 0.01 & $3.9 \times 10^{-3}$ & $52.2 * *$ & $1.0 \times 10^{-6}$ & 0.001 & 0.01 & 0.07 \\
\hline $\mathrm{T} \times \mathrm{S}$ & 2 & 0.54 & 0.54 & 0.19 & 3.14 & $6.5 \times 10^{-4}$ & $8.64^{*}$ & $8.3 \times 10^{-4}$ & 1.17 & 0.04 & 0.58 \\
\hline Error & 15 & $2.8 \times 10^{-10}$ & & 0.06 & & $7.5 \times 10^{-5}$ & & $7.1 \times 10^{-4}$ & & 0.68 & \\
\hline
\end{tabular}

Table 4.4: Results of ANOVA testing the effects of temperature (T) and salinity (S) on larval and juvenile discrimination coefficients. F statistics are significant at the level of ${ }^{*} p<0.01$ or ${ }^{* *} p<0.001$.
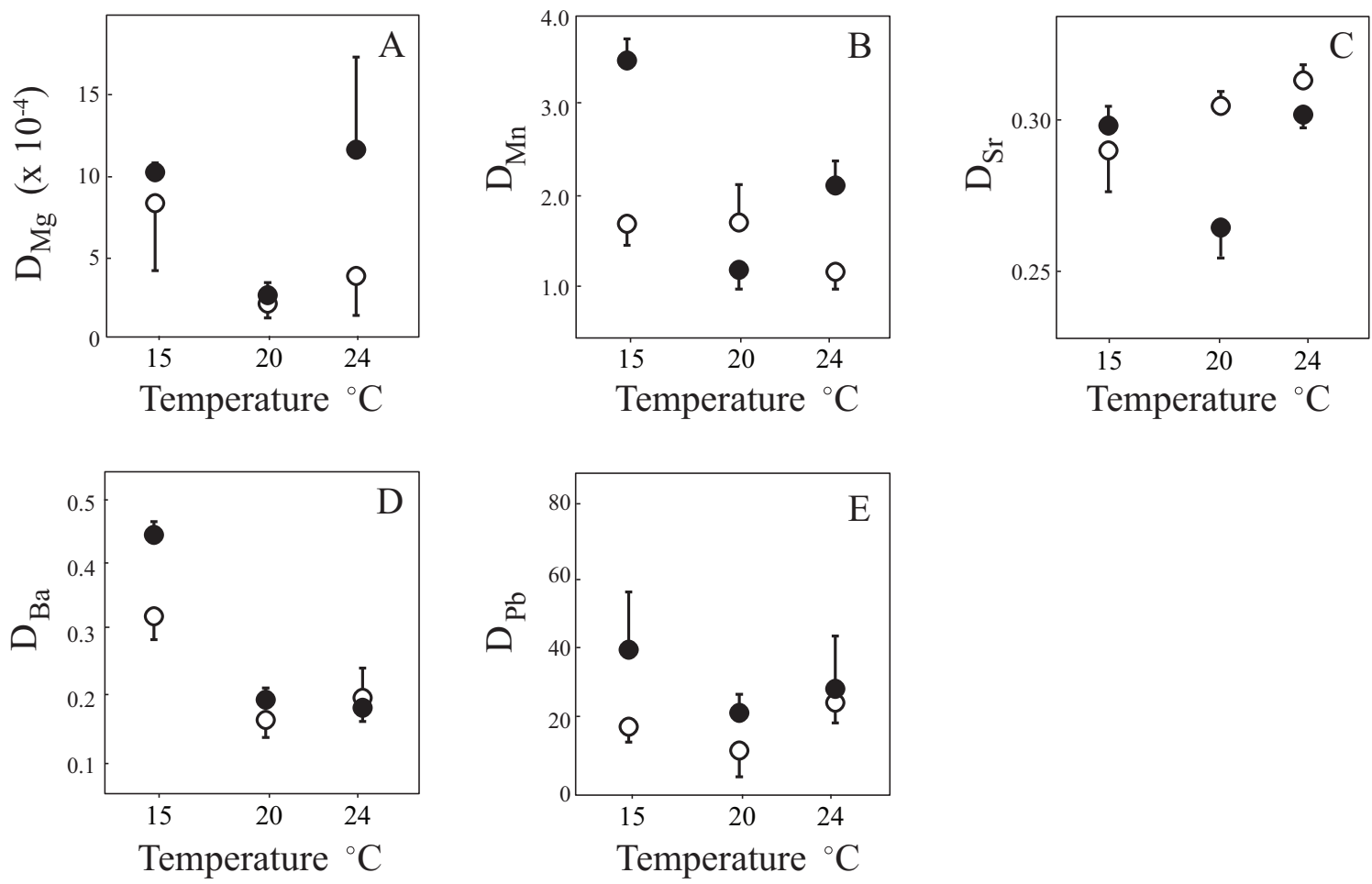

Figure 4.2: Mean discrimination coefficients $( \pm \mathrm{SE})$ for larval shell samples, averaged over replicate tanks within treatments for the five elements, (a) $\mathrm{D}_{M g}$, (b) $\mathrm{D}_{M n}$ (c) $\mathrm{D}_{S r}$, (d) $\mathrm{D}_{B a}$, and (e) $\mathrm{D}_{P b}$. Open circles are low-salinity treatments and closed circles are high-salinity treatments. 
tanks while shells from $15^{\circ} \mathrm{C}$ tanks had higher mean $\mathrm{D}_{M n}$ than both $20^{\circ} \mathrm{C}$ and $24^{\circ} \mathrm{C}$ tanks. Salinity significantly affected Mn uptake in larval shell: high-salinity tanks had significantly higher $\mathrm{D}_{M n}$ than low-salinity tanks. There was a significant interaction between salinity and temperature in larval shells, caused by a variable effect of salinity depending on temperature: low-salinity tanks had lower $\mathrm{D}_{M n}$ than high-salinity tanks at $15^{\circ} \mathrm{C}$ and $24^{\circ} \mathrm{C}$, while this trend was reversed at $20^{\circ} \mathrm{C}$.

\section{Juvenile shell}

The average $( \pm \mathrm{SE})$ juvenile shell elemental ratios across all treatments and tanks were $0.67 \pm 0.02 \mathrm{mmol} \mathrm{mol}{ }^{-1}$ for $\mathrm{Mg}: \mathrm{Ca}, 14.3 \pm 0.92 \mu \mathrm{mol} \mathrm{mol}^{-1}$ for $\mathrm{Mn}: \mathrm{Ca}, 1.99 \pm 0.04$ mmol mol${ }^{-1}$ for Sr:Ca, $1.52 \pm 0.11 \mu \mathrm{mol} \mathrm{mol}^{-1}$ for Ba:Ca, and $4.56 \pm 0.65 \mathrm{nmol} \mathrm{mol}^{-1}$ for $\mathrm{Pb}$ :Ca. All of the average discrimination coefficients for juvenile shell were less than one $\left(1.3 \times 10^{-4} \pm 1.0 \times 10^{-5}\right.$ for $\mathrm{D}_{M g}, 0.88 \pm 0.13$ for $\mathrm{D}_{M n}, 0.23 \pm 0.003$ for $\mathrm{D}_{S r}$, $0.10 \pm 0.008$ for $\mathrm{D}_{B a}$, and $0.45 \pm 0.13$ for $\left.\mathrm{D}_{P b}\right)$.

Temperature significantly affected uptake of $\mathrm{Mn}, \mathrm{Ba}$ and $\mathrm{Pb}$ in juvenile shell (Table 4.4; Fig. 4.3). Tukey-Kramer pairwise comparisons indicated the significant relationships were as follows: mean $\mathrm{D}_{M n}$ was higher for individuals from $20^{\circ} \mathrm{C}$ tanks than from either $15^{\circ} \mathrm{C}$ or $24^{\circ} \mathrm{C}$ tanks; mean $\mathrm{D}_{B a}$ was higher in $15^{\circ} \mathrm{C}$ tanks than in $24^{\circ} \mathrm{C}$ tanks; and mean $\mathrm{D}_{P b}$ was higher for individuals from $15^{\circ} \mathrm{C}$ tanks than from either $20^{\circ} \mathrm{C}$ or $24^{\circ} \mathrm{C}$ tanks. Mean $\mathrm{D}_{S r}$ did not vary consistently with temperature, but was significantly greater in low than high salinity. There was a significant interaction between salinity and temperature for $\mathrm{D}_{S r}$, likely caused by the less distinct salinity effect at $20^{\circ} \mathrm{C}$ than at $15^{\circ} \mathrm{C}$ or $24^{\circ} \mathrm{C}$.

Tests for correlations between larval and juvenile uptake in each tank showed consistently higher discrimination coefficients in larval than juvenile shells (Fig. 4.4). There was, however, little correspondence between larval and juvenile discrimination coefficients between tanks for any element except $\mathrm{Ba}(p<0.05, r=0.56)$ (Table 4.5). The discrimination coefficient used for each tank was a single value for larvae (measured from shells pooled into a vial), and a single or average value for juveniles (calculated from 1 to 15 shells). Only tanks with values for both larvae and juveniles 

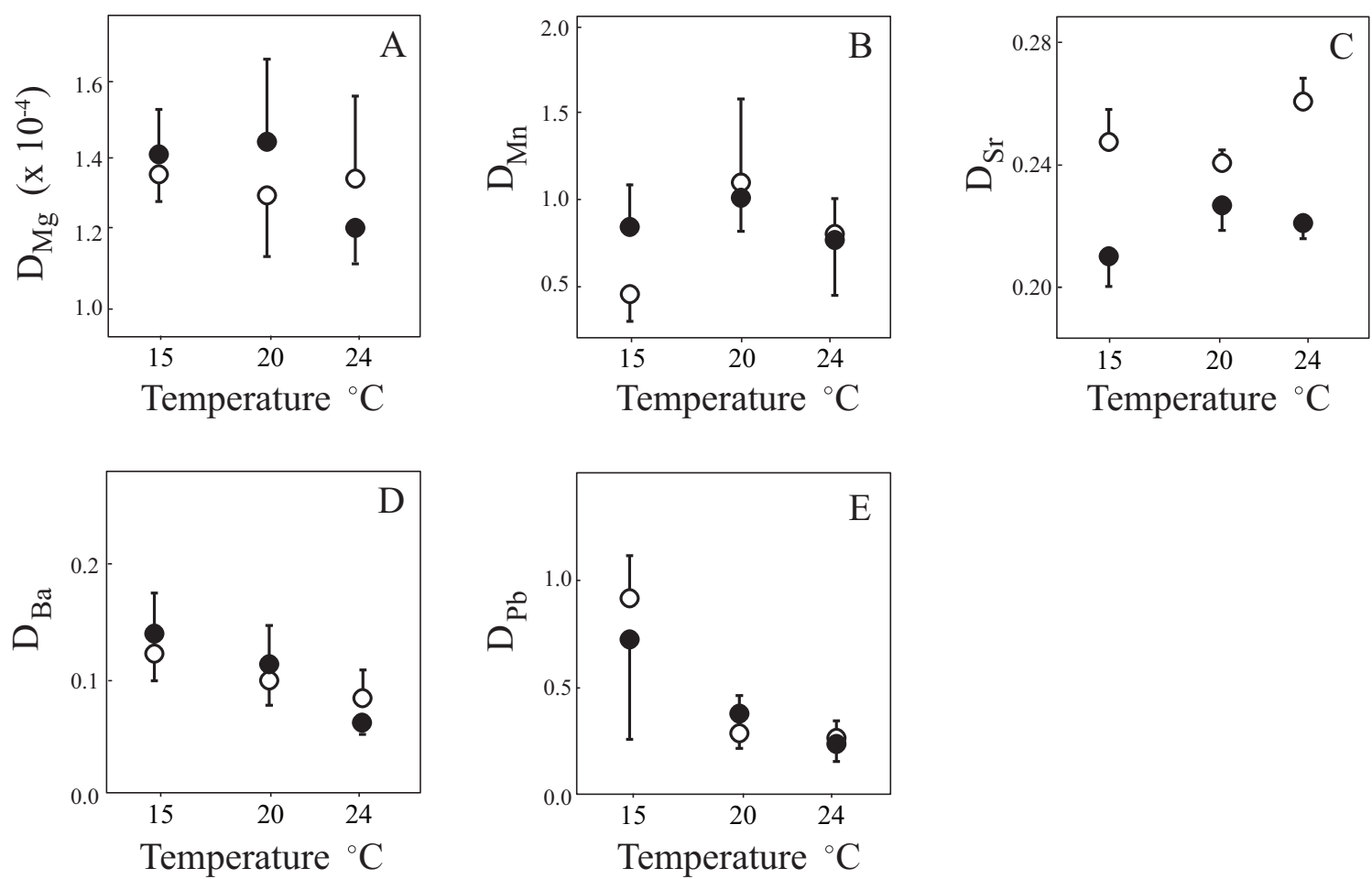

Figure 4.3: Mean discrimination coefficients $( \pm \mathrm{SE})$ for juvenile shells, averaged over replicate tanks within treatments for the five elements, (a) $\mathrm{D}_{M g}$, (b) $\mathrm{D}_{M n}$ (c) $\mathrm{D}_{S r}$, (d) $\mathrm{D}_{B a}$, and (e) $\mathrm{D}_{P b}$. Open circles are low-salinity treatments and closed circles are high-salinity treatments.

\begin{tabular}{lll}
\hline & $\mathrm{r}$ & $\mathrm{p}$ \\
\hline \hline $\mathrm{D}_{\mathrm{Mg}}$ & -0.166 & 0.51 \\
$\mathrm{D}_{\mathrm{Mn}}$ & -0.064 & 0.80 \\
$\mathrm{D}_{\mathrm{Sr}}$ & 0.120 & 0.63 \\
$\mathrm{D}_{\mathrm{Ba}}$ & $0.560^{*}$ & 0.02 \\
$\mathrm{D}_{\mathrm{Pb}}$ & 0.164 & 0.50 \\
\hline
\end{tabular}

Table 4.5: Results of analyses testing for correlations between juvenile and larval discrimination coefficients. Correlation coefficients are significant at the level of ${ }^{*} p<$ 0.05 . 

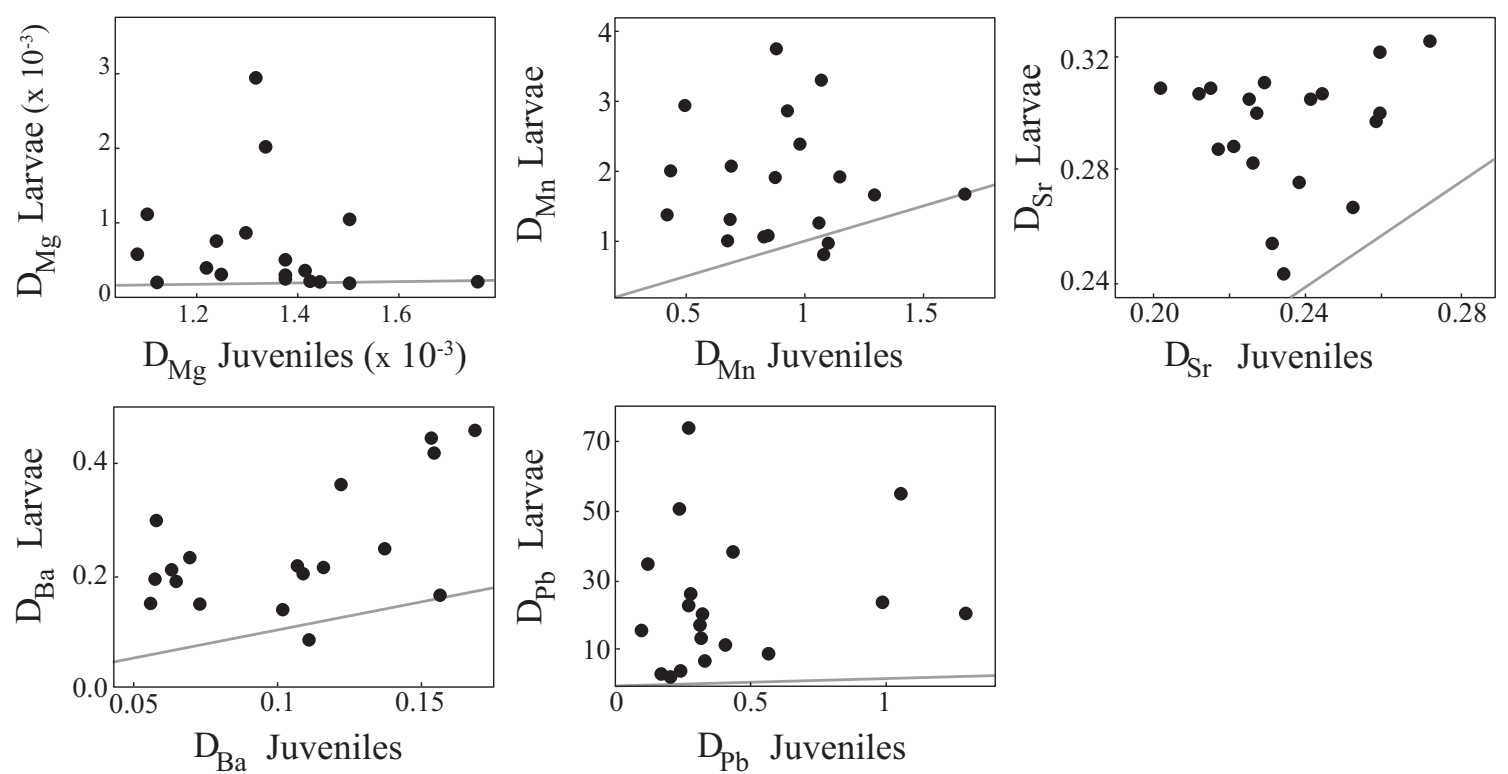

Figure 4.4: Correlations comparing larval and juvenile discrimination coefficients for (a) $\mathrm{D}_{M g}$, (b) $\mathrm{D}_{M n}$ (c) $\mathrm{D}_{S r}$, (d) $\mathrm{D}_{B a}$, and (e) $\mathrm{D}_{P b}$. Gray lines are 1:1 lines for $D_{\text {larvae }}: D_{\text {juveniles }}$.

were used in the correlations $\left(n=18,19,19,18,19\right.$ for $\mathrm{D}_{M g}, \mathrm{D}_{M n}, \mathrm{D}_{S r}, \mathrm{D}_{B a}$, and $\mathrm{D}_{P b}$ respectively).

\subsection{Discussion}

We examined the effects of temperature and salinity on discrimination coefficients (and therefore uptake) in larval and juvenile bivalve shell in order to improve our ability to interpret natural variability in elemental signatures. First, we explored relations between temperature, salinity, and elemental composition of larval Mya arenaria shells. We found that uptake of Ba was affected by temperature, and uptake of Mn was affected by temperature and salinity. Second, we compared uptake in larval and juvenile shell at various temperatures and salinities. We found significant differences between larval and juvenile discrimination coefficients for all five of the elements studied. Correlation analysis further indicated that there was no clear and predictable relationship between larval and juvenile uptake for any element except Ba. Although we expected that discrimination coefficients would differ between larval 
and juvenile shells, we were surprised to find that temperature and salinity influenced discrimination in shells of the two stages differently.

\subsubsection{Temperature \& Salinity Effects on Uptake}

\section{Magnesium Uptake}

Our observation that neither temperature nor salinity had a significant effect on $\mathrm{D}_{M g}$ in larval or juvenile Mya arenaria shells is in contrast to results from some previous studies of bivalve calcite, (Rucker and Valentine, 1961; Dodd, 1965) in which a positive correlation to temperature was reported. Lerman (1965), however, reported no effect of temperature on $\mathrm{D}_{M g}$ in oyster shells. We found no prior studies of salinity effects on $\mathrm{D}_{M g}$ in bivalve shells. Calcite and aragonite formation tend to differ with relation to solution chemistry due to their different crystal structures, even within the same organism. Lorens and Bender (1980) hypothesized that Mg was regulated by mantle cells during calcite formation but not during aragonite precipitation in the shell of the bivalve Mytilus edulis. The radius of $\mathrm{Mg}^{2+}$ ions is smaller than $\mathrm{Ca}^{2+}$ ions, and therefore although $\mathrm{Mg}$ inhibits formation of calcite due to substitution for $\mathrm{Ca}^{2+}$ in the crystal lattice (Berner, 1975), it is unlikely to be substituted into aragonite (Onuma et al., 1979; Speer, 1983). However the extremely low discrimination coefficients we

found suggest that the amount of $\mathrm{Mg}$ in shell carbonate is highly regulated by the organism during shell formation. Although the mechanisms regulating discrimination of $\mathrm{Mg}$ during shell formation in $M$. arenaria remain are unresolved, temporal changes in temperature and salinity are unlikely to complicate interpretation of $\mathrm{Mg}$ signatures.

\section{Manganese Uptake}

The influence of salinity on Mn uptake between larval and juvenile shells suggests that $\mathrm{Mn}$ regulation changes during ontogeny. Ontogenetic changes in discrimination of $\mathrm{Mn}$ have not been reported in other studies of biogenic carbonate, but investigations of otolith chemistry have found complex relations between Mn uptake and temperature and salinity. Elsdon and Gillanders (2003) found no significant relationship between 
Acanthopagrus butcheri otolith Mn:Ca and the Mn content of the water of formation. Martin and Thorrold (2005) reported complex temperature and salinity interactions for Mn:Ca in Leiostromus xanthurus otoliths. The authors attributed this result to biological processes that might be mediating the amount of biologically available Mn in the seawater of formation. For instance, microbial activity can contribute to the formation of Mn oxides (Sunda and Huntsman, 1987; Klinkhammer and McManus, 2001), which removes Mn ions from solution and makes relationships between Mn:Ca in shell and seawater unpredictable.

Despite the unpredictable nature of Mn uptake, Mn has repeatedly proven useful for elemental tagging studies (e.g. Thorrold et al., 1998, 2001; Patterson et al., 2005; Becker et al., 2007). Our study suggests that experimenters should proceed with caution when including $\mathrm{Mn}$ in the suite of elements for tagging studies due to the interactions among temperature, salinity, and biology that contribute to Mn content in aragonite. Further, salinity effects on Mn discrimination in larval shells of estuarine species (where salinity varies on small spatial scales) may result in variable signatures for larvae within a particular site and consequent misclassification of individuals in natural tagging studies.

\section{Strontium Uptake}

Our observation that temperature did not significantly affect uptake of Sr into larval or juvenile Mya arenaria shell contrasts with early molluscan studies generally reporting negative correlations between temperature and Sr (Dodd, 1965; Hallam and Price, 1968; Thorn et al., 1995). However shells analyzed in these studies were collected from the field, and the authors did not account for differences in growth rates or metabolism in their analyses. As a result, temperature-associated variation in growth rates or metabolism could have been responsible for the $\mathrm{Sr}$ uptake patterns rather than temperature itself. A more recent study of temperature effects on Sr in statoliths of the laboratory-reared cuttlefish Sepia officinalis that controlled for growth rates also reported no correlation, suggesting biological regulation of Sr ions outweighs the kinetic effects of temperature on Sr incorporation (Zumholz et al., 2007). Zacherl 
et al. (2003b) came to similar conclusions in their study of the gastropod Kelletia kelletii: they found that Sr:Ca correlated positively with temperature in protoconchs and negatively in larval statoliths. They concluded that there are strong biological controls on Sr incorporation into aragonite, likely due to the differential discrimination of Sr across different biological membranes responsible for statolith and protoconch production.

There is less ambiguity in the literature for the relationship between Sr uptake into molluscan calcium carbonate and salinity. The most commonly reported result is a lack of correlation (Dodd, 1965; Hallam and Price, 1968; Stecher et al., 1996; Zumholz et al., 2007), as we found in our larval shells. Because the low-salinity treatment was achieved by diluting seawater with ultrapure water, we did not expect to detect differences in $\mathrm{Sr}$ :Ca among treatments. However we found $\mathrm{D}_{S r}$ significantly differed with salinity for juvenile shells, which suggests that Sr concentration, as well as Sr:Ca ratios, in ambient water influenced uptake of Sr into juvenile shells. A similar result was found in otoliths by Martin and Thorrold (2005).

Our data suggest that molluscan Sr:Ca ratios in aragonite of shells are controlled by physiology. However, the exact mechanism by which these "vital effects" influence shell chemistry remains unknown. There is evidence in the literature that Sr uptake is dependent upon calcification rates in aragonitic mollusc shells (Purton et al., 1999; Takesue and van Geen, 2004). Any factor that affects calcification rates could, therefore, influence the interpretation of trends in Sr:Ca in shell (Likins et al., 1963; Stecher et al., 1996; Carre et al., 2006). This may explain reports that temperature, which is often positively correlated with growth rate, influences Sr uptake. Gillikin et al. (2005), however, carefully documented the relationship between environmental factors and Sr uptake in two species of marine bivalves with aragonitic shells, and concluded that Sr:Ca ratios in shell are regulated by biological processes rather than thermodynamics. Studies of growth rate effects on Sr incorporation into Mya arenaria juvenile shell have produced both positive and negative correlations to growth rate for juvenile shells reared in the same conditions (Strasser et al., 2008). These ambiguous results lend support to the idea that Sr incorporation may involve a num- 
ber of physical and biological processes. One example of a process that might be influencing Sr incorporation is entrapment of material on the surface of the crystal during carbonate formation. Recent studies suggests that elemental fractionation in inorganic calcite (Watson, 2004) and aragonite (Gaetani and Cohen, 2006) is dominated by non-equilibrium processes including surface entrapment. Indeed, with more study, surface entrapment may provide a powerful unifying mechanism for explaining apparently divergent behavior of $\mathrm{Sr}: \mathrm{Ca}$ in fish otoliths, bivalve shells and coral skeletons.

\section{Barium and Lead Uptake}

We found evidence for a negative correlation between temperature and Ba uptake in both larval and juvenile shells, which is consistent with results of Zacherl et al. (2003b) and Zumholz et al. (2007), who both found a negative correlation in the aragonite structures of laboratory-reared molluscans. We found no significant relationship between $\mathrm{D}_{B a}$ and salinity, which is also consistent with results from Zumholz et al. (2007). Ba is likely to be a useful addition to elemental tagging studies, even in situations where its concentration does not vary spatially, as uptake into molluscan shell appears to have a consistent relationship with temperature.

Larval shell $\mathrm{D}_{P b}$ did not vary significantly with temperature, although juvenile shell $\mathrm{D}_{P b}$ showed evidence of a significant negative correlation. Previous research generally has shown that clams incorporate $\mathrm{Pb}$ into their shells in relation to ambient water concentrations (Babukutty and Chacko, 1992; Pitts and Wallace, 1994; Almeida et al., 1998; Boisson et al., 1998), however these studies do not examine the relationship at different temperatures or salinities. More recently Mubiana and Blust (2007) showed that $\mathrm{Pb}$ uptake into soft tissue is positively correlated to temperature, but they did not examine the effects of temperature on $\mathrm{Pb}$ uptake into shell. It is difficult to discern the underlying causes of the significant relationship between temperature and juvenile shell $D_{P b}$ that we found. Therefore studies that use trace metals as part of unique geochemical signatures should be cautious until there is more information about discrimination coefficients at variable temperatures and salinities. 


\subsubsection{Differences in Larval \& Juvenile Uptake}

We found highly significant differences between uptake in larval and juvenile Mya arenaria shells. In addition, larval and juvenile discrimination coefficients were not significantly correlated for four of the five elements studied, suggesting that the physiological mechanisms influencing uptake are quite different for the two stages. Not only do discrimination coefficients change with ontogeny, but the effects of environmental conditions on discrimination coefficients change as well. The one exception we found was for Ba; discrimination coefficients correlated positively between larvae and juveniles, suggesting that incorporation of Ba into shell is not as affected by ontogeny as the other elements in this study. This may be because $\mathrm{Ba}$ is not known to be a critical element in shell construction, nor is it harmful to the organism when present in the extrapallial fluid. Ba concentrations in biogenic carbonate are therefore likely to reflect ambient levels.

The differences between larval and juvenile shell discrimination coefficients are not surprising given the disparate mechanisms that produce larval and juvenile shell in bivalves. Production of the first larval shell, or prodissoconch I, starts by evagination of a shell gland and subsequent spreading of the shell field. Prodissoconch II formation begins after the two valves surround the body and close against each other (Waller, 1981). Early in prodissoconch I formation, the shell gland transitions into the mantle structure, which is responsible for shell production thereafter (Waller, 1981). These intense morphological and developmental changes occurring during PI production are likely to cause significant differences in elemental uptake compared to juvenile shell production when the mantle has formed completely. Our results lend support to the idea that the effects of physiology on larval and juvenile shell production are sufficiently different to affect uptake and incorporation of elements into carbonate.

In a study of $\mathrm{Mg}$ and $\mathrm{Sr}$ concentrations in nautilus shells, Mann (1992) found consistently higher and more variable elemental concentrations in carbonate formed earlier in life. Three possible explanations are given: (1) an age-related change in biomineralization, wherein elemental concentrations depend on carbonate accretion 
rates; (2) maturation of the biomineralization system which results in increased control over shell chemistry; or (3) larvae are exposed to stresses related to food acquisition and protection that are less problematic in older organisms. Given the evidence that growth rate affects elemental incorporation (Onuma et al., 1979; Purton et al., 1999; Sinclair, 2005), and the fact that different processes are involved in larval and juvenile shell accretion, it is plausible that any or all of these ontogenetic explanations are applicable to our data.

Larval discrimination coefficients tended to be closer to 1 than juvenile discrimination coefficients for all elements (Fig. 4.4). This result suggests that the more advanced development of juveniles compared to larvae results in a greater ability to discriminate against ions that are not $\mathrm{Ca}^{2+}$ during shell production. Hirao et al. (1994) suggested that $\mathrm{Pb}$ content in abalone Haliotis shells decreased due to the development of a physiological mechanism for $\mathrm{Pb}$ exclusion that becomes more efficient with age. Bivalve shell composition is influenced by the efficiency of the $\mathrm{Ca}^{2+}$ channel that transports ions into the extrapallial fluid for shell construction, as well as the ability to discriminate against non-Ca ${ }^{2+}$ ions (Carre et al., 2006). Although there are no data published on differences in channel function for larval and juvenile molluscs, large changes in morphology and cell function during PI production may influence the composition of the fluid from which the shell is precipitated.

\subsubsection{Conclusions \& Implications for Future Studies}

Results from studies such as this one are crucial to studies that rely on biogenic carbonate to indicate either natal habitat or past environmental conditions. Temperature and salinity effects on discrimination coefficients of any element can be beneficial for connectivity studies when temperature and salinity vary geographically while the element itself does not. However this tool is useful only if the study focuses on a single cohort or if the temperature and salinity conditions do not vary over time. In contrast, temperature and salinity influences on discrimination coefficients complicate interpretations when variation in shell elemental composition is used as a recorder of past elemental concentrations in water, or in natural tagging studies when bio- 
genic carbonate formed outside of the spawning time frame is used to identify natal habitats.

We found that temperature and salinity significantly influenced shell chemistry of larval and juvenile Mya arenaria. However, physiological processes, whether influenced by ontogeny or environmental conditions, have the potential to complicate interpretations of elemental composition in biogenic carbonates. Variability in shell chemistry could be interpreted as indicating shifting environmental conditions when in fact composition may reflect individual (i.e. organism-level) or ontogenetic variability in physiological processes. Therefore, care must be taken to understand the potentially confounding effects of physiology before shell chemistry is used in studies as a proxy for environment or to identify natal habitat for connectivity studies.

\subsection{Acknowledgements}

This work was supported by NSF project numbers OCE-0326734 and OCE-0215905.

We thank H. Lind of the Eastham Natural Resources Department and P. Alatalo of WHOI for helpful aquaculture advice and suggestions. We also thank T. Marcotti for providing spawning stock. V. Starczak was helpful with statistical procedures and data interpretation. B. Walther and T. Elsdon were important resources for experimental design and implementation, as well as helpful manuscript discussion. We also thank D. Adams, S. Beaulieu, I. Garcia-Berdeal and S. Mills for comments on early drafts. 


\section{References}

Almeida, M., Moura, G., Pinheiro, T., Machado, J., Coimbra, J., 1998. Modifications in Crassostrea gigas shell composition exposed to high concentrations of lead. Aquatic Toxicology 40, 323-334.

Arai, T., Maeda, M., Yamakawa, H., Kamatani, A., Ohji, M., Miyazaki, N., 2003. Uptake and elimination of trace metals in shells of abalones Haliotis spp. Bulletin of Environmental Contamination and Toxicology 71 (1), 75-82.

Arkhipkin, A., Campana, S. E., FitzGerald, J., Thorrold, S. R., 2004. Spatial and temporal variation in elemental signatures of statoliths from the Patagonian longfin squid (Loligo gahi). Canadian Journal of Fisheries and Aquatic Sciences 61, $1212-$ 1224.

Babukutty, Y., Chacko, J., 1992. Trace metals in an estuarine bivalve from the southwest coast of India. Ambio 21, 292-296.

Bath, G. E., Thorrold, S. R., Jones, C. M., Campana, S. E., McLaren, J. W., Lam, J. W. H., 2000. Strontium and barium uptake in aragonitic otoliths of marine fish. Geochimica et Cosmochimica Acta 64 (10), 1705-1714.

Becker, B., Fodrie, F., McMillan, P., Levin, L., 2005. Spatial and temporal variation in trace elemental fingerprints of mytilid mussel shells: a precursor to invertebrate larval tracking. Limnology and Oceanography 50 (1), 48-61.

Becker, B., Levin, L., Fodrie, F., McMillan, P., 2007. Complex larval connectivity patterns among marine invertebrate populations. Proceedings of the National Academy of Sciences 104 (9), 3267-3272.

Berner, R. A., 1975. The role of magnesium in the crystal growth of calcite and aragonite from sea water. Geochimica et Cosmochimica Acta 39 (4), 489-494.

Boisson, F., Cotret, O., Fowler, S. W., 1998. Bioaccumulation and retention of lead 
in the mussel Mytilus galloprovincialis following uptake from seawater. Science of the Total Environment 222 (1-2), 55-61.

Bowden, K., 1980. Physical factors: salinity, temperature, circulation, and mixing processes. In: Olausson, E., Cato, I. (Eds.), Chemistry and Biogeochemistry of Estuaries. Wiley-Interscience, New York, pp. 37-70.

Campana, S. E., Thorrold, S. R., 2001. Otoliths, increments, and elements: Keys to a comprehensive understanding of fish populations? Canadian Journal of Fisheries and Aquatic Sciences 58, 30-38.

Carre, M., Bentaleb, I., Bruguier, O., Ordinola, E., Barrett, N. T., Fontugne, M., 2006. Calcification rate influence on trace element concentrations in aragonitic bivalve shells: Evidences and mechanisms. Geochimica et Cosmochimica Acta 70 (19), 4906-4920.

DiBacco, C., Levin, L. A., 2000. Development and application of elemental fingerprinting to track the dispersal of marine invertebrate larvae. Limnology and Oceanography 45 (4), 871-880.

Dodd, J., 1965. Environmental control of strontium and magnesium in Mytilus. Geochimica et Cosmochimica Acta 29, 385-398.

Dodd, J., 1967. Magnesium and strontium in calcareous skeletons: A review. Journal of Paleontology 41 (6), 1313-1329.

Dodd, J., Crisp, E., 1982. Non-linear variation with salinity of Sr/Ca and Mg/Ca ratios in water and aragonitic bivalve shells and implications for paleosalinity studies. Paleogeography, Paleoclimatology, Paleoecology 38, 45-56.

Elsdon, T., Gillanders, B., 2002. Interactive effects of temperature and salinity on otolith chemistry: Challenges for determining environmental histories of fish. Canadian Journal of Fisheries and Aquatic Sciences 59, 1796-1808. 
Elsdon, T. S., Gillanders, B. M., 2003. Reconstructing migratory patterns of fish based on environmental influences on otolith chemistry. Reviews in Fish Biology and Fisheries 13 (3), 217-235.

Gaetani, G., Cohen, A., 2006. Element partitioning during precipitation of aragonite from seawater: A framework for understanding paleoproxies. Geochimica et Cosmochimica Acta 70, 4617-4634.

Gillikin, D., Lorrain, A., Navez, J., Taylor, J., Andre, L., Keppens, E., Baeyens, W., Dehairs, F., 2005. Strong biological controls on Sr/Ca ratios in aragonitic marine bivalve shells. Geochemistry Geophysics Geosystems 6 (5), Q05009.

Hallam, A., Price, N., 1968. Environmental and biochemical control of strontium shells of Cardium edule. Geochimica et Cosmochimica Acta 32, 319-328.

Hirao, Y., Matsumoto, A., Yamakawa, H., Maeda, M., Kimura, K., 1994. Lead behavior in abalone shell. Geochimica et Cosmochimica Acta 58 (15), 3183-3189.

Hoff, G., Fuiman, L., 1995. Environmentally induced variation in elemental composition of red drum (Sciaenops ocellatus) otoliths. Bulletin of Marine Science 56 (2), $578-591$.

Kalish, J., 1989. Otolith microchemistry: Validation of the effects of physiology, age and environment on otolith composition. Journal of Experimental Marine Biology and Ecology 132, 151-178.

Klinkhammer, G. P., McManus, J., 2001. Dissolved manganese in the Columbia River Estuary: Production in the water column. Geochimica et Cosmochimica Acta 65 (17), 2835-2841.

Lazareth, C., Vander Putten, E., Andre, L., Dehairs, F., 2003. High-resolution trace element profiles in shells of the mangrove bivalve Isognomon ephippium: A record of environmental spatio-temporal variations? Estuarine Coastal and Shelf Science 57, 1103-1114. 
Lerman, A., 1965. Strontium and magnesium in water and Crassostrea calcite. Science 150 (3697), 745-746.

Levin, L., 1990. A review of methods for labeling and tracking marine invertebrate larvae. Ophelia 32 (1-2), 115-144.

Likins, R., Berry, E., Posner, A., 1963. Comparative fixation of calcium and strontium by snail shell. Annals of New York Academy of Sciences 109, 269-277.

Lorens, R. B., Bender, M. L., 1980. The impact of solution chemistry on Mytilus edulis calcite and aragonite. Geochimica et Cosmochimica Acta 44 (9), 1265-1278.

Mann, K. O., 1992. Physiological, environmental, and mineralogical controls on Mg and Sr concentrations in Nautilus. Journal of Paleontology 66 (4), 620-636.

Martin, G., Thorrold, S. R., 2005. Temperature and salinity effects on magnesium, manganese, and barium incorporation in otoliths of larval and early juvenile spot Leiostomus xanthurus. Marine Ecology Progress Series 293, 223-232.

Martin, G., Thorrold, S. R., Jones, C. M., 2004. Temperature and salinity effects on strontium incorporation in otoliths of larval spot (Leiostomus xanthurus). Canadian Journal of Fisheries and Aquatic Sciences 61, 34-42.

Moilanen, A., Nieminen, M., 2002. Simple connectivity measures in spatial ecology. Ecology 83 (4), 1131-1145.

Morse, J. W., Bender, M. L., 1990. Partition coefficients in calcite: Examination of factors influencing the validity of experimental results and their application to natural systems. Chemical Geology 82, 265-277.

Mubiana, V. K., Blust, R., 2007. Effects of temperature on scope for growth and accumulation of $\mathrm{Cd}, \mathrm{Co}, \mathrm{Cu}$ and $\mathrm{Pb}$ by the marine bivalve Mytilus edulis. Marine Environmental Research 63 (3), 219-235. 
Onuma, N., Masuda, F., Masataka, H., Wada, K., 1979. Crystal structure control on trace element partition in molluscan shell formation. Geochemical Journal 13, $187-189$.

Palumbi, S. R., 2003. Population genetics, demographic connectivity, and the design of marine reserves. Ecological Applications 13 (s1), 146-158.

Patterson, H. M., Kingsford, M. J., McCulloch, M. T., 2005. Resolution of the early life history of a reef fish using otolith chemistry. Coral Reefs 24 (2), 222-229.

Pitts, L. C., Wallace, G. T., 1994. Lead deposition in the shell of the bivalve, Mya arenaria: An indicator of dissolved lead in seawater. Estuarine, Coastal and Shelf Science 39 (1), 93-104.

Purton, L., Shields, G., Brasier, M., Grime, G., 1999. Metabolism controls Sr/Ca ratios in fossil aragonitic mollusks. Geology 27 (12), 1083-1086.

Rucker, J., Valentine, J., 1961. Salinity response of trace element concentration in Crassostrea virginica. Nature 190 (4781), 1099-1100.

Shanks, A., Grantham, B., Carr, M., 2003. Propagule dispersal distance and the size and spacing of marine reserves. Ecological Applications 13 (s1), S159-S169.

Sinclair, D. J., 2005. Correlated trace element "vital effects" in tropical corals: A new geochemical tool for probing biomineralization. Geochimica et Cosmochimica Acta 69 (13), 3265-3284.

Speer, J., 1983. Crystal chemistry and phase relations of orthorhombic carbonates. In: Reeder, R. (Ed.), Carbonates: Mineralogy and Chemistry. Vol. 11 of Reviews in Mineralogy. Mineralogy Society of America, Washington, D.C., 397 pp.

Stecher, H., Krantz, D., Lord III, C., Luther III, G., Bock, K., 1996. Profiles of strontium and barium in Mercenaria mercenaria and Spisula solidissima shells. Geochimica et Cosmochimica Acta 60 (18), 3445-3456. 
Strasser, C., Mullineaux, L. S., Walther, B., 2008. Growth rate and age effects on Mya arenaria shell chemistry: Implications for biogeochemical studies. Journal of Experimental Marine Biology and Ecology 355, 153-163.

Sturgeon, R., Willie, S., Yang, L., Greenberg, R., Spatz, R., Chen, Z., Scriver, C., Clancy, V., Lam, J. W. H., Thorrold, S. R., 2005. Certification of a fish otolith reference material in support of quality assurance for trace element analysis. Journal of Analytical Atomic Spectrometry 10, 1067-1071.

Sunda, W., Huntsman, S., 1987. Microbial oxidation of manganese in a North Carolina estuary. Limnology and Oceanography 32, 552-564.

Takesue, R. K., van Geen, A., 2004. Mg/Ca, Sr/Ca, and stable isotopes in modern and Holocene Protothaca staminea shells from a northern California coastal upwelling region. Geochimica et Cosmochimica Acta 68 (19), 3845-3861.

Thorn, K., Cerrato, R., Rivers, M., 1995. Elemental distributions in marine bivalve shells measured by synchrotron X-ray fluorescence. Biological Bulletin 188, 57-67.

Thorrold, S. R., Jones, C. M., Campana, S. E., McLaren, J. W., Lam, J. W., 1998. Trace element signatures in otoliths record natal river of juvenile american shad (Alosa sapidissima). Limnology and Oceanography 43 (8), 1826-1835.

Thorrold, S. R., Jones, G. P., Hellberg, M. E., Burton, R. S., Swearer, S. E., Neigel, J. E., Morgan, S. G., Warner, R. R., 2002. Quantifying larval retention and connectivity in marine populations with artificial and natural markers. Bulletin of Marine Science 70 (1), 291-308.

Thorrold, S. R., Latkoczy, C., Swart, P. K., Jones, C. M., 2001. Natal homing in a marine fish metapopulation. Science 291, 297-299.

Thorson, G., 1950. Reproductive and larval ecology of marine bottom invertebrates. Biological Review 25, 1-45. 
Thorson, G., 1966. Some factors influencing the recruitment and establishment of marine benthic communities. Netherlands Journal of Sea Research 3, 267-293.

Vander Putten, E., Dehairs, F., Keppens, E., Baeyens, W., 2000. High resolution distribution of trace elements in the calcite shell layer of modern Mytilus edulis: Environmental and biological controls. Geochimica et Cosmochimica Acta 64 (6), 997-1011.

Waller, T., 1981. Functional morphology and development of veliger larvae of the European Oyster, Ostrea edulis L. Smithsonian Contributions to Zoology 328.

Watson, E. B., 2004. A conceptual model for near-surface kinetic controls on the traceelement and stable isotope composition of abiogenic calcite crystals. Geochimica et Cosmochimica Acta 68 (7), 1473-1488.

Wilbur, K., 1972. Shell formation in mollusks. In: Florkin, M., Scheer, B. (Eds.), Chemical Zoology Vol. VII: Mollusca. Academic Press, New York, pp. 103-145.

Yoshinaga, J., Nakama, A., Morita, M., Edmonds, J., 2000. Fish otolith reference material for quality assurance of chemical analyses. Marine Chemistry 69, 91-97.

Zacherl, D., Manriquez, P., Paradis, G., Day, R., Castilla, J., Warner, R., Lea, D., Gaines, S., 2003a. Trace elemental fingerprinting of gastropod statoliths to study larval dispersal trajectories. Marine Ecology Progress Series 248, 297-303.

Zacherl, D., Paradis, G., Lea, D., 2003b. Barium and strontium uptake into larval protoconchs and statoliths of the marine neogastropod Kelletia kelletii. Geochimica et Cosmochimica Acta 67 (21), 4091-4099.

Zumholz, K., Hansteen, T., Piatkowski, U., Croot, P., 2007. Influence of temperature and salinity on the trace element incorporation into statoliths of the common cuttlefish (Sepia officinalis). Marine Biology 151, 1321-1330. 


\section{Chapter 5}

\section{Limited genetic variation and}

\section{structure in softshell clams (Mya}

arenaria) across their native and introduced range

\subsection{Introduction}

Benthic marine habitats of the Northwest Atlantic Ocean (NWA) are structured into distinct biogeographic provinces (Engle and Summers, 1999). These biogeographic divisions are a function of environmental gradients resulting from the synergy of the coastal geography of Eastern North America with the Gulf Stream and Labrador Currents, combined with latitudinal gradients in temperature and salinity (Hutchins, 1947). The most commonly recognized biogeographic divisions are the Nova Scotian and Virginian Provinces, with Cape Cod serving as the boundary between the two (Hall, 1964; Hutchins, 1947). Superimposed on these divisions is a history of Pleistocene glaciations that extirpated many benthic marine species from northern latitudes and formed Cape Cod (Upham, 1879a,b), reshaping regional patterns of biological and genetic diversity (Wares and Cunningham, 2001; Wares, 2002; Hewitt, 
1996).

The presence of distinct biogeographic provinces in the NWA has significant implications for management of fish and invertebrates in this region because species spanning multiple provinces of the NWA can have populations adapted to local environmental conditions. For example, the Atlantic Silverside Menidia menidia exhibits heritable local variation in growth rate and vertebral number, resulting in a latitudinal phenotypic cline across the NWA (Present and Conover, 1992; Billerbeck et al., 1997; Yamahira et al., 2006). On a smaller scale, the mussel Mytilus edulis exhibits a sharp cline in the leucine aminopeptidase (LAP) allele across salinity gradients in Long Island Sound (Gardner and Kathiravetpillai, 1997; Gardner and Palmer, 1998). The presence of regional genetic structure, particularly if it is locally adaptive, needs to be accounted for in fisheries management so that genetic diversity is conserved and locally adaptive gene complexes are not disrupted through indiscriminate stocking (Hansen, 2002).

Mya arenaria is a commercially important bivalve with a contemporary distribution that includes 1) the northwest Atlantic ranging from Nova Scotia to Virginia, 2) the North Sea and European waters, including the Black, Baltic, Wadden, White, and Mediterranean Seas, and 3) northeast Pacific from San Francisco to Alaska (Strasser, 1999). M. arenaria has a complex history of extensive global distributions, with several extinctions and re-colonization events (reviewed in Strasser 1999). M. arenaria originated in the Pacific Ocean during the Miocene then extended its range to the Atlantic and European waters in the early Pliocene. Extinction of Pacific and European populations in the early Pleistocene left the only surviving populations in the NWA until recent history (MacNeal, 1965). M. arenaria re-invaded European waters in the 17th century after being brought from the NWA by Vikings (Petersen et al., 1992). In the late 19th century M. arenaria was reintroduced into the Pacific, first accidentally then as a potential commercial fishery (Carlton, 1979; Powers et al., 2006). The natural and introduced distribution of M. arenaria results partly from the clam's ability to withstand wide salinity and temperature ranges, and its capability of inhabiting different sediment types from fine mud to coarse sand (Newell and Hidu, 
1982; Abraham and Dillon, 1986; Hidu and Newell, 1989).

Despite characteristics that made softshell clams a successful invasive species in European waters and the northeast Pacific, the last two decades have seen appreciable declines in softshell clam landings in New England (Brousseau, 2005; Anonymous, 2007). This decline has been attributed to habitat degradation or loss, overfishing, contamination, and predation by invasive species (Brousseau, 2005). Managers and state agencies have enacted various management strategies to combat these declines, including using protective nets to reduce predation on newly recruited clams, and seeding flats using hatchery-reared juveniles (Marcotti and Leavitt, 1997, H. Lind, pers. comm.).

While stocking of fish and shellfish is a long-standing practice, research is increasingly showing that the genetic impacts of stocking cannot be ignored. Stocking should seek to maintain levels of genetic diversity (Waples and Do, 1994); although multiple individuals are spawned to produce seed clams, it is unknown whether the genetic diversity represented among these individuals is reduced in comparison to naturally occurring cohorts, where entire adult populations spawn simultaneously (Brousseau, 1978). In addition, given that brood stock is not always taken from the flat into which seed clams are stocked, locally appropriate genotypes could be introduced into inappropriate areas. For example, Mya arenaria exhibit local variation in resistance to paralytic shellfish toxins (Connell et al., 2007). Seeding flats using brood stock from other clam populations may result in either reduction of the locally dominant alleles due to success of the introduced seed clams, or significant loss of seed clams due to a lack of a genetic background appropriate to the local environment. Similar declines in local fitness have been documented in salmonids (Hansen, 2002).

Previous genetic studies on softshell clams have found limited genetic diversity despite the wide geographic ranges represented among studies. Morgan et al. (1978) used allozymes to study Mya arenaria genetic variation in the NWA, and found low polymorphism and low heterozygosity per individual for both populations examined. Caporale et al. (1997) found similar low variability in three regions of the NWA (12 locations total) using the internal transcribed spacer ribosomal DNA region (nDNA), 
and concluded that although the three regions were not genetically distinct, the data from the study were insufficient to indicate a panmictic population. More recently, Lasota et al. (2004) used allozymes to study seven locations in the northeast Atlantic and two in the North Sea. They also found low genetic variability and a lack of genetic differentiation, and concluded that $M$. arenaria is a successful invader despite a high degree of genetic homogeneity. They suggested the patterns observed were evidence of rapid population expansion, allele neutrality, and high gene flow. However, nDNA is known to evolve slower than mitochondrial DNA (mtDNA), and allozyme studies may mask underlying sequence variation. Therefore the results seen in these studies might be because of the markers chosen to conduct the studies.

In this study, we examine population genetic variability of Mya arenaria across its natural range in the NWA and portions of its introduced range in the northeast Pacific and European waters using the highly variable mitochondrial cytochrome oxidase I (COI) gene that commonly resolves phylogeographic structure in marine invertebrates (Wares, 2002; Barber et al., 2006) including bivalves (King et al., 1999; May et al., 2006). First, we examine how populations may be geographically structured across the NWA to determine whether the distinct environments and biogeographic provinces partition softshell clams into genetically distinct regional stocks. Second, we compare NWA to NEP and NSE populations to examine the geographic origins of these populations and the effects of recent introduction on genetic diversity. The results of this study have implications for management of softshell clams in New England, in addition to insights gained about historical extinction and colonization events of $M$. arenaria with reference to biogeographic boundaries and glaciation.

\subsection{Methods}

Juvenile and adult M. arenaria $(N=212)$ were collected between 2001 and 2006 from 12 locations: one northeast Pacific site $(n=20)$, ten NWA sites $(n=177)$, and one North Sea, Europe site $(n=15)$ (Fig. 5.1, Table 5.1). Most M. arenaria were frozen after collection to prevent DNA degradation, and then transferred to 70-95\% 


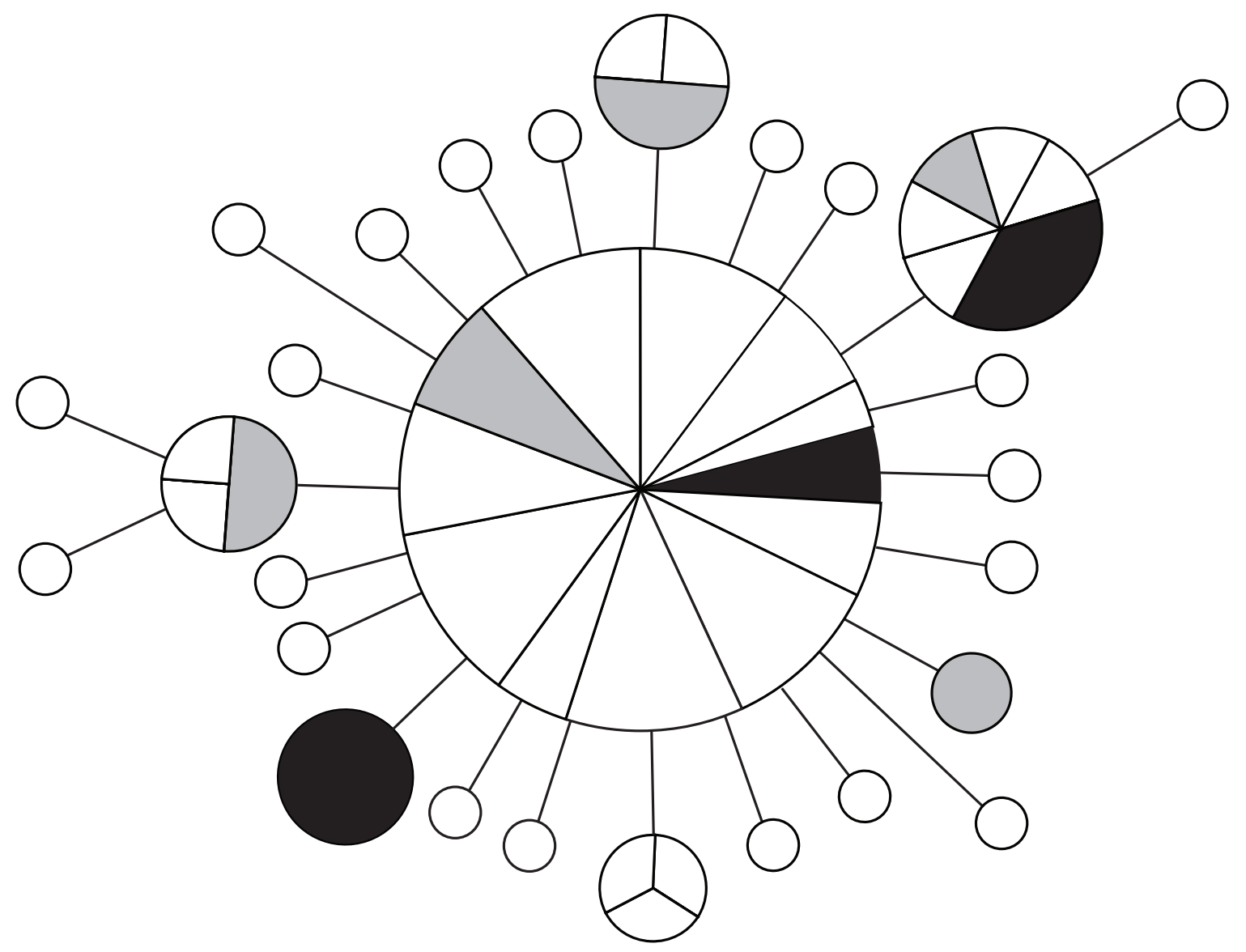

Figure 5.1: Unrooted minimum-spanning tree depicting the relationship of the 27 mitochondrial COI haplotypes from 217 Mya arenaria individuals, collected from 12 sites in the NWA (white; $n=177$ ), one site in the North Sea, Europe (black; $n=15$ ), and one site in the northeast Pacific (gray; $n=20$ ). Line distance between circles corresponds to the number of nucleotide differences (1 or 2 ); size and number of divisions in each haplotype circle correspond to the number of individuals. 


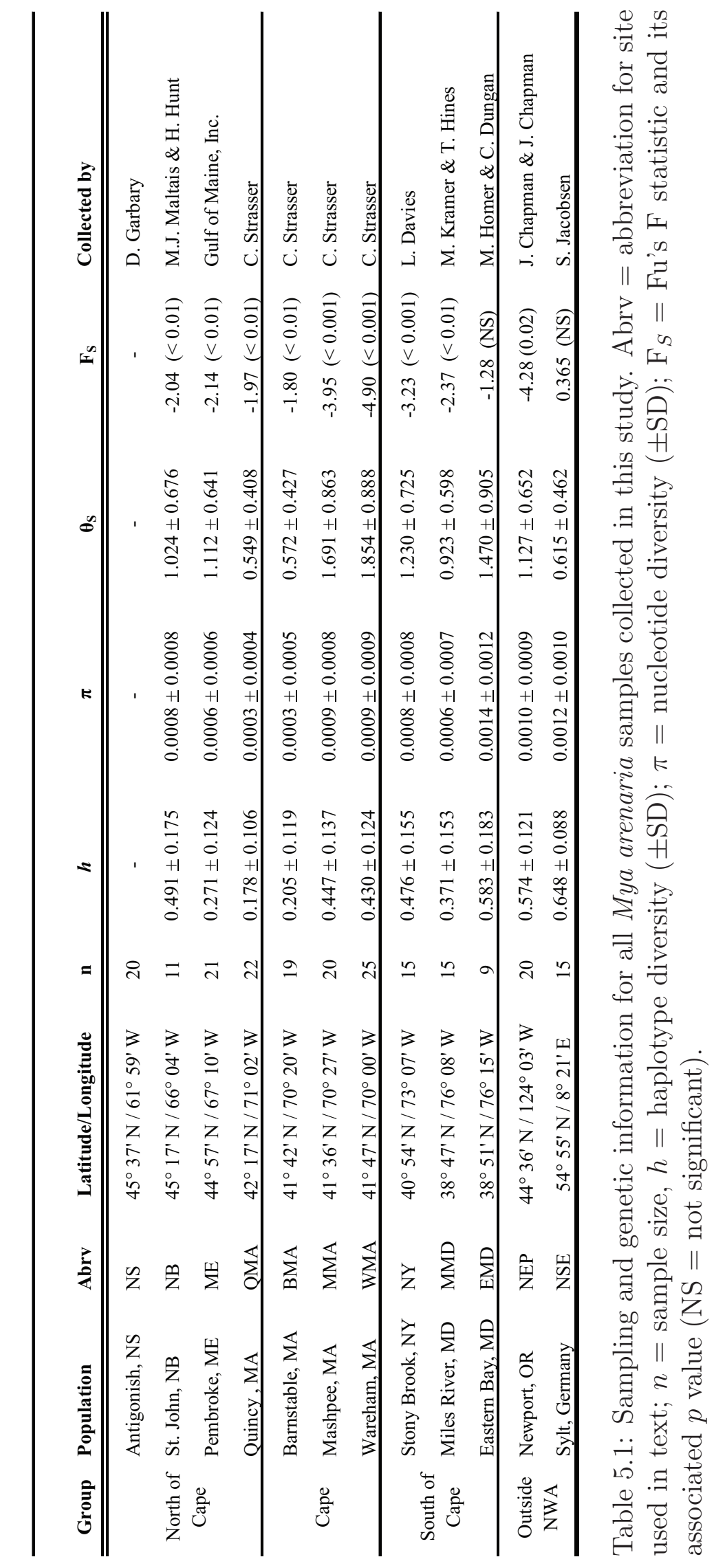


ethanol for at least 24 hours prior to DNA extraction to improve the success of DNA extractions. Some individuals were preserved directly in ethanol without freezing. For clams $<1 \mathrm{~cm}$ total length, we used the entire clam for DNA extraction. For larger clams we extracted DNA from small fibers of adductor muscle tissue. All DNA extractions were performed with a 10\% Chelex®(BioRad) solution (Walsh et al., 1991). A $661 \mathrm{bp}$ fragment of the mitochondrial cytochrome oxidase subunit-I gene (COI) was amplified via polymerase chain reaction (PCR) using the primers HCO2198 and LCO-1490 (Folmer et al., 1994). PCR occurred in 251 reactions with 2.51 of $10 \times$ buffer, $21 \mathrm{MgCl}_{2}(25 \mathrm{mM}), 2.5 \mathrm{l}$ DNTPs $(8 \mathrm{mM}), 1.25 \mathrm{l}$ of each $10 \mathrm{mM}$ primer, $1 \mathrm{l}$ of template, and 0.625 units of Amplitaq (Perkin Elmer). Hot-start thermocycling parameters were as follows: initial denaturation $94^{\circ} \mathrm{C}(3 \mathrm{~min})$; followed by 38 cycles of $94^{\circ} \mathrm{C}(30 \mathrm{~s}), 50^{\circ} \mathrm{C}(30 \mathrm{~s}), 72^{\circ} \mathrm{C}(45 \mathrm{~s})$; then a final extension of $72^{\circ} \mathrm{C}(10 \mathrm{~min})$.

PCR products were visualized on $1 \%$ agarose PAC $1 \%$ sodium hydroxide and boric acid gels, and then enzymatically prepared for sequencing by digestion in 0.5 units of Shrimp Alkaline Phosphotase and 5 units of exonuclease per $5 \mathrm{l}$ of PCR product, incubated at $37^{\circ} \mathrm{C}$ for $30 \mathrm{~min}$ followed by $80^{\circ} \mathrm{C}$ for $15 \mathrm{~min}$. PCR product was cleaned using isopropanol precipitation, and sequencing reactions were performed for both forward and reverse strands on an ABI 377 (Applied Biosystems) using BigDye@(Perkin Elmer) terminator chemistry. Complementary strands for each sample were proofread and aligned in Sequencher ${ }^{T M}$, and translations confirmed using MaClade 4.05 (Maddison and Maddison, 2002) .

To explore regional distribution of genetic diversity in Mya arenaria, we calculated haplotype diversity $(h)$, nucleotide diversity $(\pi)$, and theta $(\theta)$ for all populations using Arlequin 3.1 (Excoffier et al., 2005). To explore patterns of phylogeographic structure we constructed a minimum-spanning tree using the MINSPNET algorithm as employed in Arlequin. Frequency of haplotypes was then plotted against geography for NWA populations.

To further explore geographic genetic structure, we investigated genetic partitions in analysis of molecular variance (AMOVA) as implemented in Arlequin. Values of $\phi_{S T}$ were calculated with statistical significance determined by 20,000 random per- 
mutations. Analyses were run both unstructured, and structured into two regions $(\mathrm{NWA}+\mathrm{NEP}$ and NSE) or three regions (NWA, NEP, NSE). Patterns of genetic structure were similarly estimated within the NWA by excluding NEP and NSE populations. NWA analyses were both unstructured and assuming three regions: north of Cape Cod, Cape Cod, and South of Cape Cod. To further examine patterns of genetic exchange, pairwise $\mathrm{F}_{S T}$ values were calculated among all populations with 20,000 permutations used to establish significance.

Because of extremely low levels of genetic variation within the dataset, we tested for neutrality by calculating Fu's $\mathrm{F}_{S}$ statistics (Fu, 1997), which establishes whether non-neutrality might be due to population growth and range expansion. To further explore the possibility of recent demographic or spatial population expansion, we used mismatch distributions, which compares the expected and observed number of differences between pairs of haplotypes (Rogers and Harpending, 1992; Ray et al., 2003). Finally, we used Bayesian Markov Chain Monte Carlo analysis of molecular sequences to produce a Bayesian skyline plot using BEAST v1.4 and Tracer v1.4 (Drummond and Rambaut, 2006), which plots population size over time and estimates the approximate time since population expansion (Drummond et al., 2002, 2005). We used MODELTEST (Posada and Crandall, 1998) implemented in PAUP* ver.4.0b10 (Swofford, 1998) to find the most appropriate model for BEAST (Hasegawa, Kishino, and Yano Model). A strict molecular clock was used to produce the skyline plot, which was based on five skyline groups. We ran the program using default priors for Bayesian skyline analysis for 50 million generations, and repeated the program run four times to increase effective sample size and assure that results were converging. Results reported in mutational units were converted to years for the skyline plot by assuming a molluscan-specific COI divergence rate of either $1 \%$ per million years $\left(\% \mathrm{Myr}^{-1}\right)$ for all COI sites or $5 \% \mathrm{Myr}^{-1}$ for third positions alone (Marko, 2002). 


\subsection{Results}

A total of $661 \mathrm{bp}$ of COI was collected from 212 individuals, yielding only 27 unique haplotypes that differed by one or two nucleotide substitutions, all in the third codon position and silent with one exception, haplotype I (Table 5.2). There was one dominant haplotype (A) found at all of the locations sampled, ranging in frequency from 0.65 to 1.00 for individual populations, with an overall frequency of 0.79 . Of the remaining 26 haplotypes, only five were found more than once in a single population, ranging in frequency from 0.10 to 0.27 (haplotypes B-F). Two private alleles, haplotypes that occur more than one time in only one site (Slatkin, 1985), were found in NSE (Haplotype E) and NEP (Haplotype G).

Haplotype diversity $(h)$ in the NWA ranged from 0.178 to 0.648 (Table 5.1). Comparable levels of haplotype diversity occurred in NSE $(h=0.65)$ and NEP $(h=0.57)$ populations. Nucleotide diversity was low for all NWA populations, ranging from 0.0003 to 0.001 (Table 5.1), while $\pi=0.0010$ in NSE and $\pi=0.0012$ in NEP. Theta ranged from 1.854 to 0.549 in the NWA and was 0.615 and 1.127 in NSE and NEP, respectively (Table 5.1). There were no clear geographic patterns in genetic diversity measures.

Consistent with the low nucleotide diversity, the minimum spanning tree of $M$. arenaria COI haplotypes revealed a star-shaped phylogeny (Fig. 5.1). The dominant haplotype (A) was located at the center of the star with 21 of 26 remaining haplotypes differing from haplotype A by a single nucleotide substitution. Five haplotypes differed by 2 mutational steps (haplotypes J, O, T, U, AA). No geographic structure is evident in the minimum spanning tree topology and NEP and NSE haplotypes are scattered throughout the tree. Plotting the frequency of the 6 non-singleton haplotypes revealed no clear phylogeographic patterns in the NWA except for the lack of genetic diversity in Nova Scotia (Fig. 5.2).

Results from AMOVA found the majority of variability was within populations, regardless of any structure imposed on the locations sampled (Table 5.3). Unstructured AMOVA analyses indicated the presence of subtle but significant genetic structure 


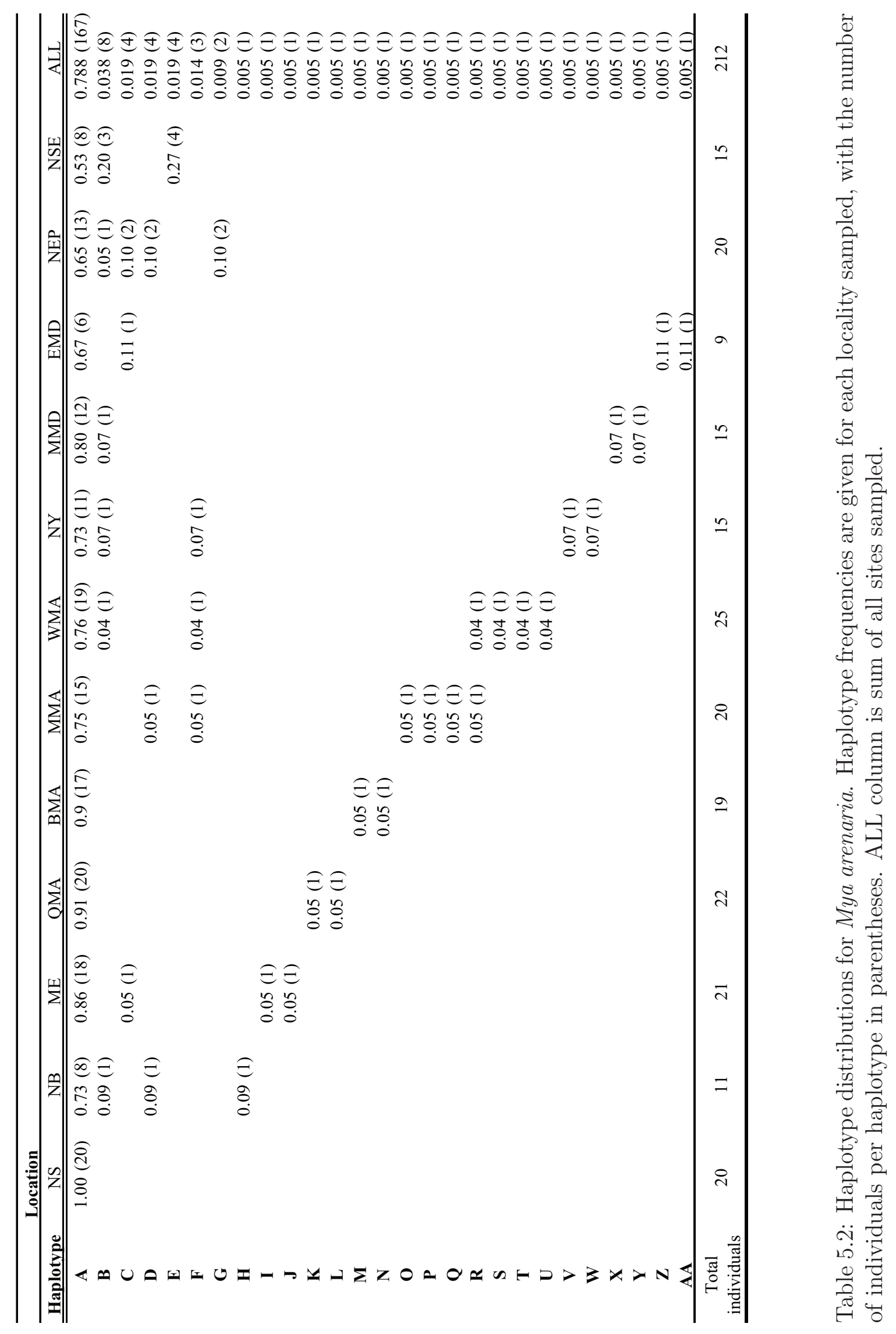




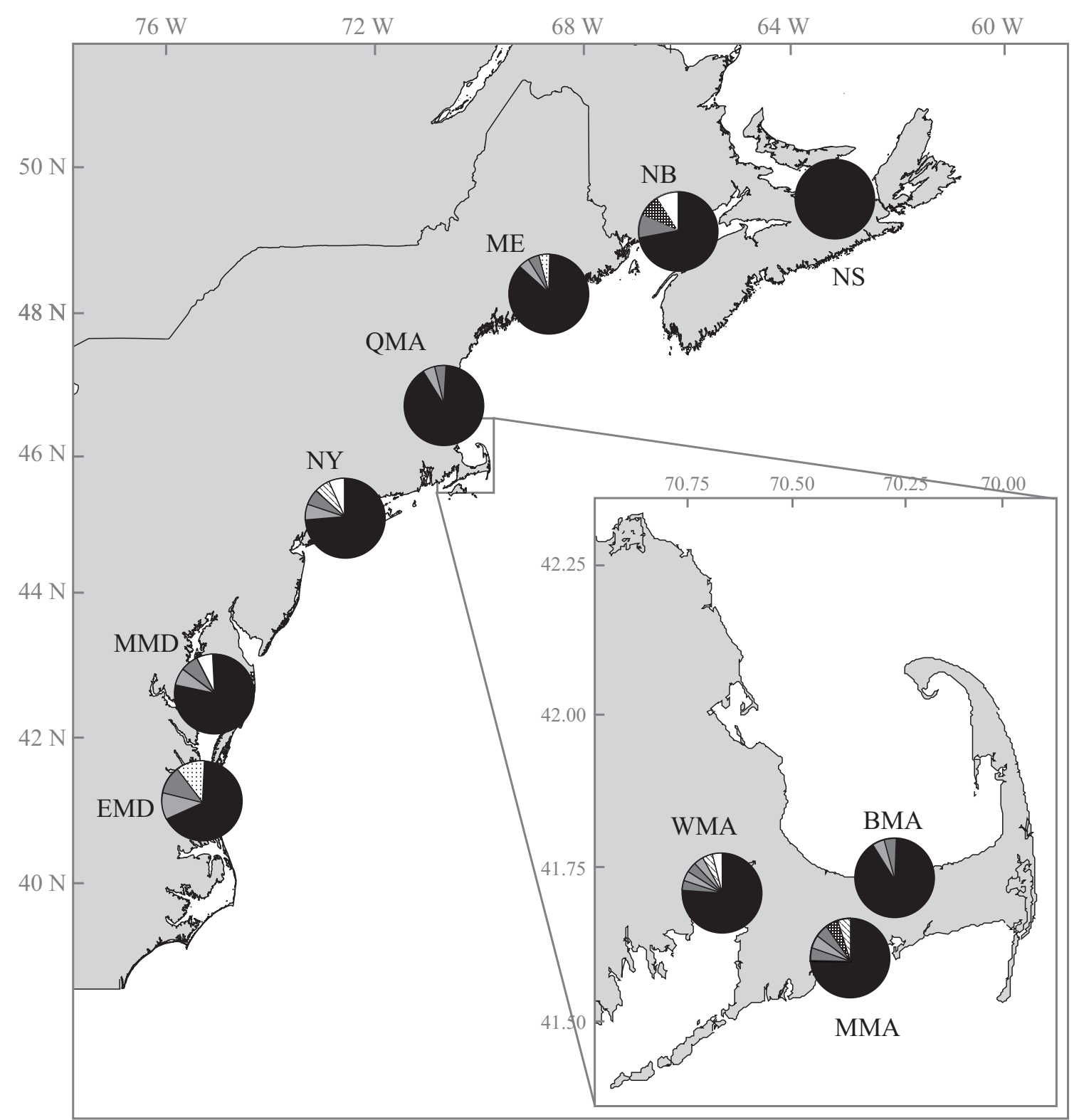

Figure 5.2: Distribution of mitochondrial COI haplotypes for Mya arenaria in the NWA. Gray shades are unique haplotypes found in only one location; patterns are haplotypes shared among two or more locations. See Table 5.1 for site abbreviations and sample sizes. 


\begin{tabular}{|c|c|c|c|c|c|c|c|c|c|c|c|c|}
\hline & \multicolumn{4}{|c|}{ Among regions } & \multicolumn{4}{|c|}{ Among populations within regions } & \multicolumn{4}{|c|}{ Within populations } \\
\hline & $\mathrm{df}$ & Var. & $\%$ Var. & $\Phi_{\mathrm{CT}}$ & $\mathrm{df}$ & Var. & $\%$ Var. & $\Phi_{\mathrm{SC}}$ & $\mathrm{df}$ & Var. & $\%$ Var. & $\Phi_{\mathrm{ST}}$ \\
\hline \multicolumn{13}{|l|}{ All Locations } \\
\hline Structured: 2 groups & 1 & 0.0429 & 15.9 & 0.159 & 10 & 0.00003 & 0.01 & 0.0001 & 200 & 0.2271 & 84.1 & $0.1591 *$ \\
\hline Structured: 3 groups & 2 & 0.0239 & 9.57 & 0.957 & 9 & -0.0014 & -0.54 & -0.0060 & 200 & 0.2271 & 91.0 & $0.0903 *$ \\
\hline Structured & 2 & 0.00043 & 0.21 & 0.0021 & 7 & -0.0002 & -0.12 & -0.0012 & 167 & 0.2020 & 99.9 & 0.0010 \\
\hline
\end{tabular}

Table 5.3: Results of AMOVAs to determine the source of genetic variation in Mya arenaria COI. ${ }^{*}$ indicates that the value is significant at the $p=0.005$ level. See text for group descriptions.

$\left(\phi_{S T}=0.0267, p<0.005\right)$ with $3 \%$ of the variation between populations and $97 \%$ of the variation within populations. Imposing regional partitions comparing North American (NWA+NEP) and European (NSE) populations produced $\phi_{S T}=0.159$ $(p<0.005)$ with $15.9 \%$ of variation among regions, $0.01 \%$ among populations within regions, and $84.1 \%$ of the variation within populations. When we imposed three regional partitions, NWA, NEP, and NSE, $\phi_{S T}=0.0903(p<0.005)$ with $91 \%$ of the variation within populations, $9 \%$ among regions, and no variation among populations within regions.

Unstructured AMOVA analyses across the NWA revealed no significant genetic structure with $99.9 \%$ of all genetic variation contained within populations (Table 5.3). Similarly, when locations were grouped into regions north of Cape Cod, Cape Cod, and south of Cape Cod (Table 5.1), $\phi_{S T}=0.0010$ (n.s.) with $99.9 \%$ of all genetic variation contained within populations and no significant variation among regions or among populations within regions.

Population pairwise $\mathrm{F}_{S T}$ 's were significant and high between NSE and 7 populations, including NEP $\left(\mathrm{F}_{S T}=0.09\right.$ to $\left.0.222 ; p<0.05\right)$ (Table 5.4). In addition, NEP showed moderate divergence with QMA $\left(\mathrm{F}_{S T}=0.039 ; p=0.006\right)$. Within the NWA, sites showed low variability between populations. Only the northernmost population (Nova Scotia) had significant $\mathrm{F}_{S T}$ values, with moderate divergence between Nova Scotia and populations from New Brunswick $\left(\mathrm{F}_{S T}=0.058\right)$ and Eastern Bay Maryland $\left(\mathrm{F}_{S T}=0.097\right)$. In addition, there was minimal divergence $\left(\mathrm{F}_{S T}=0.02\right)$ between 


\begin{tabular}{ccccccccccccc}
\hline & NSE & NS & NB & ME & QMA & BMA & MMA & WMA & NY & MMD & EMD & NEP \\
\hline \hline NSE & - & 0.0007 & & 0 & 0.0003 & 0.001 & 0.0003 & 0.009 & & 0.008 \\
NS & $0.222^{*}$ & - & 0.036 & & & & & & 0.026 & \\
NB & 0.065 & $0.058^{*}$ & - & & & & & & \\
ME & $0.143^{*}$ & -0.002 & 0.008 & - & & & & & \\
QMA & $0.182^{*}$ & -0.004 & 0.028 & 0.001 & - & & & & & \\
BMA & $0.166^{*}$ & 0.003 & 0.006 & -0.001 & 0.001 & - & & & \\
MMA & $0.115^{*}$ & 0.000 & -0.018 & 0.001 & 0.003 & -0.008 & - & & & \\
WMA & $0.099^{*}$ & 0.000 & -0.010 & -0.010 & 0.005 & 0.001 & -0.001 & - & & \\
NY & 0.084 & $0.02 *$ & -0.023 & 0.003 & 0.012 & 0.007 & -0.013 & -0.015 & - & \\
MMD & 0.092 & 0.020 & -0.023 & 0.000 & 0.009 & 0.005 & -0.003 & -0.010 & -0.019 & - \\
EMD & 0.052 & $0.097 *$ & -0.024 & 0.012 & 0.060 & 0.047 & 0.013 & -0.020 & -0.010 & -0.006 & - \\
NEP & $0.104 *$ & 0.045 & -0.023 & 0.013 & $0.039 *$ & 0.022 & 0.009 & -0.001 & 0.013 & 0.012 & -0.015 \\
\hline
\end{tabular}

Table 5.4: Pairwise population comparisons, $\mathrm{F}_{S T}$ (below diagonal) and their associated $\mathrm{p}$ values if significant (above diagonal). * indicates that the value is significant at the $p=0.05$ level.

Nova Scotia and New York. However, no other pairwise $F_{S T}$ 's were significant at the $p<0.05$ level.

Some haplotypes found in NSE and NEP were not shared with the NWA. To determine whether this was due to inadequate sampling, we constructed a rarefaction curve for the NWA (Fig. 5.3) using equations appropriate for population sample sizes much smaller than total sample size (Heck et al., 1975). The rarefaction curve did not reach an asymptote over the range of the number of individuals sampled. Although it is not valid to extrapolate the curve and predict how many haplotypes might be present in the NWA, the slope of the curve does appear to be leveling off, which suggests that a majority of the available haplotypes were sampled.

Fu's $\mathrm{F}_{S}$ Statistic was significantly large and negative for 9 of the 12 populations (Table 5.1) suggesting non-equilibrium dynamics. Mismatch analysis revealed no significant fit to the models of recent spatial or demographic expansion (data not shown). However, p-values were generally lower (i.e. the model was a better fit) for the spatial expansion hypothesis.

Support for a range expansion comes from the Bayesian skyline plot indicating that Mya arenaria populations in the NWA were much smaller in recent history (Fig. 5.4). The plot indicates that a pronounced demographic expansion event took place in NWA populations of M. arenaria between 75,000 and 15,000 years ago. These 


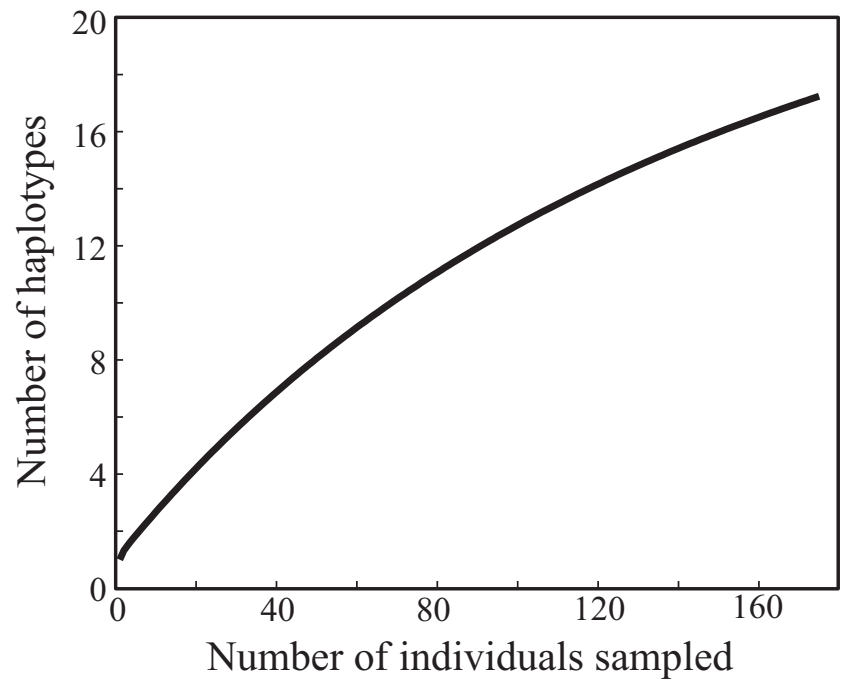

Figure 5.3: Rarefaction curve constructed using data from Mya arenaria populations in the NWA.

values correspond to 0.00035 mutational units and a mutation rate of 0.005 to 0.025 mutations $\mathrm{Myr}^{-1}$, based on the clock calibrations of Marko (2002).

\subsection{Discussion}

\subsubsection{Patterns in the Northwest Atlantic}

Genetic analysis of Mya arenaria populations across the Northwest Atlantic revealed a near complete absence of genetic structure. This result stands in contrast to previous studies of other marine species that show pronounced phylogeographic structure in the NWA (see Wares 2002 for a review), particularly among populations along the northern and southern coastline of the NWA (e.g. Waldman et al., 1996; Smith et al., 1998; Dahlgren et al., 2000; Brown et al., 2001). Within the NWA the only evidence for differentiation among northern and southern populations comes from three significant pairwise $\mathrm{F}_{S T}$ values among Nova Scotia populations and those to the south. These significant differences are likely driven by the lack of diversity in the NS sample, where only the dominant haplotype was observed.

The lack of genetic diversity and limited genetic structure reported here echoes previous genetic studies on softshell clams (Morgan et al., 1978; Caporale et al., 1997; 


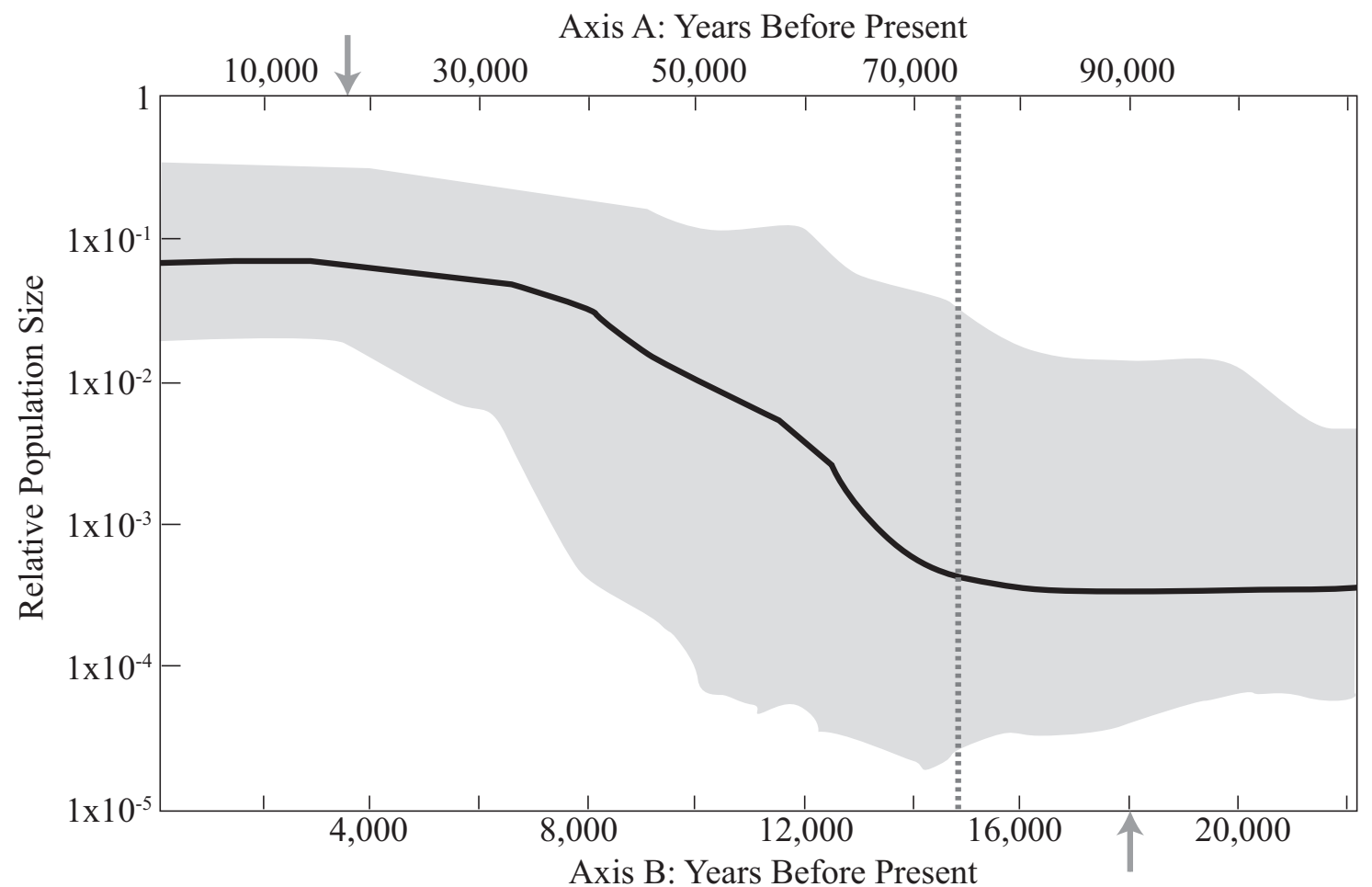

Figure 5.4: Bayesian skyline plot derived from Mya arenaria NWA sequences. The solid line is the median estimate of population size, and the shaded region shows 95\% highest posterior density limits (see Drummond et al., 2005). The dashed line indicates where in time the population expanded. Axis A is the years before present when a $1 \%$ per million years divergence rate is used; Axis B is the years before present when a $5 \%$ per million years divergence rate is used (see text for details). The gray arrows on each axis represent the approximate timing of the last glacial maximum. Population size on the y-axis is relative to its current size. 
Lasota et al., 2004). The concordant results among these multiple studies provide strong evidence for lack of genetic boundaries in Mya arenaria. The lack of genetic structure among NWA populations of $M$. arenaria could result from high levels of gene flow, as suggested by Lasota et al. (2004), due to extensive dispersal and open population dynamics. This species has a planktonic larval phase that can last up to three weeks in the water column, during which time the larva feeds on algae and is transported by currents (Abraham and Dillon, 1986). Transport via strong currents along the NWA could promote high dispersal and gene flow among NWA populations. Genetic mixing could be further augmented by human-mediated transport within the NWA. High gene flow, however, should increase the effective population size, reducing drift and resulting in high levels of genetic diversity. This expectation is contradicted by the minimum spanning tree and the minimal genetic diversity measures. Thus, while high dispersal may contribute to genetic homogeneity in $M$. arenaria, other processes must also be acting to reduce diversity within populations.

One process that could contribute to limited genetic structure across the NWA is a recent population expansion event, also suggested by Lasota et al. (2004). The NWA was heavily impacted by ice sheets during the Pleistocene glacial period approximately 2.5 million years ago, with the southern limit of glaciation near Cape Cod, Massachusetts (Shackleton et al., 1984; Cronin, 1988). It is hypothesized that the ice sheet caused a southward shift in population ranges of NWA intertidal species. After glaciers subsided approximately 18,000 years ago, individuals from the south spread into previously unavailable northern habitats (Wares and Cunningham, 2001; Wares, 2002). These re-invasions may manifest themselves in genetic structure that suggests population expansion, i.e. limited genetic structure across areas affected by glaciation. Wares (2002) compiled a comprehensive map of genetic variability in NWA intertidal species and found substantial evidence of recolonization of ice-covered areas. Generally modern populations located north of the southern extent of the ice sheet have lower genetic diversity than those located to the south, with shifts in genetic structure located near Cape Cod.

Given the contemporary distribution of Mya arenaria and the geographic extent 
of Pleistocene glaciations, northern populations in the NWA likely represent a recent range expansion. Evidence for a demographic expansion comes from the star-like phylogeny, low genetic diversity measures, and the significantly large and negative values of Fu's $\mathrm{F}_{S}$. Further evidence of demographic expansion comes from the Bayesian skyline plot produced using NWA data (Fig. 5.4). The plot shows that M. arenaria populations in the NWA expanded between 15,000 and 75,000 years ago depending on mutation rate. Pleistocene ice sheets retreated beginning approximately 18,000 years ago, which is within this range. Although the data from Bayesian Skyline plot analyses do not produce exact estimates without stringent assumptions regarding mutation rates and molecular clocks, the data do not contradict the hypothesis of post-glacial expansion.

Given a northward range expansion following glacial retreat, one might predict decreasing genetic diversity measures with increasing latitude. Although the northernmost population in Nova Scotia had the lowest diversity measures, there was no pattern across the remainder of the NWA. This result suggests that while dispersal and gene flow may be high among most populations spanning the NWA, Nova Scotia populations may be relatively isolated.

An alternative explanation for the signal of demographic expansion is recovery following a selective sweep, where selectively advantageous haplotypes go to fixation (e.g. Berry et al., 1991). Recovery from a recent selective sweep could also yield a starlike phylogeny and lower genetic diversity that would inflate genetic similarity and gene flow estimates among populations. While a selective sweep cannot be excluded, given the signal of demographic expansion during the Pleistocene when demographic expansion would be required to achieve contemporary distributions, a selective sweep may be a less parsimonious explanation. 


\subsubsection{Patterns across the Northwest Atlantic, European wa- ters and the northeast Pacific}

While populations in the NWA had minimal genetic structure, the strongest signal of regional genetic structure comes from comparing NWA populations to NSE. Structured AMOVA results with NSE, NEP, and NWA defined as separate regions resulted in a significant $\phi_{S T}$ of 0.0903 (Table 5.3). Furthermore, of 11 pair-wise comparisons, a total of 7 pair-wise $\mathrm{F}_{S T}$ values among NSE and the NWA were significant (Table 5.2). This result indicates that despite being introduced from NWA populations, there are significant genetic differences among these regions.

Surprisingly, NEP and NSE populations also exhibited the highest levels of genetic diversity. Previous studies have found higher than expected genetic diversity in recently colonized habitats due to multiple invasions that reduced the founder effect (e.g. Stepien et al., 2002; Voisin et al., 2005; Simon-Bouhet et al., 2006). In these studies, however, the diversity observed was not higher than that of the region of origin, as was the case in our study. The unusually high levels of haplotypes and nucleotide diversity observed in the introduced North Sea population (Table 5.1) potentially suggests introductions from multiple source populations, a result that is consistent with significant $\mathrm{F}_{S T}$ values among NSE and some NWA populations but no others (Table 5.3).

Curiously, both Pacific and European populations also contained private haplotypes (Fig. 5.1). The presence of unique haplotypes found multiple times in a single population suggests genetic isolation (Hartl and Clark, 1997). Given the geographic separation of the NWA, Pacific and European waters, observation of genetic isolation should be expected. However, this result is surprising given that both NEP and NSE populations are thought to have been introduced from the NWA within the last 150 and 400 years, respectively. This seems a particularly short amount of time for local variation to both evolve in situ and increase in frequency sufficiently to be detected by sampling 15-20 individuals. In contrast, no private haplotypes were detected in sampling of 177 individuals from the entire range of $M$. arenaria in the NWA. 
As a heuristic we constructed a rarefaction curve plotting number of haplotypes versus number of samples. Although the slope shallows, it did not asymptote over the range of number of individuals sampled (Fig. 5.3) indicating that sampling 177 individuals was insufficient in the NWA to detect the rare haplotypes that founded NEP and NSE populations. Paradoxically, if they are in very low frequencies in the NWA, it seems unlikely that they would be introduced to the Pacific and European waters. One interpretation of this result is that these private haplotypes may represent ancestral polymorphism from relic populations that survived the extinction events in the Pacific and European waters. However if these were relic haplotypes, genetic divergence in excess of one mutational step would be expected, suggesting that these are indeed introductions of rare NWA haplotypes.

\subsubsection{Management Implications}

One of the current management strategies for NWA softshell clam populations is to increase local abundances by seeding flats with hatchery-reared juvenile clams. As has been demonstrated in fish, this approach has the potential to decrease or alter genetic variability by introducing non-native genotypes that may affect the fitness of both introduced and native stocks (Hansen, 2002).

The low genetic diversity and minimal genetic structure observed in COI combined with previous results showing limited genetic diversity in Mya arenaria using nuclear sequences (Caporale et al., 1997) and allozymes (Morgan et al., 1978; Lasota et al., 2004) suggests that the brood stock origins may not be critical to maintaining levels of genetic diversity and patterns of genetic structure across the NWA. Results of this study suggest that brood stocks should be quite similar regardless of their locality, and their resulting juvenile seed clams are likely interchangeable across geography.

Although we did not detect genetic structure using the mitochondrial COI gene, there may yet be other genes that might show variability within the NWA. However, given that Mya arenaria is recovering from a severe reduction in genetic diversity, the

odds of detecting neutral genetic variation that correspond to locally adaptive gene complexes is remote. Given that local adaptation has been noted in the softshell clam 
for toxin resistance (Connell et al., 2007), there may very well be important regional genetic differences among clam stocks in non-neutral genes. As such, seeding from local stocks should be preferred.

\subsection{Acknowledgements}

This work was supported by NSF grants OCE-0241855 and OCE-0215905 to L. Mullineaux and OCE- 0349177 (Biological Oceanography) to PHB. Initial stages of this work were conducted as part of course BI536 (Molecular Ecology and Evolution) at Boston University and is contribution 003 from this course. We are grateful to the many people who collected samples for this study. We also thank L. Mullineaux, E. Crandall, E. Jones, J. Drew, D. Adams, and R. Jennings for helpful advice and discussion. E. Crandall, L. Mullineaux, S. Mills, and S. Beaulieu provided useful comments on early drafts. The experiments in this study comply with the current laws of the United States of America. 


\section{References}

Abraham, B., Dillon, P., 1986. Species profiles: Life histories and environmental requirements of coastal fishes and invertebrates (mid-Atlantic): Softshell clam. USFWS Biological Report TR EL-82-4, 18pp.

Anonymous, 2007. Massachusetts commercial shellfish harvest; 1996-2000. Technical report, Massachusetts Department of Marine Fisheries, Available at www.mass.gov. Cited 8 Nov 2007.

Barber, P. H., Erdmann, M. V., Palumbi, S. R., 2006. Comparative phylogeography of three codistributed stomatopods: Origins and timing of regional lineage diversification in the coral triangle. Evolution 60 (9), 1825-1839.

Berry, A. J., Ajioka, J. W., Kreitman, M., 1991. Lack of polymorphism on the Drosophila fourth chromosome resulting from selection. Genetics 129 (4), 11111117.

Billerbeck, J., Orti, G., Conover, D. O., 1997. Latitudinal variation in vertebral number has a genetic basis in the Atlantic silverside, Menidia menidia. Canadian Journal of Fisheries and Aquatic Sciences 54 (8), 1796-1801.

Brousseau, D. J., 1978. Spawning cycle, fecundity, and recruitment in a population of soft-shell clam, Mya arenaria, from Cape Ann, Massachusetts. Fisheries Bulletin 76 (1), 155-166.

Brousseau, D. J., 2005. Effects of natural mortality and harvesting on inshore bivalve population trends. In: Buchsbaum, R., Pederson, J., Robinson, W. (Eds.), The decline of fisheries resources in New England: Evaluating the impact of overfishing, contamination, and habitat degradation. MIT Sea Grant 05-5, Cambridge, MA, pp. $97-118$.

Brown, A. F., Kann, L. M., Rand, D. M., 2001. Gene flow versus local adaptation in the northern acorn barnacle, Semibalanus balanoides: Insights from mitochondrial DNA variation. Evolution 55 (10), 1972-1979. 
Caporale, D. A., Beal, B. F., Roxby, R., VanBeneden, R. J., 1997. Population structure of Mya arenaria along the New England coastline. Molecular Marine Biology and Biotechnology 6 (1), 33-39.

Carlton, J., 1979. History, biogeography and ecology of the introduced marine and estuarine invertebrates of the Pacific coast of North America. PhD thesis, University of California Davis.

Connell, L. B., MacQuarrie, S. P., Twarog, B. M., Iszard, M., Bricelj, V. M., 2007. Population differences in nerve resistance to paralytic shellfish toxins in softshell clam, Mya arenaria, associated with sodium channel mutations. Marine Biology 150 (6), 1227-1236.

Cronin, T. M., 1988. Evolution of marine climates of the U.S. Atlantic coast during the past four million years. Philosophical Transactions of the Royal Society of London. Series B, Biological Sciences 318 (1191), 661-678.

Dahlgren, T., Weinberg, J., Halanych, K., 2000. Phylogeography of the ocean quahog (Arctica islandica): Influences of paleoclimate on genetic diversity and species range. Marine Biology 137, 487-495.

Drummond, A. J., Nicholls, G. K., Rodrigo, A. G., Solomon, W., 2002. Estimating mutation parameters, population history and genealogy simultaneously from temporally spaced sequence data. Genetics 161 (3), 1307-1320.

Drummond, A. J., Rambaut, A., 2006. BEAST v.1.4. Available from http://beast.bio.ed.ac.uk/.

Drummond, A. J., Rambaut, A., Shapiro, B., Pybus, O. G., 2005. Bayesian coalescent inference of past population dynamics from molecular sequences. Molecular Biology and Evolution 22 (5), 1185-1192.

Engle, V. D., Summers, J. K., 1999. Latitudinal gradients in benthic community composition in western Atlantic estuaries. Journal of Biogeography 26 (5), 10071023. 
Excoffier, L., Laval, G., Schneider, S., 2005. Arlequin ver. 3.0: An integrated software package for population genetics data analysis. Evolutionary Bioinformatics Online $1,47-50$.

Folmer, O., Black, M., Hoeh, W., Lutz, R., Vrijenhoek, R., 1994. DNA primers for amplification of mitochondrial cytochrome c oxidase subunit 1 from diverse metazoan invertebrates. Molecular Marine Biology and Biotechnology 3, 294-299.

Fu, Y. X., 1997. Statistical tests of neutrality of mutations against population growth, hitchhiking and background selection. Genetics 147 (2), 915-925.

Gardner, J., Kathiravetpillai, G., 1997. Biochemical genetic variation at a leucine aminopeptidase (LAP) locus in blue (Mytilus galloprovincialis) and greenshell (Perna canaliculus) mussel populations along a salinity gradient. Marine Biology 128, 619-625.

Gardner, J., Palmer, N., 1998. Size-dependent, spatial and temporal genetic variation at a leucine aminopeptidase (LAP) locus among blue mussel (Mytilus galloprovincialis) populations along a salinity gradient. Marine Biology 132, 275-281.

Hall, Clarence A., J., 1964. Shallow-water marine climates and molluscan provinces. Ecology 45 (2), 226-234.

Hansen, M. M., 2002. Estimating the long-term effects of stocking domesticated trout into wild brown trout (Salmo trutta) populations: An approach using microsatellite DNA analysis of historical and contemporary samples. Molecular Ecology 11 (6), $1003-1015$.

Hartl, D., Clark, A., 1997. Principles of Population Genetics. Sinauer, Sunderland MA, Ch. Population Substructure, pp. 111-162.

Heck, Kenneth L., J., van Belle, G., Simberloff, D., 1975. Explicit calculation of the rarefaction diversity measurement and the determination of sufficient sample size. Ecology 56 (6), 1459-1461. 
Hewitt, G. M., 1996. Some genetic consequences of ice ages, and their role in divergence and speciation. Biological Journal of the Linnean Society 58 (3), 247-276.

Hidu, H., Newell, C., 1989. Culture and ecology of the soft-shelled clam Mya arenaria. In: Manzi, J., Castagna, M. (Eds.), Clam mariculture in North America. Elsevier, Amsterdam, pp. 277-292.

Hutchins, L. W., 1947. The bases for temperature zonation in geographical distribution. Ecological Monographs 17 (3), 325-335.

King, T. L., Eackles, M. S., Gjetvaj, B., Hoeh, W. R., 1999. Intraspecific phylogeography of Lasmigona subviridis (Bivalvia: Unionidae): Conservation implications of range discontinuity. Molecular Ecology 8 (s1), S65-S78.

Lasota, R., Hummel, H., Wolowicz, M., 2004. Genetic diversity of European populations of the invasive soft-shell clam Mya arenaria (Bivalvia). Journal of the Marine Biological Association of the United Kingdom 84, 1051-1056.

MacNeal, F., 1965. Evolution and distribution of the genus Mya, and tertiary migrations of mollusca. Professional Papers of the USGS 483-G, 1-51.

Maddison, D., Maddison, W., 2002. MacClade 4: Analysis of phylogeny and character evolution. Sinauer Associates.

Marcotti, T., Leavitt, D., 1997. The barnstable harbor shellfish recruitment enhancement project (BHSREP): A final report. Technical Report T-97-001, Woods Hole Oceanographic Institution.

Marko, P. B., 2002. Fossil calibration of molecular clocks and the divergence times of geminate species pairs separated by the Isthmus of Panama. Molecular Biology and Evolution 19 (11), 2005-2021.

May, G. E., Gelembiuk, G. W., Panov, V. E., Orlova, M. I., Lee, C. E., 2006. Molecular ecology of zebra mussel invasions. Molecular Ecology 15 (4), 1021-1031. 
Morgan, R., Block, S., Ulanowicz, N., Buys, C., 1978. Genetic variation in the softshelled clam, Mya arenaria. Estuaries 1 (4), 255-258.

Newell, C., Hidu, H., 1982. The effects of sediment type on growth rate and shell allometry in the soft shelled clam, Mya arenaria L. Journal of Experimental Marine Biology and Ecology 65, 285-295.

Petersen, K., Rasmussen, K., Heinemeler, J., Rud, N., 1992. Clams before Columbus? Nature 359, 679.

Posada, D., Crandall, K., 1998. Modeltest: Testing the model of DNA substitution. Bioinformatics 14 (9), 817-818.

Powers, S., Bishop, M., Grabowski, J., Peterson, C. H., 2006. Distribution of the invasive bivalve Mya arenaria L. on intertidal flats of south central Alaska. Journal of Sea Research 55, 207-216.

Present, T. M. C., Conover, D. O., 1992. Physiological basis of latitudinal growth differences in Menidia menidia: Variation in consumption or efficiency? Functional Ecology 6 (1), 23-31.

Ray, N., Currat, M., Excoffier, L., 2003. Intra-deme molecular diversity in spatially expanding populations. Molecular Biology and Evolution 20 (1), 76-86.

Rogers, A. R., Harpending, H., 1992. Population growth makes waves in the distribution of pairwise genetic differences. Molecular Biology and Evolution 9 (3), $552-569$.

Shackleton, N., Backman, J., Zimmerman, H., Kent, D., Hall, M., Roberts, D., Schnitker, D., Baldauf, J., Desprairies, A., Homrighausen, R., Huddlestun, P., Keene, J., Kaltenback, A., Krumsiek, K., Morton, A., Murray, J., Westberg-Smith, J., 1984. Oxygen isotope calibration of the onset of ice-rafting and history of glaciation in the North Atlantic region. Nature 307 (16), 620-623. 
Simon-Bouhet, B., Garcia-Meunier, P., Viard, F., 2006. Multiple introductions promote range expansion of the mollusc Cyclope neritea (Nassariidae) in France: Evidence from mitochondrial sequence data. Molecular Ecology 15 (6), 1699-1711.

Slatkin, M., 1985. Rare alleles as indicators of gene flow. Evolution 39 (1), 53-65.

Smith, M., Chapman, R., Powers, D., 1998. Mitochondrial DNA analysis of Atlantic coast, Chesapeake Bay, and Delaware Bay populations of the teleost Fundulus heteroclitus indicates temporally unstable distributions over geologic time. Molecular Marine Biology and Biotechnology 7, 79-87.

Stepien, C. A., Taylor, C. D., Dabrowska, K. A., 2002. Genetic variability and phylogeographical patterns of a nonindigenous species invasion: A comparison of exotic vs. native zebra and quagga mussel populations. Journal of Evolutionary Biology $15(2), 314-328$.

Strasser, M., 1999. Mya arenaria- an ancient invader of the North Sea coast. Helgolaender Meeresuntersuchungen 52, 309-324.

Swofford, D., 1998. Phylogenetic analysis using parsimony and other methods (PAUP*). Available from paup.csit.fsu.edu.

Upham, W., 1879a. The formation of Cape Cod. The American Naturalist 13 (8), $489-502$.

Upham, W., 1879b. The formation of Cape Cod (continued). The American Naturalist $13(9), 552-565$.

Voisin, M., Engel, C. R., Viard, F., 2005. Differential shuffling of native genetic diversity across introduced regions in a brown alga: Aquaculture vs. maritime traffic effects. PNAS 102 (15), 5432-5437.

Waldman, J. R., Nolan, K., Hart, J., Wirgin, I. I., 1996. Genetic differentiation of three key anadromous fish populations of the Hudson River. Estuaries 19 (4), 759768. 
Walsh, P., Metzger, D., Higuchi, R., 1991. Chelex-100 as a medium for simple extraction of DNA for PCR based typing from forensic material. Biotechniques 10, $506-513$.

Waples, R., Do, C., 1994. Genetic risk associated with supplementation of Pacific salmonids: Captive broodstock programs. Canadian Journal of Fisheries and Aquatic Sciences 51 (s1), 310-329.

Wares, J. P., 2002. Community genetics in the Northwestern Atlantic intertidal. Molecular Ecology 11 (7), 1131-1144.

Wares, J. P., Cunningham, C. W., 2001. Phylogeography and historical ecology of the North Atlantic intertidal. Evolution 55 (12), 2455-2469.

Yamahira, K., Lankford Jr., T. E., Conover, D. O., 2006. Intra- and interspecific latitudinal variation in vertebral number of Menidia spp. (Teleostei: Atherinopsidae). Copeia 2006 (3), 431-436. 


\section{Chapter 6}

\section{Sensitivity analyses of a metapopulation model}

\subsection{Introduction}

The dynamics of most populations are governed by interactions between demographic processes, spatial processes (e.g. dispersal), and stochastic environmental variability (e.g. disturbance). Each of these processes is sufficiently complex that ecologists have tended, depending on their objectives, to focus on one at at time. For instance, conservation ecologists tend to concentrate on demographic structure (e.g. Mertz, 1971; Crouse et al., 1987; Pascual and Adkison, 1994) since population growth or decline is of primary concern, and is ultimately determined by demographic parameters. Managers of harvested populations, such as fish or deer, also tend to focus on demography and devise management strategies that are based on parameters such as such as sex, size, or age (e.g. Brenden et al., 2007; Collier and Krementz, 2007). In recent years, interest in implementing marine protected areas has shifted some attention towards spatial structure (Roughgarden and Iwasa, 1986; Thorrold et al., 2001; Fagan and Lutscher, 2006). Similarly, growing interest in metapopulation theory (Hanski, 1999) has increased the number of studies that focus on spatial processes (Kritzer and Sale, 2006).

Ideally, demographic and spatial structure, as well as environmental variability, 
would be taken into account when deciding how best to manage real populations. In addition, since management efforts are inevitably limited by resources (i.e. time, manpower, money etc.), it is necessary to have a quantitative way of choosing the patches and/or stages on which to focus. One way to select patches is according to their ability to contribute to metapopulation growth rate. Of the many different indices used for population assessment, growth rate is the most important because of the power of exponential growth (Caswell, 2001, Chap. 18).

In addition to demography and dispersal, we are interested in how patch dynamics are influenced by the presence of environmental variability; we therefore added stochastic disturbance to our model. We are specifically interested in how elasticities to individual patch demographic parameters change with relation to one another. We explore the case where, in the absence of disturbance, one patch has a positive growth rate (the "good" patch) and the other has a negative growth rate (the "bad" patch). We use the "elasticity ratio" throughout this manuscript to quantitatively assess the relative elasticities of growth rates in the good and bad patches to their respective parameters. We define this ratio as the elasticity of growth rate to parameters in the good patch, divided by the elasticity to those same parameters in the bad patch.

The elasticity ratio $(E)$ has the potential to be useful when deciding on the best strategy to increase metapopulation growth rate. Assuming all things are equal in the good and bad patch (other than the parameters responsible for causing one to be good and the other bad), using the elasticity ratio is straightforward. In this simplest case, if $E>1$, efforts should focus on the good patch, and if $E<1$, efforts should focus on the bad patch. Rarely in natural metapopulations, however, are all things equal among patches. For instance, it may be more costly to enact changes in one patch versus another, and the difference in cost should be accounted for in analyses. If acting in patch 1 is 10 times more expensive than in patch 2, then $E$ need not be less than 1 but only less than 0.10 to suggest efforts focus on the bad patch. Although we examine here only on the simplest case where the deciding quantity for $E$ is 1 , it is important to remember that the decision-making process must take into account the relative effect of managing each patch, including cost, feasibility, legality, etc.. 
In this manuscript, we combine demographic and spatial structure in a matrix metapopulation model. We are not the first to explore this combination, however. One example is using a "megamatrix" approach (Pascarella and Horvitz, 1998; Tuljapurkar et al., 2003; Petr, 2007), introduced by Horvitz and Schemske (1986). In this method, both the spatial and demographic dynamic processes are included in the projection matrix. More recently Hunter and Caswell (2005) showed how to combine demographic and spatial structuring in a way that simplifies calculations, particularly calculations involving the sensitivity of growth rate to lower-level parameters. Their approach uses the vec-permutation matrix to rearrange demographic matrices arranged by patch and dispersal matrices arranged by stage, thereby allowing both types of structure within the same model.

Here, we build on the work of Hunter and Caswell (2005), expanding the technique to stochastic models and calculating the elasticities of metapopulation growth rate to individual parameters in the demographic and dispersal matrices (Caswell, 2005, 2007). Our construction facilitates the efficient calculation of sensitivity of metapopulation growth rate to demographic, dispersal, and other parameters. The formulae maintain these processes as distinct matrices, which allows for more intuitive exploration of the dynamics of each process.

We begin by examining a two-patch metapopulation with no disturbance or stage structure using a deterministic model. We then determine the effects of stochastic disturbance on the population by adding a variable environment to the model and re-evaluating our results. We explore the elasticity of metapopulation growth rate to migration parameters specifically since migration dictates the demographic connectivity of metapopulation patches (Stacey et al., 1997) and is especially critical for long-term metapopulation success when patches are subjected to stochastic environmental variability (Howe and Davis, 1991; Bascompte et al., 2002; Hill et al., 2002). Finally, we include stage structure to more closely resemble a natural population and compare the outcomes to previous simpler versions of the model. Throughout this study, we use "patch 1" to refer to the good patch and "patch 2" to refer to the bad patch. 


\subsection{One Stage, No Disturbance}

Imagine a metapopulation consisting of two patches. Let $n_{i}(t)$ be the population density in patch $i$ at time $t$, referred to hereafter as population $i$. Two processes acting sequentially will account for changes in $n_{i}(t)$. First, individuals survive and reproduce with a net per capita rate $R_{i}$ in patch $i$. Next, a proportion $m_{i}$ of individuals from patch $i$ emigrate to patch $j$. Combining these two processes, we can write the following matrix model to project the population from time $t$ to $t+1$ :

$$
\mathbf{n}(t+1)=\mathbf{A n}(t)
$$

where $\mathbf{n}(t)=\left[n_{1}(t), n_{2}(t)\right]^{\top}$ and

$$
\mathbf{A}=\left(\begin{array}{cc}
R_{1}\left(1-m_{1}\right) & R_{2} m_{2} \\
R_{1} m_{1} & R_{2}\left(1-m_{2}\right)
\end{array}\right)
$$

In our model, we set $R_{1}>1$ and $R_{2}<1$. Thus in the absence of migration, population 1 is increasing in size and population 2 is decreasing in size. In this simple model, the metapopulation growth rate $\lambda$ is the dominant eigenvalue of $\mathbf{A}$, and the stable patch distribution $\mathbf{w}$ is the right eigenvector corresponding to $\lambda$.

We used sensitivity analysis to determine the relative effects of changes to $R_{1}$ and $R_{2}$ on $\lambda$. The sensitivities of $\lambda$ to the elements of $\mathbf{A}$ are given by the sensitivity matrix with entries

$$
s_{i j}=\frac{\partial \lambda}{\partial a_{i j}}
$$

This matrix is

$$
\mathbf{S}=\frac{\mathbf{v w}^{\top}}{\mathbf{v}^{*} \mathbf{w}}
$$

where $\mathbf{v}$ is the left eigenvector corresponding to $\lambda$ (Caswell, 2001). The entries of $\mathbf{S}$ are the sensitivity of $\lambda$ to the corresponding entry in $\mathbf{A}$, and therefore depend on a combination of the parameters that make up that entry. A more interesting analysis is the sensitivity of $\lambda$ to the lower level parameters that compose A. From Caswell 

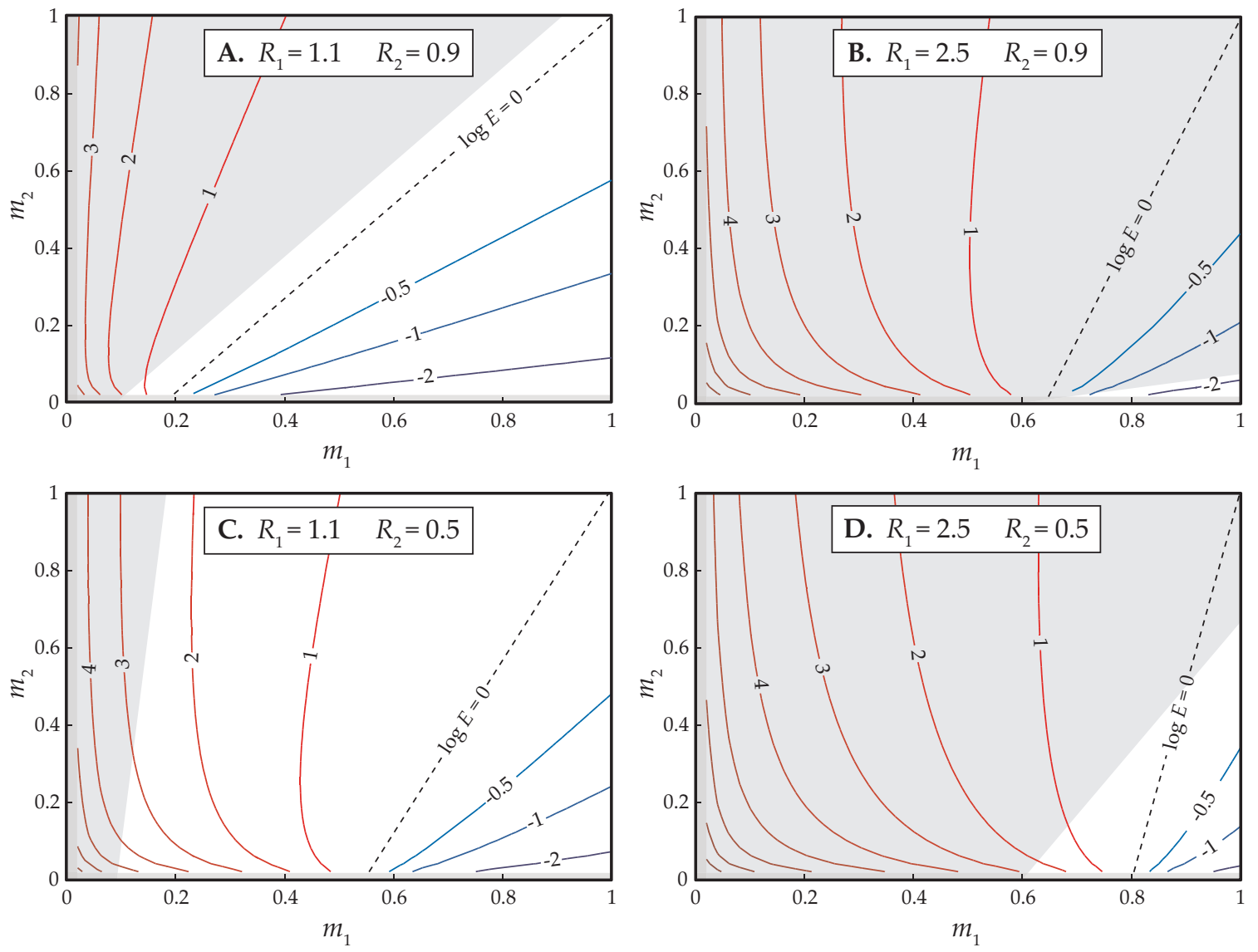

Figure 6.1: Contour plots of $\log E$; red contours are where $E>1$ and blue contours are where $E<1$. Shaded regions are where $\lambda>1$.

(2001, Chap. 9), we calculate the proportional sensitivity, or elasticity, of $\lambda$ to the lower level parameter $R_{i}$ as

$$
\frac{R_{i}}{\lambda} \frac{\partial \lambda}{\partial R_{i}}=\frac{R_{i}}{\lambda} \sum_{i j} \frac{\partial \lambda}{\partial a_{i j}} \frac{\partial a_{i j}}{\partial R_{i}} .
$$

We then define the elasticity ratio of $\lambda$ to $R_{i}$ as

$$
E=\frac{R_{1}}{R_{2}} \cdot \frac{\partial \lambda / \partial R_{1}}{\partial \lambda / \partial R_{2}}
$$

If $E>1$, then $\lambda$ is more elastic to changes in $R_{1}$. If $E<1$, then $\lambda$ is more elastic to changes in $R_{2}$. The value of $E$ can be used to choose patches on which to focus efforts when the goal is to increase metapopulation growth rate efficiently. 
Figure 6.1 shows $\log E$ for different combinations of net reproductive rates, with $m_{1}$ and $m_{2}$ ranging from zero to one. When migration out of the good patch was low, $\log E$ tended to be less than 0. (Fig. 6.1). That is, if individuals in the good patch tend to stay in that patch, then regardless of the fraction of individuals who migrate out of the bad patch $\left(m_{2}\right)$, metapopulation growth rate is more sensitive to changes in $R_{1}$ than $R_{2}$. As migration out of the good patch $m_{1}$ increases, the proportion of individuals located in the bad patch also increases and $E$ becomes less than 1 .

Using equations (6.4)-(6.6), we can write an expression for $E$ in terms of the model parameters $R_{i}$ and $m_{i}$ and entries of the right and left eigenvectors $\mathbf{v}$ and $\mathbf{w}$ :

$$
E=\frac{R_{1} w_{1}\left[v_{1}\left(1-m_{1}\right)+v_{2} m_{1}\right]}{R_{2} w_{2}\left[v_{2}\left(1-m_{2}\right)+v_{1} m_{2}\right]}
$$

The equation for the line where $E=1$ (the dashed line in Fig. 6.1) is

$$
m_{2}=1+\frac{R_{1}}{R_{2}}\left(m_{1}-1\right)
$$

To the left of this line (as $m_{1}$ decreases), $E>1$ and increasing $R_{1}$ results in the largest proportional increase in $\lambda$. To the right of this line (as $m_{1}$ increases), $E<1$ and increasing $R_{2}$ results in the largest proportional increase in $\lambda$.

The values for $\lambda$ are also of importance for patch prioritization, as the transition from $\lambda<1$ to $\lambda>1$ indicates where the metapopulation switches from declining to growing. As one might expect, increasing net reproductive rate in either patch increases the area of parameter space where $\lambda>1$ (shaded areas in Fig. 6.1).

An unexpected result is that there are instances when $E<1$ and $\lambda>1$ (Fig. 6.1B, 6.1D). That is, there are times when the metapopulation growth rate is positive and is more sensitive to net reproductive rate in the bad patch. In these instances, migration rates are such that the majority of the metapopulation is found in the bad patch. This can be seen if one imagines a 1:1 line in any of the plots of Fig. 6.1; this line is where $m_{1}=m_{2}$. Below the line there are more individuals in patch 2 , and above this line, there are more individuals in patch 1 . Cases where $E<1$ and $\lambda>1$ are always below, suggesting that a necessary condition for this result is that the majority 


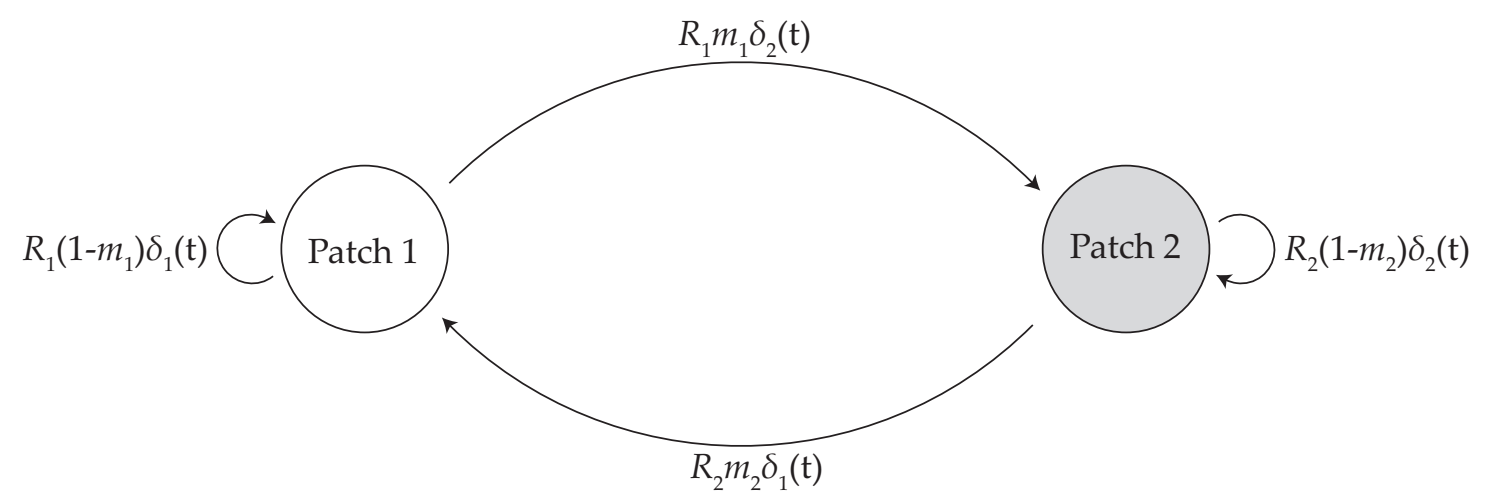

Figure 6.2: Life cycle graph for one-stage, two-patch model with stochastic disturbance.

of the metapopulation is found in the bad patch. One might assume that if the majority of individuals are in the bad patch then growth rate of the metapopulation would be negative; however, this is clearly not the case. This result indicates that increasing $R_{2}$ has a larger effect because it impacts more individuals than increasing $R_{1}$. It also suggests that not only should individual patch growth rates be considered when determining a patch's "goodness" or "badness", but also the distribution of individuals among patches within the metapopulation.

\subsection{One Stage, With Disturbance}

Metapopulations in nature are subject to stochastic environmental variability. We would therefore like to add stochastic disturbance to our model and reassess the elasticity ratio. One typical way that disturbance affects a metapopulation is by reducing its size. Here we model disturbance as a random event with probability $p$ that acts by reducing population size in patch $i$ by a proportion $\delta_{i}(t)$ (Fig. 6.2).

To construct $\boldsymbol{\delta}(t)=\left[\delta_{1}(t), \delta_{2}(t)\right]^{\top}$, we first let $x_{i}(t)$ be an indicator variable for the event that population $i$ is disturbed, such that

$$
x_{i}(t)= \begin{cases}1 & \text { if population } i \text { is disturbed } \\ 0 & \text { otherwise }\end{cases}
$$


We then collect these events into the random vector $\mathbf{x}(t)$, and set

$$
\boldsymbol{\delta}(t)=1-D \mathbf{x}(t), \quad D \in[0,1]
$$

Thus $D$ is a measure of disturbance intensity; given that patch $i$ is disturbed, then $x_{i}(t)=1$ and the population in that patch is reduced by the proportion $D . \delta(t)$ is therefore the number that survive the disturbance, equal to $1-D$. Large values of $D$ result in high disturbance intensity.

We next assume that $\mathbf{x}(t)$ is drawn from a bivariate Bernoulli distribution (Marshall and Olkin, 1985). We set the expectation

$$
\mathrm{E}[\mathbf{x}(t)]=\left(\begin{array}{c}
p \\
p
\end{array}\right)
$$

so that the patches are disturbed with equal probability at each time. One can imagine that the occurrence of disturbance at two patches may be independent, or it may be positively or negatively correlated. If, for instance, the disturbance event is a large weather event such as a hurricane, it might affect all of the patches in a metapopulation and therefore covariance of patch disturbances $(c)$ would be positive. With $c=\operatorname{cov}\left(x_{1}, x_{2}\right)$, the variance-covariance matrix for $\mathbf{x}(t)$ is the constant matrix

$$
\operatorname{var}[\mathbf{x}(t)]=\left(\begin{array}{cc}
p(1-p) & c \\
c & p(1-p)
\end{array}\right)
$$

One can show (Appendix) that $p$ and $c$ must satisfy the inequalities

$$
\begin{aligned}
& c \leq p(1-p), \\
& c \geq-p^{2}, \\
& c \geq-(1-p)^{2},
\end{aligned}
$$

and that the sum of probabilities of all possible disturbance events equals 1 . Inequalities (6.13)-(6.15) define a two-dimensional parameter space of all allowable combina- 


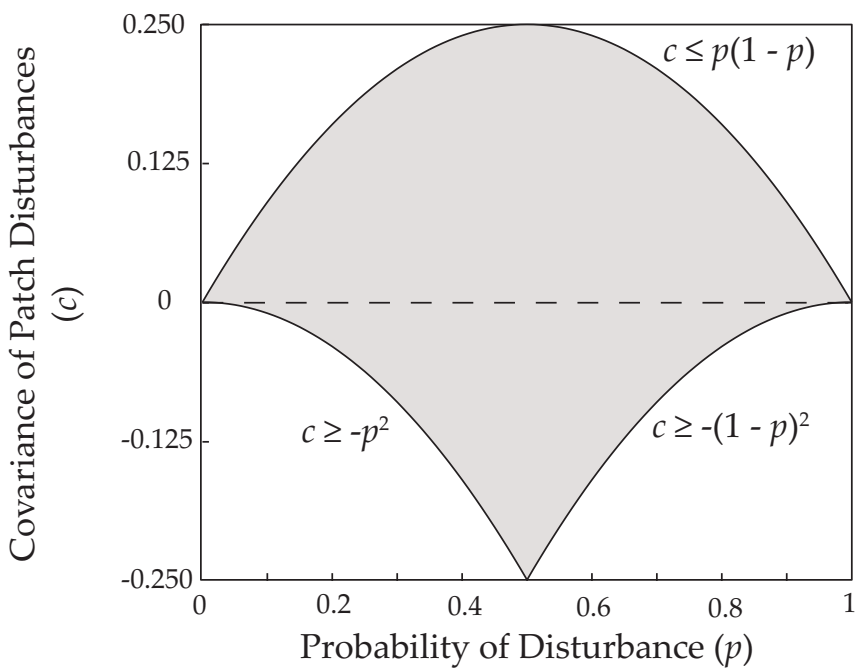

Figure 6.3: Allowable combinations (shaded), as defined by inequalities (6.13)-(6.15), of the probability of disturbance $(p)$ and the covariance of disturbance events $(c)$ at the two patches in model (6.9)-(6.16).

tions of $p$ and $c$ (Fig. 6.3).

Including disturbance, the deterministic projection matrix (6.2) becomes the stochastic matrix

$$
\mathbf{A}_{t}=\left(\begin{array}{cc}
R_{1}\left(1-m_{1}\right) \delta_{1}(t) & R_{2} m_{2} \delta_{1}(t) \\
R_{1} m_{1} \delta_{2}(t) & R_{2}\left(1-m_{2}\right) \delta_{2}(t)
\end{array}\right)
$$

The stochastic growth rate

$$
\log \lambda_{s}=\lim _{T \rightarrow \infty} \frac{1}{T} \log \left\|\mathbf{A}_{T-1} \cdots \mathbf{A}_{0} \mathbf{n}_{0}\right\|
$$

is (except under bizarre circumstances) the long-term average growth rate of every realization of the model with probability 1 (Furstenberg and Kesten, 1960; Cohen, 1976; Tuljapurkar and Orzack, 1980; Caswell, 2001). The elasticity of the stochastic growth rate to the net reproductive rate in patch $i$ is

$$
\frac{\partial \log \lambda_{s}}{\partial \log R_{i}}=\lim _{T \rightarrow \infty} \frac{1}{T} \sum_{t=0}^{T-1} \frac{R_{i} \mathbf{v}^{\top}(t+1) \frac{\partial \mathbf{A}_{t}}{\partial R_{i}} \mathbf{w}(t)}{r(t) \mathbf{v}^{\top}(t+1) \mathbf{w}(t+1)}
$$

(Caswell, 2005, pg. 80). Here $\mathbf{v}(t)$ and $\mathbf{w}(t)$ are the stochastic analogs to the left 
and right eigenvectors of the deterministic projection matrix, and $r(t)$ is the one-step growth rate

$$
r(t)=\frac{\left\|\mathbf{A}_{t} \mathbf{w}(t)\right\|}{\|\mathbf{w}(t)\|}
$$

Equation (6.18) gives the proportional change in $\log \lambda_{s}$ with net reproductive rate over many stochastic simulations. Bigger values for (6.18) indicate bigger changes in $\log \lambda_{s}$ with a proportional change in $R_{i}$. We define the stochastic elasticity ratio of $\log \lambda_{s}$ to the $R_{i}$ as

$$
E_{s}=\frac{\partial \log \lambda_{s} / \partial \log R_{1}}{\partial \log \lambda_{s} / \partial \log R_{2}}
$$

As in the deterministic case, if $E_{s}>1$ then $\log \lambda_{s}$ is more elastic to changes in $R_{1}$. Conversely, if $E_{s}<1$, then $\log \lambda_{s}$ is more elastic to changes in $R_{2}$.

We calculated $\log \lambda_{s}$ and the elasticity ratio (6.20) for $R_{1}=2.5, R_{2}=0.9, D=0.9$, and for four migration scenarios in which migration is high or low from the patches and either equal or not:

$$
\left(m_{1}, m_{2}\right) \in\left\{\begin{array}{c}
(0.1,0.1) \\
(0.1,0.9) \\
(0.9,0.1) \\
(0.9,0.9)
\end{array} .\right.
$$

As in the deterministic case, the elasticity ratio is correlated to the distribution of individuals among patches in the metapopulation. Determining where the majority of individuals are located is not as straightforward in the stochastic case. Rather than determine this based on migration rates, we must instead calculate the long-term average patch distribution.

In (6.4A), there are, on average, more individuals in patch 1 than in patch 2 since few individuals leave patch $1 m_{1}=0.1$ and most individuals from patch 2 migrate to patch $1 m_{2}=0.9$. As expected, elasticity ratio is greater than 1 and changes to the good patch will result in proportionally greater increases in metapopulation growth rate. In the case where migration rates are equal (6.4B-C), individuals are, on average, distributed equally between the two patches. Again, the elasticity ratio is greater than 1 . 

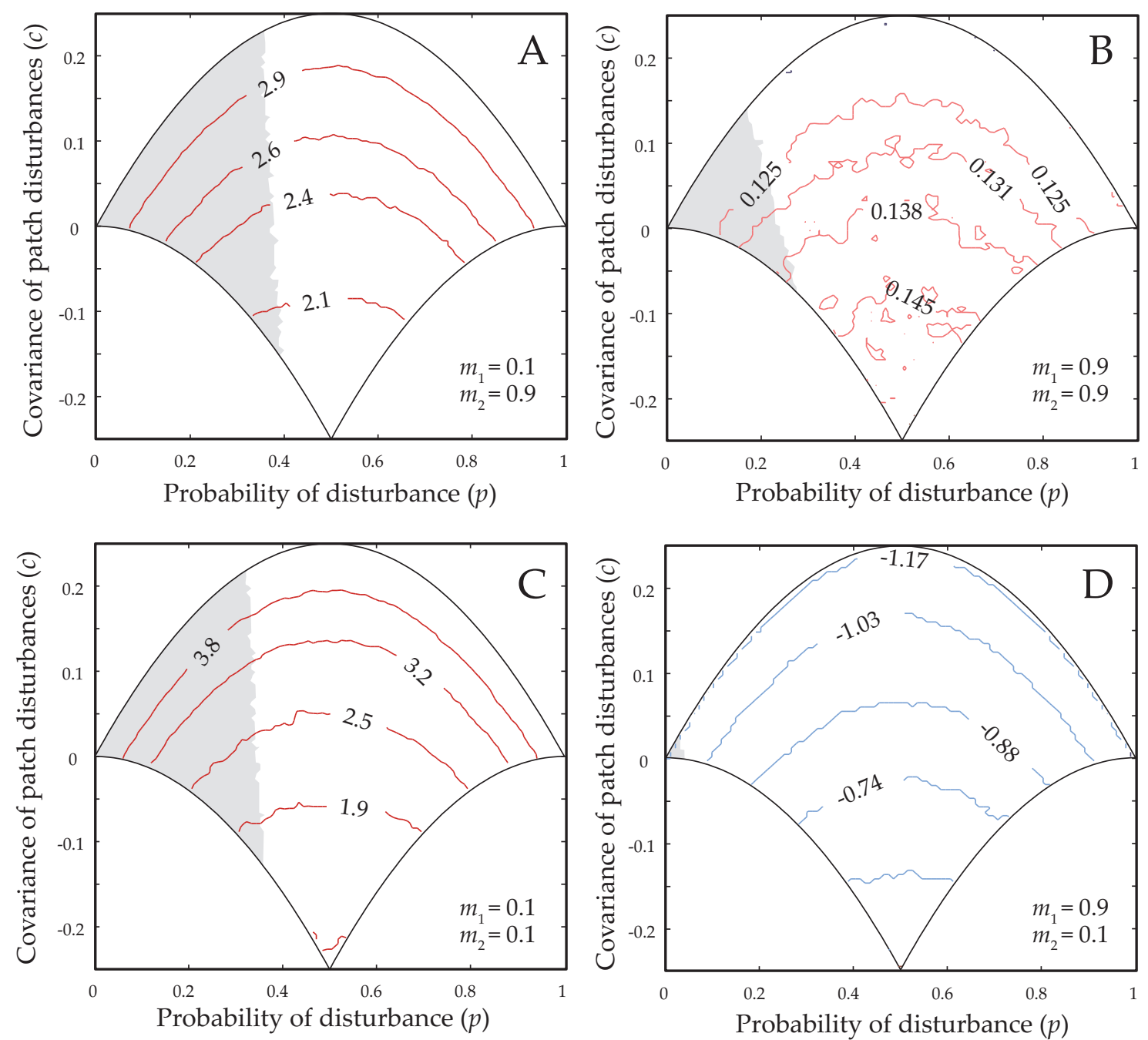

Figure 6.4: Contour plots of $\log E_{s}$ over the range of possible values for disturbance parameters $p$ and $c$, for four combinations of $m_{1}$ and $m_{2}$. Shaded regions indicate where $\log \lambda_{s}>0$. Blue contours are where $E_{s}<1$; red contours are where $E_{s}>1$. For all panels, $R_{1}=2.5, R_{2}=0.9$, and $D=0.9$. Here, contours are $\log E_{s}$ to show the details of the response of $\log \lambda_{s}$ at small values and for comparing results to the no disturbance case (Fig. 6.1). 
The result changes if emigration from patch 1 is high and emigration from patch 2 is low (Fig. 6.4D). Migration rates in this case result in more individuals, on average, in patch 2. This is because migration out of patch 1 is high $\left(m_{1}=0.9\right.$ and most individuals from patch 2 do not migrate $\left(m_{2}=0.1\right)$. Consequently $E_{s}<1$ for all combinations of disturbance parameters $p$ and $c$. These results parallel those of the deterministic model: $E_{s}<1$ only if there are more individuals on average in population 2 than in population 1 . Changes to parameters in patch 2 will affect more individuals of the metapopulation, resulting in proportionally greater increase in metapopulation growth rate.

For the reproductive rate and disturbance intensity used for Fig. 6.4, the stochastic metapopulation growth rate is positive only when the probability of disturbance is low (shaded areas, Fig. 6.4). In addition, the probability of disturbance appears to have a greater effect on population growth rate than the covariance of patch disturbance. The set of disturbance parameters $p$ and $c$ for which $\log \lambda_{s}>0$ is largest when on average population 1 is larger than population 2. The set shrinks as individuals become more evenly distributed between the two patches. When population 2 is larger, as in Fig. $6.4 \mathrm{D}, \log \lambda_{s}>0$ only for the smallest values of the disturbance probability $p$.

Although there is only a small amount of variability in $E_{s}$ within a given panel, $E_{s}$ varies dramatically among the four panels (note the log scale). Migration rates appear to affect $E_{s}$ to a much greater extent than disturbance parameters. $E_{s}<1$ only when emigration was high from patch 1 and low from patch 2 (Fig. 6.4D), and in that migration scenario $\log \lambda_{s}<0$ for most combinations of $p$ and $c$. There is a small set of disturbance parameter values $(p<0.05, c \approx 0)$ where both $\log \lambda_{s}>0$ and $E_{s}<1$; this occurs at the lowest values of $p$, when disturbance is so improbable that results from the stochastic model are comparable to those of the deterministic model (Fig. 6.1B).

To further understand the effects of migration on metapopulation dynamics, we calculated the elasticity of $\log \lambda_{s}$ to both $m_{1}$ and $m_{2}$ under the same four migration scenarios explored in Fig. 6.4 (Fig. 6.5). We did not calculate elasticity ratios since 
Elasticity of $\log \lambda_{s}$ to $m_{1}$
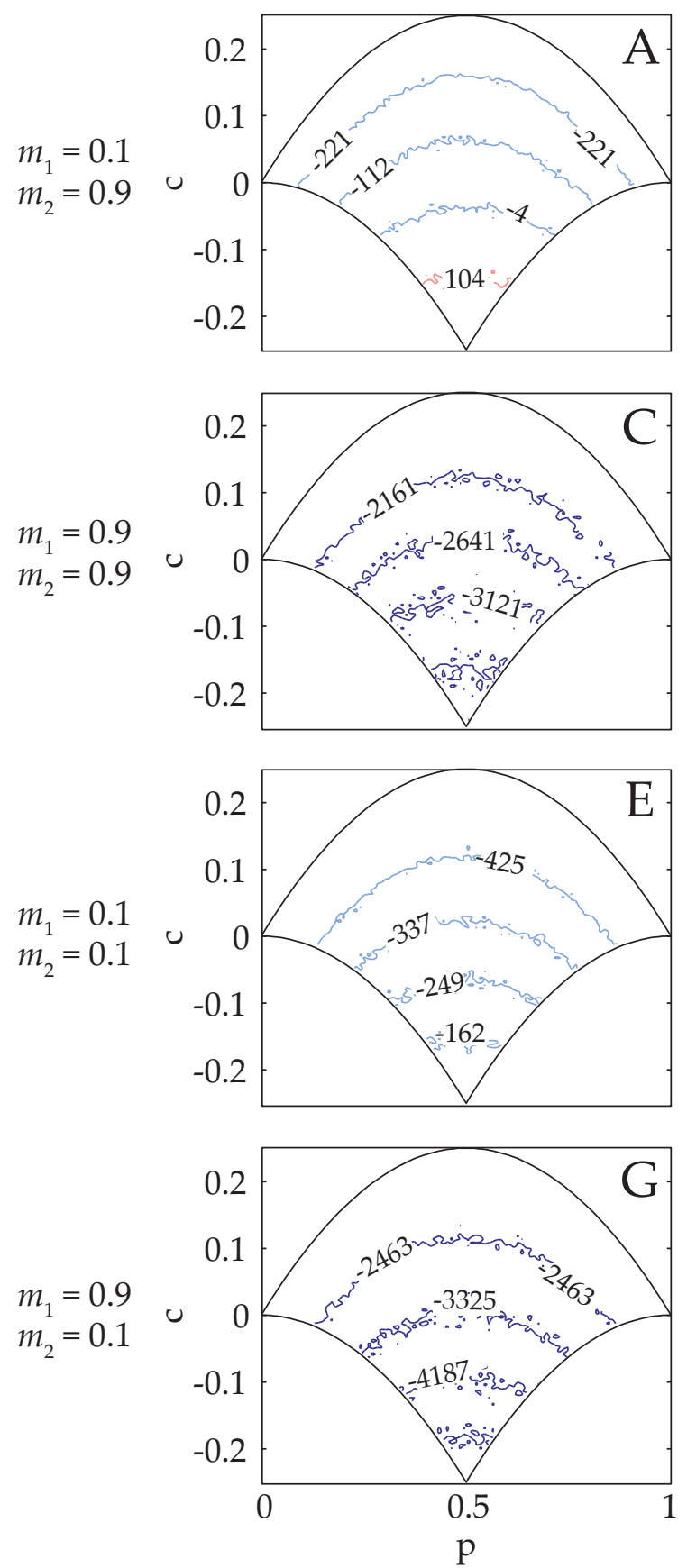

Elasticity of $\log \lambda_{s}$ to $m_{2}$
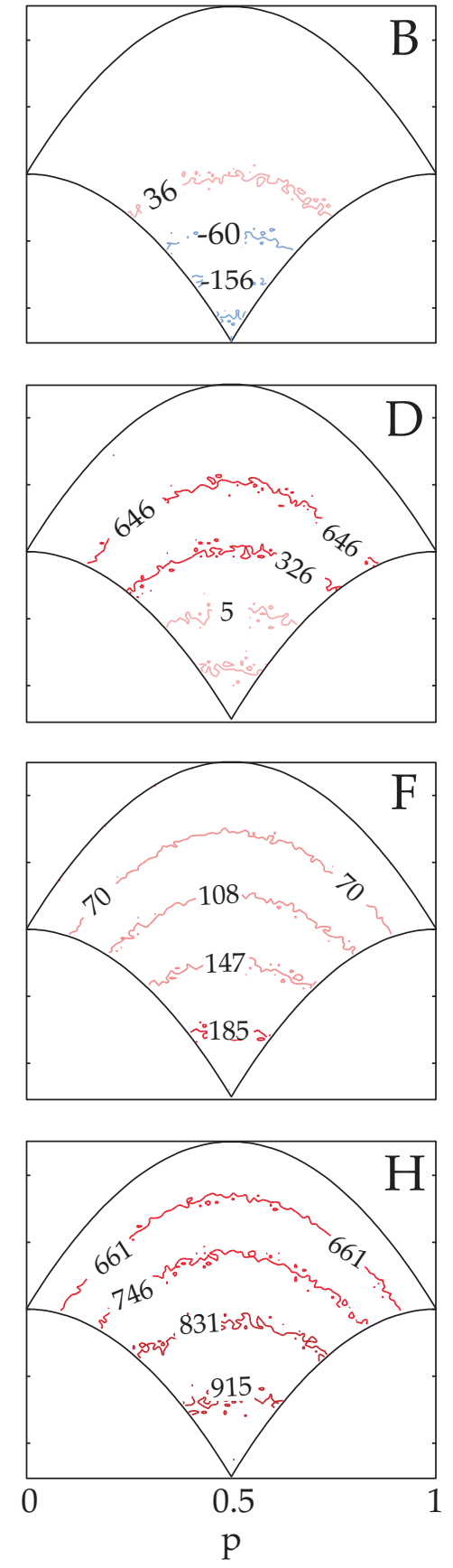

Figure 6.5: Elasticity of $\log \lambda_{s}$ to changes in migration for four migration scenarios. Blue contours are where elasticity is negative; red contours are where elasticity is positive. For all panels, $R_{1}=2.5, R_{2}=0.9$, and $D=0.9$. 
elasticity values were both positive and negative, thereby complicating the interpretation of such a ratio. In general, when migration was such that there were, on average, an equal number of individuals in the two patches $(6.5 \mathrm{C}-6.5 \mathrm{~F})$ or there were more individuals in patch $2(6.5 \mathrm{G}-6.5 \mathrm{H})$, elasticity to $m_{1}$ was less than 0 and elasticity to $m_{2}$ was greater than zero. These results indicate that $\log \lambda_{s}$ was negatively impacted by increasing migration from the good patch, and positively impacted by increasing migration from the bad patch. Results were more complicated when migration resulted in more individuals on average in patch 1 (6.5A-6.5B). As covariance decreased, elasticity to $m_{1}$ switched from negative to positive and elasticity to $m_{2}$ switched from positive to negative. This corresponds to the good and bad patches essentially switching their "goodness" and "badness" when covariance is negative, so that increasing migration from patch 1 results in increased metapopulation growth rate, and increasing migration from patch 2 causes decreases in metapopulation growth rate.

\subsection{Two Stages, With Disturbance}

The softshell clam, Mya arenaria, is a commercially important bivalve commonly found in New England estuaries. M. arenaria's life cycle is typical of nearshore marine benthic invertebrates (Thorson, 1950; Abraham and Dillon, 1986). It is characterized by a relatively sedentary adult stage, with adults highly aggregated into patches of suitable habitat. Dispersal between these populations is accomplished by a shortlived larval stage. In many species, larvae are produced in vast quantities during a short reproductive season. Almost all of the larvae die before recruiting to the adult phase.

To model such a population requires at least two patches, with dispersal between them, and two stages: adults and larvae/juveniles (Fig. 6.6). We assume that demography, migration, and disturbance act sequentially (in the intervals $\left(t, t_{1}\right),\left(t_{1}, t_{2}\right)$ and $\left(t_{2}, t+1\right)$ respectively) within a given projection interval $(t, t+1)$.

Between times $t$ and $t_{1}$, the population undergoes demographic processes. The demographic transitions within population $i$ are given by the matrix $\mathbf{B}_{i}$, with entries 


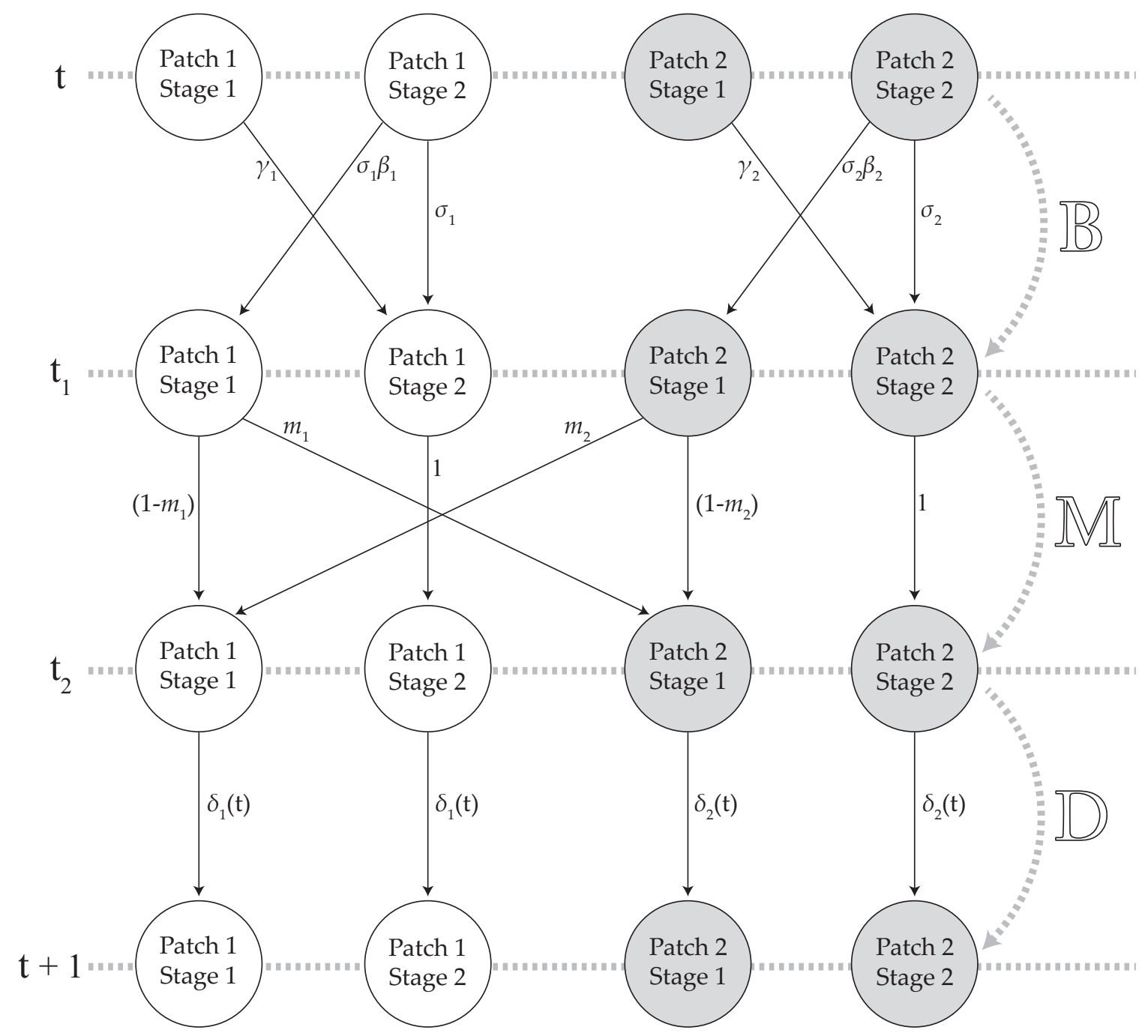

Figure 6.6: Life cycle graph for two-stage, two-patch model with stochastic disturbance. $\mathrm{B}, \mathrm{M}$, and $\mathrm{D}$ denote the block-diagonal matrices for demography, migration, and disturbance, respectively (Equations (6.25), (6.29), and (6.31)). 
composed of adult survival $\left(\sigma_{i}\right)$, per capita larval production and survival $\left(\beta_{i}\right)$, and survival and maturation of new recruits $\left(\gamma_{i}\right)$ :

$$
\mathbf{B}_{i}=\left(\begin{array}{cc}
0 & \sigma_{i} \beta_{i} \\
\gamma_{i} & \sigma_{i}
\end{array}\right)
$$

If we define the entries $n_{i j}(t)$ of the vector $\mathbf{n}(t)$ to be the number of individuals in stage $j$ of population $i$ at time $t$ and arrange the elements as

$$
\mathbf{n}(t)=\left(\begin{array}{c}
n_{11}(t) \\
n_{12}(t) \\
n_{21}(t) \\
n_{22}(t)
\end{array}\right)
$$

then the demographic transitions are described by

$$
\mathbf{n}\left(t_{1}\right)=\mathbb{B} \mathbf{n}(t)
$$

where

$$
\mathbb{B}=\left(\begin{array}{cc}
\mathbf{B}_{1} & \mathbf{0} \\
\mathbf{0} & \mathbf{B}_{2}
\end{array}\right)
$$

Next, individuals migrate between patches. Let $\mathbf{M}_{j}$ be the matrix of migration rates for individuals in stage $j$. A simple model for migration has these stage- $j$ individuals migrating from patch $i$ at the per capita rate $m_{i j}$. Thus,

$$
\mathbf{M}_{j}=\left(\begin{array}{cc}
1-m_{1 j} & m_{2 j} \\
m_{1 j} & 1-m_{2 j}
\end{array}\right)
$$


If we now rearrange the vector $\mathbf{n}\left(t_{1}\right)$ as

$$
\tilde{\mathbf{n}}\left(t_{1}\right)=\left(\begin{array}{c}
n_{11}\left(t_{1}\right) \\
n_{21}\left(t_{1}\right) \\
n_{12}\left(t_{1}\right) \\
n_{22}\left(t_{1}\right)
\end{array}\right) \text {, }
$$

then

$$
\tilde{\mathbf{n}}\left(t_{2}\right)=\mathbb{M} \tilde{\mathbf{n}}\left(t_{1}\right),
$$

where

$$
\mathbb{M}=\left(\begin{array}{cc}
\mathbf{M}_{1} & \mathbf{0} \\
\mathbf{0} & \mathbf{M}_{2}
\end{array}\right)
$$

Since $M$. arenaria adults are sedentary, we set $\mathbf{M}_{2}=\mathbf{I}$. To simplify notation, we will set $m_{11}=m_{1}$ and $m_{21}=m_{2}$ from here on.

Finally, disturbance reduces the number of individuals in population $i$ by the fraction $\delta_{i}$, as described in equations (6.10) through (6.15). If we return to the original arrangement (6.23), we then have

$$
\mathbf{n}(t+1)=\mathbb{D}_{t} \mathbf{n}\left(t_{2}\right),
$$

where

$$
\mathbb{D}_{t}=\left(\begin{array}{cc}
\mathbf{D}_{1}(t) & \mathbf{0} \\
\mathbf{0} & \mathbf{D}_{2}(t)
\end{array}\right)
$$

and

$$
\mathbf{D}_{i}(t)=\left(\begin{array}{cc}
\delta_{i}(t) & 0 \\
0 & \delta_{i}(t)
\end{array}\right)
$$

To convert between the vectors $\mathbf{n}$ and $\tilde{\mathbf{n}}$, conversions that are required at every time step, we employ the vec-permutation matrix P (Henderson and Searle, 1981):

$$
\begin{aligned}
\tilde{\mathbf{n}} & =\mathbf{P} \mathbf{n}, \\
\mathbf{n} & =\mathbf{P}^{\top} \tilde{\mathbf{n}} .
\end{aligned}
$$


For the two-patch, two-stage case

$$
\mathbf{P}=\left(\begin{array}{llll}
1 & 0 & 0 & 0 \\
0 & 0 & 1 & 0 \\
0 & 1 & 0 & 0 \\
0 & 0 & 0 & 1
\end{array}\right)
$$

At last, combining the demographic, migration, and disturbance processes gives the model

$$
\mathbf{n}(t+1)=\mathbf{A}_{t} \mathbf{n}(t)
$$

where

$$
\mathbf{A}_{t}=\mathbb{D}_{t} \mathbf{P}^{\top} \mathbb{M} \mathbf{P} \mathbb{B}
$$

This decomposition of the projection matrix into its demographic, migratory and disturbance components is useful. It allows us to use matrix calculus to calculate the elasticity of the stochastic metapopulation growth rate to each of the demographic parameters (Caswell, 2007).

The elasticity of $\log \lambda_{s}$ to parameter changes is

$$
\frac{\partial \log \lambda_{s}}{\partial \log \boldsymbol{\theta}^{\boldsymbol{\top}}}=\lim _{T \rightarrow \infty} \frac{1}{T} \sum_{t=0}^{T-1}\left[\frac{\boldsymbol{\theta}(t) \mathbf{w}^{\boldsymbol{\top}}(t) \otimes \mathbf{v}^{\boldsymbol{\top}}(t+1)}{r(t) \mathbf{v}^{\boldsymbol{\top}}(t+1) \mathbf{w}(t+1)} \frac{\partial \operatorname{vec} \mathbf{A}_{t}}{\partial \boldsymbol{\theta}^{\boldsymbol{\top}}}\right]
$$

where $\boldsymbol{\theta}$ is a column vector of parameters, and the operator vec $(\cdot)$ stacks the columns of a matrix on top of each other (Caswell, unpublished). The matrix $\partial v \operatorname{vec} \mathbf{A}_{t} / \partial \boldsymbol{\theta}^{\top}$ is the derivative of the projection matrix at each time step with respect to each lowerlevel parameter in $\theta$. In our model, $\mathbf{A}_{t}$ is the product of several matrices, therefore the calculation of $\partial \mathrm{vec} \mathbf{A}_{t} / \partial \boldsymbol{\theta}^{\top}$ is not trivial.

Taking the differential of both sides of equation (6.37) gives

$$
d \mathbf{A}=(d \mathbb{D}) \mathbf{P}^{\top} \mathbb{M} \mathbf{P} \mathbb{B}+\mathbb{D} \mathbf{P}^{\top}(d \mathbb{M}) \mathbf{P} \mathbb{B}+\mathbb{D} \mathbf{P}^{\top} \mathbb{M} \mathbf{P}(d \mathbb{B})
$$

Multiplying the first and third terms in equation (6.39) by the identity matrix leaves 
those terms unchanged.

$$
d \mathbf{A}=\mathbf{I}(d \mathbb{D}) \mathbf{P}^{\top} \mathbb{M} \mathbf{P} \mathbb{B}+\mathbb{D} \mathbf{P}^{\top}(d \mathbb{M}) \mathbf{P} \mathbb{B}+\mathbb{D} \mathbf{P}^{\top} \mathbb{M} \mathbf{P}(d \mathbb{B}) \mathbf{I}
$$

We can then apply the vec operator to each term in (6.40). Using the fact that $\operatorname{vec}(\mathbf{A B C})=\left(\mathbf{C}^{\boldsymbol{\top}} \otimes \mathbf{A}\right) \operatorname{vec} \mathbf{B}$, we obtain an equation for $d \operatorname{vec} \mathbf{A}$ in terms of the component matrices:

$$
\begin{aligned}
d \operatorname{vec} \mathbf{A}= & {\left[\left(\mathbf{P}^{\top} \mathbb{M} \mathbf{P B}\right) \otimes \mathbf{I}\right] d \operatorname{vec} \mathbb{D} } \\
& +\left[(\mathbf{P} \mathbb{B})^{\top} \otimes\left(\mathbb{D} \mathbf{P}^{\top}\right)\right] d v e c \mathbb{M} \\
& +\left[\mathbf{I}^{\top} \otimes\left(\mathbb{D} \mathbf{P}^{\top} \mathbb{M} \mathbf{P}\right)\right] d \operatorname{vec} \mathbb{B} .
\end{aligned}
$$

Using the chain rule, along with the first identification theorem of Magnus and Neudecker (1985) then gives

$$
\begin{aligned}
\frac{d \mathrm{vec} \mathbf{A}}{d \boldsymbol{\theta}^{\top}}=\left[\left(\mathbf{P}^{\top} \mathbb{M} \mathbf{P B}\right) \otimes \mathbf{I}\right] \frac{d \mathrm{vec} \mathbb{D}}{d \boldsymbol{\theta}^{\top}} & \\
+ & {\left[(\mathbf{P} \mathbb{B})^{\top} \otimes\left(\mathbb{D} \mathbf{P}^{\top}\right)\right] \frac{d \mathrm{vec} \mathbb{M}}{d \boldsymbol{\theta}^{\top}}+\left[\mathbf{I}^{\top} \otimes\left(\mathbb{D} \mathbf{P}^{\top} \mathbb{M} \mathbf{P}\right)\right] \frac{d \mathrm{vec} \mathbb{B}}{d \boldsymbol{\theta}^{\top}} }
\end{aligned}
$$

The matrices $d \mathrm{vec} \mathbb{D} / d \boldsymbol{\theta}^{\top}, d \mathrm{vec} \mathbb{M} / d \boldsymbol{\theta}^{\top}$ and $d \mathrm{vec} \mathbb{B} / d \boldsymbol{\theta}^{\top}$ can be rewritten as in terms of their component matrices (i.e. $\mathbf{D}_{i}, \mathbf{M}_{i}$, and $\mathbf{B}_{i}$ ). For example,

$$
\frac{d \mathrm{vec} \mathbb{D}}{d \boldsymbol{\theta}^{\boldsymbol{\top}}}=\sum_{i=0}^{2}\left(\mathbf{H} \otimes \mathbf{I}_{2}\right) \frac{d \mathrm{vec} \mathbf{D}_{i}}{d \boldsymbol{\theta}^{\top}}
$$

where

$$
\mathbf{H}=\left(\mathbf{I}_{2} \otimes \mathbf{P}\right)\left(\operatorname{vec} \mathbf{E}_{i} \otimes \mathbf{I}_{2}\right)
$$

and $\mathbf{E}_{i}$ is the $2 \times 2$ matrix with every entry zero, save the $(i, i)$-th, which is 1 (Magnus and Neudecker, 1985). To calculate $d \mathrm{vec} \mathbb{M} / d \boldsymbol{\theta}^{\top}$, simply replace $\mathbb{D}$ and $\mathbf{D}_{i}$ in (6.43) by $\mathbb{M}$ and $\mathbf{M}_{i}$ respectively. Analogous steps yield $d \mathrm{vec} \mathbb{B} / d \boldsymbol{\theta}^{\top}$.

\footnotetext{
${ }^{1}$ The procedure described in equations (6.22) through (6.44) are valid for the two-stage, twopatch case. The elasticity equation corresponding to $(6.42)$ for the general $s$-stage, $k$-patch case is more complicated but can be similarly derived.
} 
We analyzed model (6.36)-(6.37) with the parameters set at: $\sigma_{1}=0.9, \sigma_{2}=0.3$, $\gamma_{1}=0.8, \gamma_{2}=0.24, \beta_{1}=5.6$, and $\beta_{2}=7.5$. We chose these parameter values so that (1) the individual patch growth rates would be similar to the net reproductive rates for the one-stage case above, i.e. $R_{1}=2.5$ and $R_{2}=0.9$; and (2), so that they would roughly comport with the results of Ripley and Caswell (2006) who estimated demographic parameters for $M$. arenaria from field studies. Migration rates are difficult to obtain for $M$. arenaria, as they are for all benthic invertebrates with pelagic larvae, but the values $m_{1}=m_{2}=0.1$ are arguably realistic. We assumed that disturbance affects all patches and stages with intensity $D=0.9$, and set the probability of disturbance at the two patches to $p=0.5$.

When the covariance of patch disturbance $c$ is positive, both patches tend to be disturbed simultaneously. This preserves the inherently higher quality of population 1, and the resulting elasticities of $\log \lambda_{s}$ to population 1 parameters (Fig. 6.7A) are much larger than the elasticities to population 2 parameters (i.e. $E_{s}>>1$ ). When covariance is negative, the patches tend to be disturbed at different times. As a result, population 2 can be temporarily of higher quality than population 1 . The elasticities of $\log \lambda_{s}$ to population 2 parameters are therefore larger than they are when $c>0$ (Fig. 6.7B). Nevertheless elasticities to population 2 parameters are still much smaller than those to population 1 parameters. These results parallel those we obtained for the one-stage model (cf. Fig. 6.4C). In both disturbance scenarios, the elasticity of $\log \lambda_{s}$ was negative to $m_{1}$ and positive to $m_{2}$; the magnitude of these elasticities was quite small, however, compared to the other parameters investigated.

We also explored the effects of dispersal scenarios that resulted in the majority of the metapopulation density being in patch $1\left(m_{1}=0.1, m_{2}=0.9\right.$; Fig. 6.8A) or patch $2\left(m_{1}=0.9, m_{2}=0.1\right.$; Fig. $\left.6.8 \mathrm{~B}\right)$. We chose a low probability of intense disturbance $(p=0.15, D=0.9)$ and no covariance between patches $(c=0)$. In both dispersal scenarios, $\log \lambda_{s}$ is more elastic to changes in population 1 parameters than it is to the corresponding parameters in population 2. When the population in patch 1 is larger than the population in patch 2 (Fig. 6.8A), elasticities to population 2 parameters are much smaller than to population 1 . When the majority of individu- 

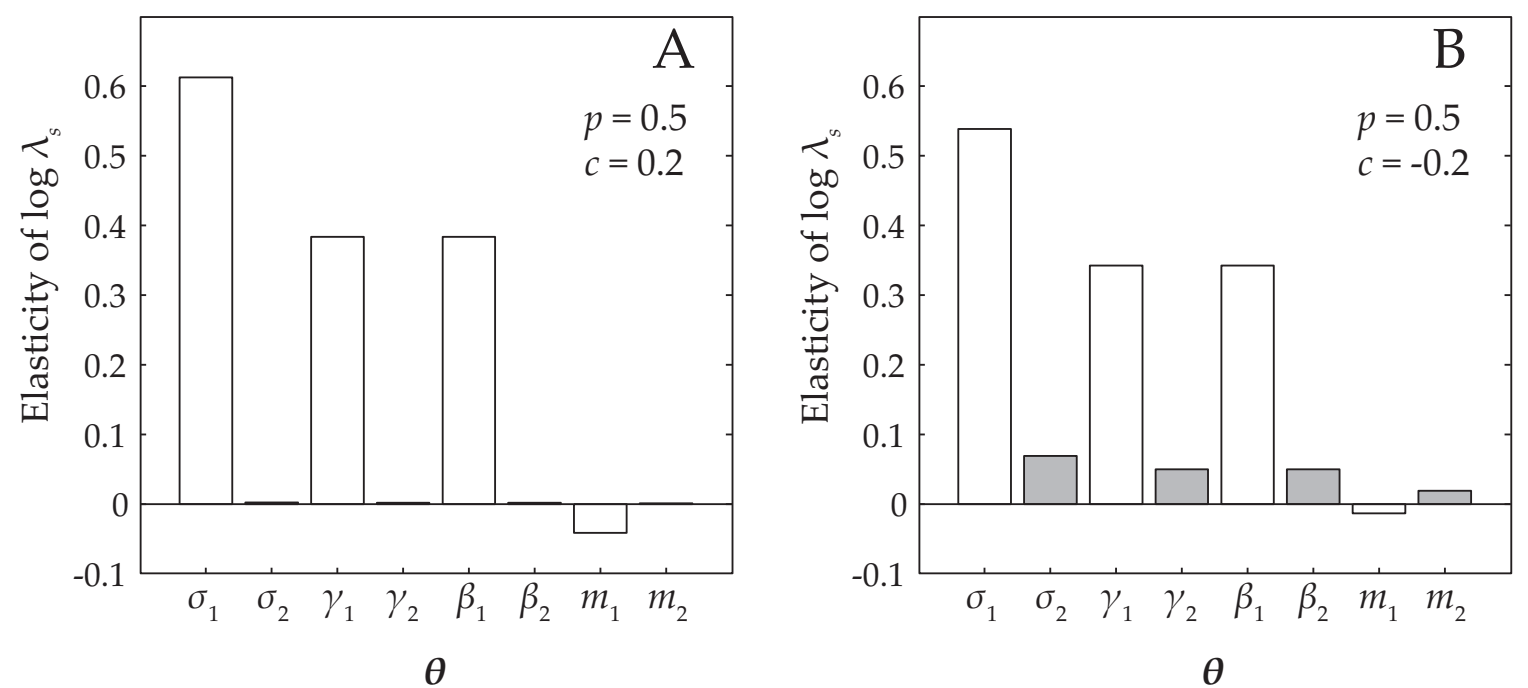

Figure 6.7: Elasticity of $\log \lambda_{s}$ to changes in lower-level parameters, $\boldsymbol{\theta}$ under two disturbance scenarios: probability of disturbance $p$ is 0.5 , with covariance either positive (A) or negative (B). White bars are elasticities in patch 1; gray bars are elasticities in patch 2. In both plots, $m_{1}=0.1, m_{2}=0.1, D=0.9$, and $\log \lambda_{s}<0(-0.27$ and -0.23 for (A) and (B) respectively).

als are found in population 2 (Fig. 6.8B), elasticity to population 2 parameters are much closer to those to population 1, but $\log \lambda_{s}$ still is most elastic to population 1 parameters. For both migration scenarios, the elasticity of $\log \lambda_{s}$ was negative to $m_{1}$ and positive to $m_{2}$. The magnitudes of these elasticities were quite small for the migration scenario that resulted in more individuals in patch $1(6.8 \mathrm{~A})$, and much larger for the second migration scenario that resulted in more individuals in patch 2 (6.8B). When the model complexity was increased by adding a second stage, the elasticities of stochastic metapopulation growth rate to population 1 parameters increased, while those same elasticities to population 2 parameters decreased. Even when the majority of individuals were in the bad patch, growth rate elasticity was still greatest to parameters in the good patch.

\subsection{Discussion \& Conclusions}

We have demonstrated how to incorporate stochastic disturbance into matrix population model with two patches. Our results suggest that stochastic metapopulation 


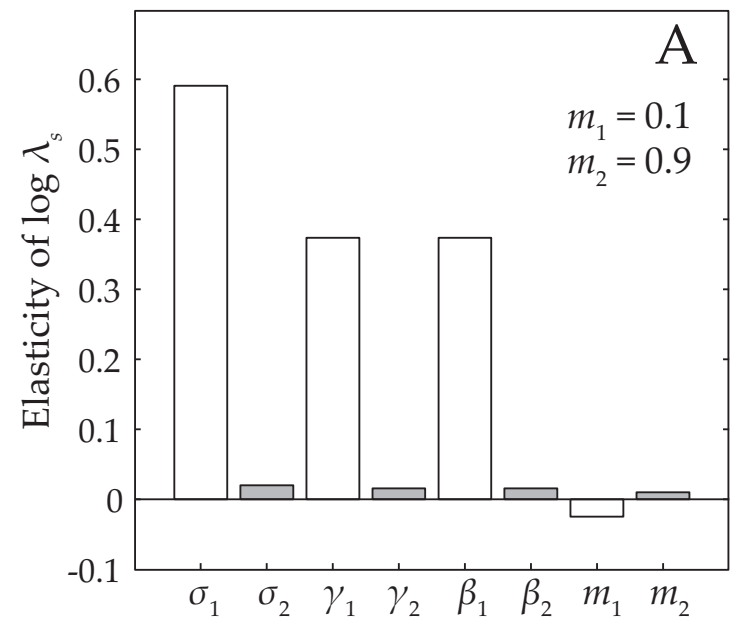

$\theta$

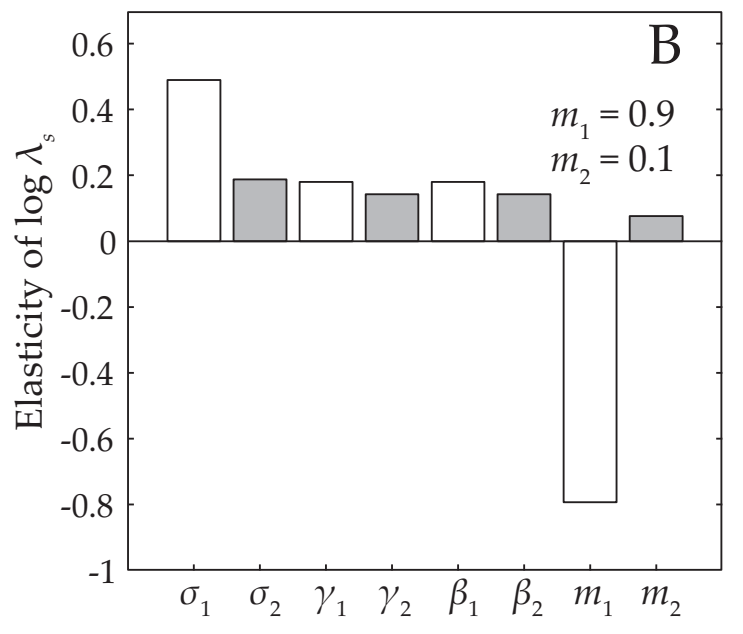

$\theta$

Figure 6.8: Elasticity of $\log \lambda_{s}$ to changes in lower-level parameters $(\boldsymbol{\theta})$ under two migration scenarios: (A) $m_{1}$ small and $m_{2}$ large, resulting in more individuals in patch 1 , and (B) $m_{1}$ large and $m_{2}$ small, resulting in more individuals in patch 2 . White bars are elasticities in patch 1; gray bars are elasticities in patch 2 . In both plots, $p=0.15, c=0$, and $D=0.9$, and $\log \lambda_{s}>0$ (0.53 and 0.05 for (A) and (B) respectively).

growth rate tends to be more sensitive to the population that holds the larger proportion of the total metapopulation. This is true with or without stochastic disturbance, although as expected metapopulation growth rate is lower when disturbance occurs. When a second stage was added, the elasticities of stochastic metapopulation growth rate to population 1 parameters increased, while those same elasticities to population 2 parameters decreased. Metapopulation growth rate is most elastic to adult survival in population 1 for all scenarios we examined. If the majority of the metapopulation is located in the bad patch, then the elasticity to changes in parameters of that population increase but do not surpass elasticity to changes in the good patch.

Previous studies have reported that the distribution of individuals is important for determining the relative effects of good and bad patches, but have approached the problem from a different perspective. Managers sometimes use abundance as an indicator of habitat quality (i.e. for determining good and bad patches) because it is easily determined by surveys (e.g. Peres, 2001). This strategy is not valid, however, since low-abundance good patches can support high-abundance bad patches 
via dispersal (Pulliam, 1988). When managers neglect to identify processes that drive changes in abundance, the may incorrectly infer the status of patches based solely on abundance (Van Horne, 1983). Our results suggest that the problem can be reversed; one may assume it ineffective to invest in improving the bad patch, while if abundances are factored in, focusing management efforts on the bad patch will result in the most efficient increases in metapopulation growth rate.

A more common way of referring to good and bad patches is as "sources" and "sinks". The source/sink literature (Runge et al., 2006; Howe and Davis, 1991; Pulliam, 1988) and intuition suggest that if one must choose between focusing management efforts on a source or a sink, one should always choose the source. Our results comport with this choice, especially when there is no available information about exchange rates via migration. This result does not, however, preclude the necessity of the sink populations to long-term metapopulation persistence. In a constant environment with density-dependent recruitment, individuals unable to settle at source populations due to high densities can migrate to sinks. In this way, the presence of a sink results in larger overall metapopulation size (Pulliam, 1988). Emigration from the source patch becomes beneficial, as it offers "insurance" against catastrophe (Levin et al., 1984). This is especially true if the environmental variability is spatially negatively correlated (Wiener and Tuljapurkar, 1994). We found that this was true for both one-stage and two-stage cases we examined. As covariance of patch disturbances decreases, the elasticity ratio also decreases. That is, effects of parameters in the bad patch increase, and effects of those same parameters in the good patch decrease (Figs. 6.4, 6.7-6.8).

The benefits of sinks are even more pronounced when the environment varies over time. If population density in the source falls below a sustainable level due to a stochastic event, the sink can serve as a refuge for the metapopulation and provide emigrants to recolonize the source (Runge et al., 2006). Based on their model of source/sink dynamics, Howe and Davis (1991) similarly concluded that although sinks may not persist independently, they contribute to metapopulation size and longevity. Runge et al. (2006) also found that sinks may be critical to metapopulation 
persistence. They found that although populations may appear to be a sink based on demographic parameters, there may be a sufficient number of emigrants to classify it as a source. We similarly found that migration rates to and from the bad patch are critical for determining their roles in affecting stochastic metapopulation growth rate. Migration rates that result in more individuals in the bad patch also result in decreases in the elasticity ratio.

Migration strongly affects metapopulation growth rate, in some cases surpassing in magnitude the elasticity to demographic parameters (e.g. Fig. 6.8B). The directional relationship between elasticity and metapopulation growth rate is dictated by patch quality. Elasticity of metapopulation growth rate to migration from the highquality patch tended to be negative, while the same elasticity for the low-quality patch was positive. These relationships switched when covariance of patch disturbance was negative, further indicating that the interactive effects of dispersal and demography cannot be ignored. Results here strongly suggest that migration rates play a substantial role in patch dynamics and metapopulation growth rate, and therefore offer further evidence that metapopulation studies should move towards obtaining estimates of connectivity to advance the field.

Although the elasticity ratio is a useful metric for determining the relative effects of patches on metapopulation growth rate, other factors might be necessary to consider when deciding where to focus management efforts. If one patch is inside a protected area (e.g. a national park), it may be illegal to take steps towards increasing parameters such as survival or reproduction. One patch may be much more accessible than another patch due to geography, making it more realistic for managers to focus on that patch irrespective of the elasticity ratio. Other costs associated with management efforts might result in similar situations where, once "real world" factors are considered, the outcome of the elasticity ratio may be a poor indicator of the most logical management plan. This ratio is therefore useful as a tool for guiding management decisions, along with associated costs, legality issues, accessibility, and other considerations. 


\section{References}

Abraham, B., Dillon, P., 1986. Species profiles: Life histories and environmental requirements of coastal fishes and invertebrates (mid-atlantic): Softshell clam. USFWS Biological Report TR EL-82-4, 18pp.

Bascompte, J., Possingham, H., Roughgarden, J., 2002. Patchy populations in stochastic environments: Critical number of patches for persistence. American Naturalist 159 (2), 128-137.

Brenden, T., Hallerman, E., Murphy, B., Copeland, J., Williams, J., 2007. The new river, virginia, muskellunge fishery: Population dynamics, harvest regulation modeling, and angler attitudes. Evironmental Biology of Fishes 79, 11-25.

Caswell, H., 2001. Matrix Population Models, 2nd Edition. Sinauer Associates, Inc., Sunderland, MA.

Caswell, H., 2005. Sensitivity analysis of the stochastic growth rate: Three extensions. Australian \& New Zealand Journal of Statistics 47 (1), 75-85.

Caswell, H., 2007. Sensitivity analysis of transient population dynamics. Ecology Letters $10(1), 1-15$.

Cohen, J., 1976. Ergodicity of age structure in populations with markovian vital rates, i: Countable states. Journal of the American Statistical Association 71 (354), 335339.

Collier, B. A., Krementz, D. G., 2007. Uncertainty in age-specific harvest estimates and consequences for white-tailed deer management. Ecological Modelling 201 (2), 194-204.

Crouse, D. T., Crowder, L. B., Caswell, H., 1987. A stage-based population model for loggerhead sea turtles and implications for conservation. Ecology 68 (5), 1412-1423. 
Fagan, W. F., Lutscher, F., 2006. Average dispersal success: Linking home range, dispersal, and metapopulation dynamics to reserve design. Ecological Applications $16(2), 820-828$.

Furstenberg, H., Kesten, H., 1960. Products of random matrices. The Annals of Mathematical Statistics 31 (2), 457-469.

Hanski, I., 1999. Metapopulation Ecology. Oxford University Press, Oxford, United Kingdom.

Henderson, H., Searle, S., 1981. The vec-permutation, the vec operator and kronecker products: A review. Linear and Multilinear Algebra 9 (4), 271-288.

Hill, M., Hastings, A., Botsford, L., 2002. The effects of small dispersal rates on extinction times in structured metapopulation models. American Naturalist 160 (3), 389-402.

Horvitz, C. C., Schemske, D., 1986. Seed dispersal and environmental heterogeneity in a neotropical herb: A model of population and patch dynamics. In: Estrada, A., Fleming, T. (Eds.), Frugivores and seed dispersal. Dr. W. Junk, Dordrecht, The Netherlands, pp. 169-186.

Howe, R., Davis, G., 1991. The demographic significance of 'sink' populations. Biological Conservation 57, 239-255.

Hunter, C., Caswell, H., 2005. The use of the vec-permutation matrix in spatial matrix population models. Ecological Modelling 188, 15-21.

Kritzer, J. P., Sale, P. F., 2006. Marine Metapopulations. Elsevier Academic Press, Amsterdam.

Levin, S., Cohen, D., Hastings, A., 1984. Dispersal strategies in patchy environments. Theoretical Population Biology 26 (2), 165-191. 
Magnus, J. R., Neudecker, H., 1985. Matrix differential calculus with applications to simple, hadamard, and kronecker products. Journal of Mathematical Psychology 29 (4), 474-492.

Marshall, A., Olkin, I., 1985. A family of bivariate distributions generated by the bivariate bernoulli distribution. Journal of the American Statistical Association 80 (390), 332-338.

Mertz, D. B., 1971. The mathematical demography of the california condor population. The American Naturalist 105 (945), 437-453.

Pascarella, J. B., Horvitz, C. C., 1998. Hurricane disturbance and the population dynamics of a tropical understory shrub: Megamatrix elasticity analysis. Ecology $79(2), 547-563$.

Pascual, M. A., Adkison, M. D., 1994. The decline of the steller sea lion in the northeast pacific: Demography, harvest or environment? Ecological Applications $4(2), 393-403$.

Peres, C. A., 2001. Synergistic effects of subsistence hunting and habitat fragmentation on Amazonian forest vertebrates. Conservation Biology 15 (6), 1490-1505.

Petr, D., 2007. Population dynamics of annuals in perennial grassland controlled by ants and environmental stochasticity. Journal of Vegetation Science 18, 91-102.

Pulliam, H. R., 1988. Sources, sinks, and population regulation. The American Naturalist $132(5), 652-661$.

Ripley, B., Caswell, H., 2006. Recruitment variability and stochastic population growth of the soft-shell clam, Mya arenaria. Ecological Modelling 193, 517-530.

Roughgarden, J., Iwasa, Y., 1986. Dynamics of a metapopulation with space-limited subpopulations. Theoretical Population Biology 29 (2), 235-261. 
Runge, J., Runge, M., Nichols, J., 2006. The role of local populations within a landscape context: Defining and classifying sources and sinks. The American Naturalist 167 (6), 925-938.

Stacey, P., Johnson, V., Taper, M., 1997. Metapopulation Biology: Ecology, Genetics, and Evolution. Academic Press, San Diego, CA, Ch. 12: Migration within Metapopulations: The impact on local population dynamics, pp. 267-292.

Thorrold, S. R., Latkoczy, C., Swart, P. K., Jones, C. M., 2001. Natal homing in a marine fish metapopulation. Science 291, 297-299.

Thorson, G., 1950. Reproductive and larval ecology of marine bottom invertebrates. Biol. Rev. 25, 1-45.

Tuljapurkar, S., Horvitz, C. C., Pascarella, J. B., 2003. The many growth rates and elasticities of populations in random environments. The American Naturalist $162(4), 489-502$.

Tuljapurkar, S., Orzack, S., 1980. Population dynamics in variable environments I. Long-run growth rates and extinction. Theoretical Population Biology 18 (3), 314342.

Van Horne, B., 1983. Density as a misleading indicator of habitat quality. Journal of Wildlife Management 47 (4), 893-901.

Wiener, P., Tuljapurkar, S., 1994. Migration in variable environments: Exploring life-history evolution using structured population models. Journal of Theoretical Biology 166, 75-90. 


\subsection{Appendix}

\subsubsection{Bivariate Bernoulli Distribution}

There are four possible disturbance scenarios:

1. Both populations are disturbed $\left(\delta_{1}, \delta_{2}=d\right)$;

2. Population 1 is disturbed and Population 2 is not $\left(\delta_{1}=d, \delta_{2}=1\right)$;

3. Population 2 is disturbed and Population 1 is not $\left(\delta_{1}=1, \delta_{2}=d\right)$;

4. Both populations are not disturbed $\left(\delta_{1}, \delta_{2}=1\right)$.

If we assign each of these four possibilities a probability $q_{j}$, we can establish a set of rules under which disturbance acts. First,

$$
q_{1}+q_{2}+q_{3}+q_{4}=1
$$

where $0 \leq q_{j} \leq 1$. That is, the four disturbance scenarios described above are the only four possible scenarios that can occur. Second, disturbance must be equally probable in the two populations so that any differences in sensitivity of metapopulation $\log \lambda_{s}$ to the demography of the populations is due to their inherent "goodness" and "badness", i.e. their $R_{i}$, rather than the nature of the disturbance. If this is true, then

$$
\begin{aligned}
& q_{1}+q_{2}=p \\
& q_{1}+q_{3}=p
\end{aligned}
$$

and therefore

$$
q_{2}=q_{3}
$$

Finally, we establish the covariance of disturbance for the two populations. The covariance of disturbance events at patches 1 and 2 is given by the equation

$$
\operatorname{Cov}\left(X_{1}, X_{2}\right)=E\left(X_{1} X_{2}\right)-E\left(X_{1}\right) \cdot E\left(X_{2}\right)
$$

Only one of the four possible scenarios ((1) above) results in a non-zero value for 
covariance. We can therefore simplify equation 6.50 in terms of $q_{i}, p$, and covariance of disturbance between the two patches $(c)$ to for our purposes to

$$
c=q_{1}-p^{2}
$$

where disturbance tends to occur at both patches simultaneously if $c>0$, and tends to occur at only one of the two patches at a time if $c<0$.

\subsubsection{Derivation of $c$ and $p$ Inequalities}

If $c=q_{1}-p^{2}$, and (6.45) through (6.51) are true, then the following inequalities are also true:

\section{Inequality I}

Rearranging (6.46),

$$
q_{1}=p-q_{2} .
$$

Given (6.51) and substituting,

$$
c=\left(p-q_{2}\right)-p^{2} .
$$

Rearranging,

$$
p-p^{2}-c=q_{2} \text {. }
$$

Since $0 \leq q_{2} \leq 1$,

$0 \leq p-p^{2}-c \leq 1$

and therefore

$$
c \leq p(1-p) .
$$




\section{Inequality II}

$$
\begin{aligned}
& \text { Rearranging (6.51), } \\
& \qquad q_{1}=c-p^{2} . \\
& \text { Since } 0 \leq q_{1} \leq 1, \\
& 0 \leq c-p^{2} \leq 1 \\
& \text { and therefore } \\
& \quad c \geq-p^{2} .
\end{aligned}
$$

\section{Inequality III}

Given (6.45) and substituting (6.49),

$$
q_{1}+2 q_{2}+q_{4}=1
$$

Rearranging (6.46),

$$
q_{2}=p-q_{1} .
$$

Combining these gives

$$
\begin{aligned}
& q_{1}+2\left(p-q_{1}\right)+q_{4}=1 \\
& \text { and } 2 p-q_{1}+q_{4}=1 .
\end{aligned}
$$

Rearranging 6.51, $q_{1}=c+p^{2}$.

Substitution gives

$$
2 p-\left(c+p^{2}\right)+q_{4}=1
$$

and $2 p-c-p^{2}-1=q_{4}$.

Since $0 \leq q_{4} \leq 1$,

$$
0 \leq 2 p-c-p^{2}-1 \leq 1 \text {. }
$$

Rearranging,

$$
\begin{gathered}
c \geq-p^{2}+2 p-1 \\
c \geq-\left(p^{2}-2 p+1\right) \\
c \geq-(1-p)^{2} .
\end{gathered}
$$




\section{Chapter 7}

\section{Conclusions}

\subsection{General Summary}

The goal of this dissertation was to explore metapopulation dynamics and population connectivity, with a focus on the softshell clam, Mya arenaria. I first worked towards developing a method for using elemental signatures retained in the larval shell as a tag of natal habitat. In concert with this method, I designed and implemented experiments to understand environmental and biological factors that may influence elemental signatures. Next, I used a genetic marker to study regional patterns of diversity over the current distribution of $M$. arenaria, including populations outside of the Northwest Atlantic. Finally, I used theoretical approaches to understand the importance of migration in determining patch connectivity, and the impacts of disturbance on metapopulation patch dynamics.

\subsection{Chapter Summaries \& Future Directions}

In Chapter 2, I reported on experiments designed to determine whether laser ablation ICP-MS was able to remove and measure the first larval shell of $M$. arenaria reliably, without burning through to the juvenile shell material underneath. I found that ICP-MS, in its current configuration, consistently ablated material beneath the first larval shell, rendering the measurements unreliable for determining natal habitat 
based on elemental composition. Results from Chapter 2 have consequences for invertebrate ecologists who wish to use elemental chemistry to explore questions about population connectivity. Methods that have proven useful for other study systems, such as otoliths in fishes, should be carefully examined and tested before they are transferred to a new system.

Although I was not able to measure connectivity of New England softshell clam populations using their larval shell elemental composition, there may be other sensors or configurations of the ICP-MS that would be able to accomplish this task. For these studies, or any study that uses shell elemental chemistry as an environmental indicator, it is important to understand the effects of factors potentially affecting shell composition. Such factors may be environmental (e.g. temperature, salinity, seawater elemental concentrations) or biological (e.g. growth rate, age, physiological condition).

Chapter 3 investigated the effects of biological factors on elemental composition in juvenile $M$. arenaria shells, specifically age and growth rate. I found that growth rate was negatively correlated to some elements and unresolved in others; one explanation of the negative correlation with growth rate is that ability to discriminate against non- $\mathrm{Ca}^{2+}$ ions increases with the animal's size. I found that age significantly affected incorporation of some elements into shell. This was evident in the large differences in shell chemistry earlier versus later in the juvenile clam's life. Both of these results suggest that age and growth rate should be considered when designing and implementing studies where shell elemental composition is used as a proxy for environment, including connectivity studies.

In Chapter 4, I continued with my investigation of the factors affecting shell elemental composition. I determined the effects of temperature and salinity on shell composition of larval and juvenile $M$. arenaria, and compared the effects of these factors between the two stages. I found that both of these environmental variables influenced shell chemistry for some elements in both life stages, but this relationship was different for the two stages. The conclusions of Chapter 4 are therefore similar to those of Chapter 3: environmental factors have the potential to affect shell composi- 
tion, and therefore must be taken into account in studies that use biogenic carbonate as an environmental indicator. It is important to note, however, that geographic variability in temperature and salinity may serve to create unique elemental signatures in habitats that might otherwise produce similar shell chemical compositions.

Chapters 3 and 4 are useful for future studies that use elemental composition of shell as an indicator of environment, for the purposes of studying population connectivity, climate, pollution, or otherwise. Experiments like those reported in chapters 3 and 4 are essential for interpreting the results of fine-scale chemical analyses that modern technology, such as ICP-MS, has made possible.

In Chapter 5, I investigated the genetic structure of $M$. arenaria populations across the current distribution of the species, testing for patterns of regional differentiation. I found that populations exhibited extremely low genetic variation, with a single haplotype of the COI gene dominating at all of the sites. Populations sampled outside of the Northwest Atlantic exhibited higher diversities despite their more recent introduction. Chapter 5 has implications for management of $M$. arenaria. One of the most commonly used management strategies for increasing softshell clam populations in New England is by seeding less productive flats with juvenile clams that usually originated from other locations. Our results suggest that this management strategy is not likely to significantly impact the regional distribution of genetic variation.

I developed a matrix population model in Chapter 6 to explore the relationship between migration rates and metapopulation growth rate, and to understand the effects of disturbance on metapopulation dynamics. Although my model was applied to $M$. arenaria for demonstrative purposes, it is broadly applicable to any population that experiences stochastic environmental variability. First, I used the model to determine what population parameters should be maximized to most efficiently increase metapopulation growth rate. I found that it is usually best to focus efforts on the patch with the highest individual population growth rate. It is also important, however, to determine the spatial distribution of individuals in the metapopulation (i.e. the migration rates). If migration is such that the majority of individuals are located in the lower-quality patch, it can be more efficient to focus efforts on protecting that 
patch over the higher-quality patch. I then introduced disturbance and reexamined the results, finding that they held true when the environment varied stochastically. Finally, I expanded the model to include two stages in each patch. For the particular set of parameters I chose, I found that it was always best to focus on the higher quality patch. The addition of the second stage appeared to reduce the importance of where individuals are distributed within the metapopulation.

Metapopulations are a useful framework under which to consider many marine populations. Coastal benthic invertebrates, like $M$. arenaria, are especially suited for analysis as a metapopulation: they occur in geographically separated habitats that are connected via dispersal of the larval phase in the water column. Measuring larval connectivity (i.e. migration rates) is difficult due to the characteristics of the larval phase, but this fact does not diminish the importance of migration processes for influencing metapopulation dynamics. Therefore it is important to have both theoretical studies (e.g. Chapter 6 of this dissertation) that quantify the importance of migration, as well as empirical studies (e.g. Chapters 2-5) that seek to measure actual migration rates. 